\title{
Arquitectura y paisaje. Aproximaciones desde la arqueología*
}

\section{Architecture and Landscape. Approaches from archaeology}

\author{
Rebeca Blanco-Rotea ${ }^{1}$ \\ Síncrisis, Universidade de Santiago de Compostela. \\ Unidade de Arqueologia, Universidade de Minho
}

A la memoria de Albert López Mullor. Todo un ejemplo personal y profesional

\section{RESUMEN}

El presente trabajo constituye la base teórica y conceptual desde la que se ha abordado el estudio de los paisajes fortificados de época moderna en la parte occidental de la frontera luso-galaica y se ha diseñado un programa de investigación para tal fin. Se propone una aproximación al estudio de ambas realidades del registro arqueológico desde una aproximación simbiótica entre la Arqueología del Paisaje y la Arqueología de la Arquitectura, introduciendo los conceptos de espacio construido y Arqueología del Espacio Construido.

Palabras clave: Registro Arqueológico; Espacio Construido; Paisaje Fortificado; Arqueología del Paisaje; Arqueología de la Arquitectura; Arqueología del Espacio Construido; Modelado Conceptual del Patrimonio; Programas de Investigación.

\section{ABSTRACT}

This work proposes a theoretical and conceptual basis for the study of the fortified landscapes of the GalicianPortuguese border in the Modern Age. From this theoretical framework there was designed a research program that studies these landscapes. It proposes an approach to the study of this type of archaeological record from the Landscape Archeology and the Archeology of Architecture, introducing the concepts of built space and Archeology of Built Space.

Key words: Archaeological Record; Built Space; Fortified Landscape; Landscape A rchaeology; A rcheology of Architecture; Archeology of Built Space; Conceptual Modelling of Heritage; Research Programs.

Recibido: 12-12-2016. Aceptado: 20-07-2017. Publicado online: 27-11-2017

\section{Cómo citar este artículo / Citation}

Blanco-Rotea, R., 2017: "Arquitectura y paisaje. Aproximaciones desde la arqueología", Arqueología de la Arquitectura, 14: e051, doi: http:// dx.doi.org/10.3989/arq.arqt.2017.007.

\section{Copyright}

(C) 2017 CSIC. Este es un artículo de acceso abierto distribuido bajo los términos de una licencia de uso y distribución Creative Commons Attribution (CC-by) España 3.0.

\footnotetext{
* La investigación que conllevó estas reflexiones teóricas estuvo financiada parcialmente por el Programa de investigación en tecnologías para la valoración y conservación del patrimonio cultural; Programa Consolider-Ingenio 2010, convocatoria 2007 (Ref. CSD2007-00058). Vigencia del programa: 2007-2011. Investigador Coordinador Prof. Felipe Criado-Boado. El manuscrito se llevó a cabo gracias a un contrato postdoctoral de la Xunta de Galicia, convocado por la Orde do 18 de febreiro de 2016 (DOG número 44, do 4 de marzo), mediante el cual la autora desarrolla el proyecto: "Paisajes culturales de frontera: arquitectura, territorio, arqueología y modelos metodológicos (PAIX)”, que tiene una duración de tres años. Este contrato está vinculado a la Universidad de Santiago, con dos primeros años de estancia en la Universidade do Minho (Portugal).
} 


\section{INTRODUCCIÓN²}

\author{
[...] la inteligencia arqueo-lógica es la capacidad \\ actual para hacer simultáneamente tres cosas: recupe- \\ rar a través de los objetos la memoria de la razón per- \\ dida, preservar debidamente esos objetos y, con ello, la \\ memoria perdida de una otredad radical, y resignificar \\ y revalorizar en la actualidad esos objetos utilizando \\ para ello la razón recuperada.
}

Felipe Criado-Boado 2012. Arqueológicas. La razón perdida

¿Es cierto que "Vivimos una realidad fragmentada y ésta sólo permite saberes fragmentados, superpuestos y autónomos entre sí" (Martín Hernández 1997)? Nosotros creemos que no, que precisamente estamos asistiendo a una realidad totalmente conectada, ${ }^{3}$ rizomática, trans, donde los saberes no se muestran fragmentados, superpuestos y autónomos, sino integrados y dependientes. Creemos además que los proyectos ya no se articulan en base a esos saberes o disciplinas, sino que saberes y disciplinas se conectan en torno a proyectos. La investigación bajo la cual se ha desarrollado este texto se rige por esta filosofía. El objeto ya no es la disciplina académica desde la cual nos enfrentemos al estudio del patrimonio, sino que lo realmente importante es el objeto, el patrimonio. Del modo en que queramos enfrentarnos a él y de la visión que tengamos del mismo, surgirá el entramado disciplinar desde el que abordemos su estudio y construyamos un discurso sobre éste. Este enfoque es el que está detrás de los planteamientos teóricos que aquí se muestran, ya que ha sido el objeto de estudio al que nos hemos enfrentado el que ha demandado un programa de trabajo concreto, en función de su especificidad, ${ }^{4}$

\footnotetext{
Este texto está basado en parte de la tesis de la autora, defendida en la Universidad del País Vasco el 18 de julio del 2015: https://www.academia. edu/13166836/Arquitectura_y_paisaje._Fortificaciones_de_frontera_en_el_ sur_de_Galicia_y_norte_de_Portugal._Tesis_doctoral._2015.

3 Hoy no podemos separar el trabajo en Patrimonio Cultural (PC) del nuevo significado social que ha adquirido gracias a su vinculación a determinadas tecnologías. Estos instrumentos conectan distintas realidades en relación con el PC y con cómo se construye el discurso en torno al mismo, conectan disciplinas y agentes. Iniciativas como Patrimoniogalego.net (http://patrimoniogalego.net/) liderada por Manuel Gago, cuyo objetivo es elaborar un Catálogo Social del PC gallego sobre la base de las nuevas tecnologías y la cooperación social (fundamentado en lo que se denomina inteligencia colectiva -González Sabater 2012: 21-22), son un buen ejemplo de ello (para una explicación de la gestación de Patrimoniogalego. net véase Ayán y Gago 2012: 233-238; recomendamos también en esta misma obra "Eu quero ser andaluz" - Ayán y Gago 2012: 133-135).

4 Este enfoque se ha orientado desde el "modo 2" de producción de conocimiento (Nowotny et al. 2003, Strathern 2003).
}

un programa desarrollado para el estudio de los paisajes fortificados de época moderna, que aunque no trataremos aquí, de él derivan algunas consideraciones que sí expondremos.

Las reflexiones que traemos a colación surgen de una investigación que tuvo varios objetivos transversales. Uno de ellos intentaba comprender el paisaje fortificado que se construyó en la frontera miñota entre el sur de Galicia y el norte de Portugal durante la Guerra de la Restauração Portuguesa (1640-1668), atendiendo también a procesos previos y a las transformaciones que afectarán después de la firma del tratado de paz en 1668, que establece la frontera administrativa entre Portugal y España.

Para estudiar este fenómeno se atendió a las distintas arquitecturas defensivas edificadas en este entorno, que contribuyeron a la transformación de un paisaje de defensa heredero de tradiciones arquitectónicas anteriores y a la construcción de un nuevo paisaje que quedó parcialmente fosilizado en el bajo valle del río Miño. Partimos de la hipótesis de que este paisaje es resultado de la suma de varios procesos patrimoniales. Nuestra investigación intentó entonces identificar uno de estos procesos procurando, a través de la aplicación de la Cadena de Valor del Patrimonio, ${ }^{5}$ comprender cómo se había gestado y transformado a lo largo del tiempo. ${ }^{6}$

En este texto no se trata el estudio de ese paisaje de forma directa, de ello se ocupan otros trabajos de la autora (Blanco-Rotea 2011 y 2015), sino de la reflexión sobre los conceptos de registro arqueológico, arquitectura y paisaje utilizados en ese estudio, así como sobre distintas estrategias de investigación que se ocupan de la comprensión de los espacios construidos desde la arqueología.

\footnotetext{
La Cadena de Valor o Cadena Valorativa del Patrimonio Cultural, fue desarrollada inicialmente por F. Criado-Boado (1996a: 27-30 y 1996c) bajo el concepto de cadena interpretativa y recogida posteriormente por $\mathrm{M}$. González Méndez en su tesis doctoral (1999: 17-23). Será posteriormente cuando se otorgue esta nueva denominación (Amado et al. 2002) porque se considera que "Es más acertado el concepto de cadena valorativa o cadena de valor porque en el proceso [...] entran en juego diferentes estrategias para la producción de conocimiento, no sólo la interpretación" (Barreiro 2009: 10).

6 Esta forma de entender el paisaje como proceso, conlleva entender el registro arqueológico desde su textualidad: "Frente a la concepción de un registro fósil que ha de ser descubierto a través de una metodología eficaz, se planteará un modelo que concibe el registro arqueológico como si de un texto se tratase, es decir, que los artefactos, estructuras arquitectónicas, residuos, sepulcros, etc., no serían, como podrían plantear los arqueólogos procesuales, resultado de la respuesta dada por las poblaciones del pasado a las condiciones cambiantes de su medio ambiente, sino que serían símbolos materiales que se codifican dando lugar a significados" (Soler 2007: 47-48).
} 


\section{CONCEPTOS. DEL REGISTRO ARQUEOLÓGICO AL PAISAJE}

Arquitectura y Paisaje son dos conceptos clave en este trabajo. A pesar de la aparente diferencia que pueda existir entre ambos, la arquitectura es una parte del paisaje, son realidades que están íntimamente relacionadas porque en ambas la acción constructiva está presente tanto en su génesis como en su transformación. Evidentemente hay otros aspectos que en mayor o menor grado las separan, su materialidad, por ejemplo. Pero lo cierto es que entre arquitectura y paisaje existen límites muy difusos que son difíciles de identificar cuando abordamos su estudio de forma conjunta. ${ }^{7}$

No es nuestra intención hacer aquí un estudio pormenorizado que nos permita responder a las preguntas ¿qué es el paisaje? o ¿qué es la arquitectura?, sino delimitar cuáles son los conceptos de arquitectura y paisaje que hemos manejado para abordar su estudio desde el enfoque que nos interesa $\mathrm{y}$, sobre todo, teniendo en cuenta ese marco conceptual, identificar qué información puede aportar el estudio de la arquitectura y el paisaje al análisis de la fortificación miñota de época moderna (Figura 1).

\section{Sobre registro arqueológico}

Partiremos de varias premisas. La primera supone que tanto la arquitectura como el paisaje son resultado de un

\footnotetext{
En la Carta de Cracovia (Rivera y Pérez 2000) cuando se tratan las clases de patrimonio edificado, se alude a las siguientes categorías: patrimonio arqueológico, edificios históricos y monumentos en contextos rurales o urbanos, la decoración arquitectónica, esculturas y elementos artísticos integrados en el patrimonio construido, las ciudades históricas y los pueblos en su contexto territorial y los paisajes.
}

proceso de apropiación del espacio ${ }^{8}$ y artificialización del medio. Entendemos que son objetos que pueden ser estudiados desde distintas perspectivas para poder acceder a los mecanismos que los han producido; que son también documentos que nos informan sobre distintos aspectos de las sociedades que los han generado (su saber tecnológico, su orden económico, social o cultural, en definitiva, su sistema de saber-poder); y que son recursos en el presente, como objetos y documentos debemos estudiarlos y gestionarlos. Estas premisas siguen planteamientos que ya han sido formulados en Arqueología de la Arquitectura $(\mathrm{AA})^{9}$ y Arqueología del Paisaje (ArPa). ${ }^{10}$

En concreto, hemos usado como modelo conceptual la matriz empleada por Criado-Boado (2012: 193-194) que representa la ontología del Patrimonio Arqueológico (PA) que se resuelve en las tres dimensiones que recogemos arriba, el PA como documento (del pasado), como objeto (del pasado en el presente) y como recurso (en el presente). Esta concepción, no deja de ver el objeto (cultura material mueble o inmueble, paisaje) como eslabón entre pasado y presente, tendiendo puentes entre

\footnotetext{
"Cuando un espacio comienza a ser aprehendido, encerrado, conformado y estructurado por los elementos de la forma, la arquitectura empieza a existir" (Ching 1984: 108).

9 El autor que quizás más haya incidido en estas tres dimensiones de la arquitectura es Azkarate (2001, 2002b y 2013, por ejemplo). De manera similar González en su Restauración Objetiva nos habla también de las dimensiones documental, arquitectónica y significativa de la realidad construida (González Moreno-Navarro 1999b: 13). Caballero apunta el doble valor documental y comunicativo o social que tienen los edificios históricos, y, en cierto modo, alude a su valor como recurso cuando además apunta el compromiso que deben asumir los profesionales que trabajan con patrimonio para preservarlo y actualizarlo (Caballero Zoreda 2009: 18).

10 Esta triple dimensionalidad de los bienes patrimoniales ha sido tratada ampliamente en el seno del grupo de investigación en Arqueología del Paisaje, englobado en el actual Incipit, CSIC (véase, por ejemplo, Amado et al. 2002).
}

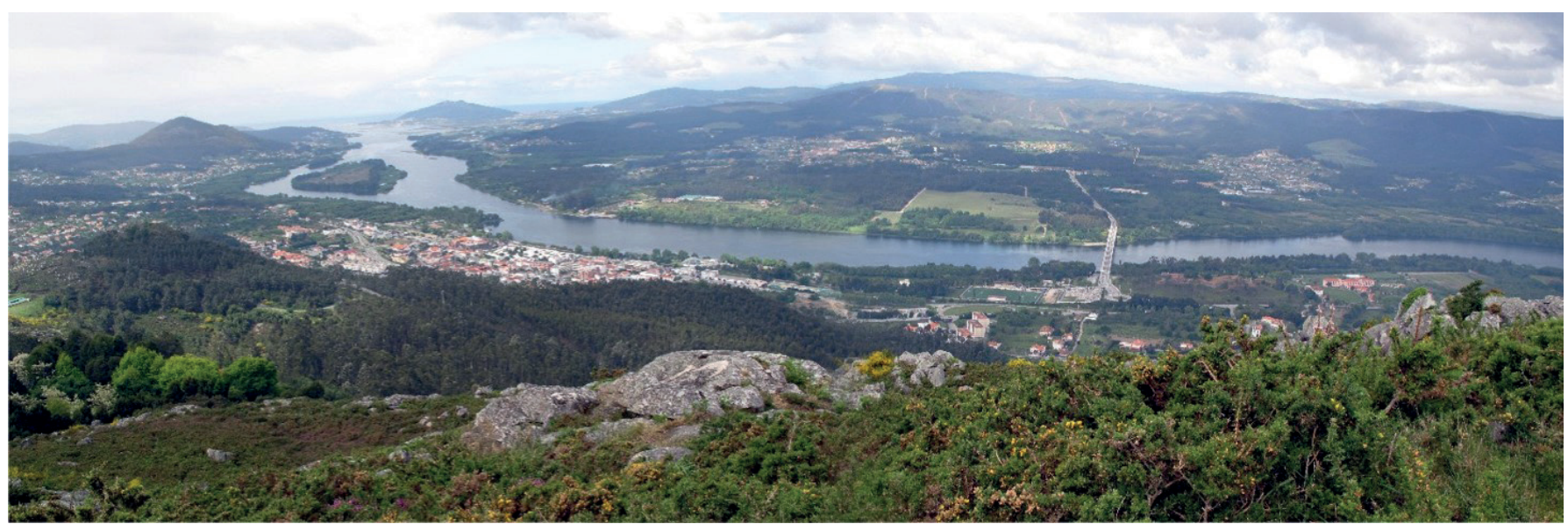

Figura 1. Último tramo del río Miño desde el Alto do Cervo (Vila Nova de Cerveira, Portugal). ¿Qué es paisaje y qué arquitectura? 
su dimensión documental y como recurso. A esta matriz que relaciona el pasado y el presente del PA, habría que añadir el componente temporal del futuro, puesto que nuestra valorización del Registro Arqueológico (RA) supone su transformación en el presente y la creación de nuevas relaciones con la sociedad, estableciendo un proceso retroalimentado.

La segunda premisa supone que abordaremos el estudio de ambas entidades, arquitectura y paisaje, desde una perspectiva arqueológica, pues ambos se entienden como objetos que pueden ser estudiados y gestionados arqueológicamente, es decir, pasan a formar parte del RA y, sobre todo, del PA. ${ }^{11}$ Detrás de la nueva forma de abordar el estudio de los espacios construidos (arquitectónicos y paisajísticos), que se produce a partir de las décadas de 1970-1980, hay un cambio conceptual. En el caso de la arquitectura este cambio se produjo cuando el patrimonio construido pasó a considerarse como documento histórico y, además, como un elemento pluriestratificado. En consecuencia, se demandó el desarrollo de un método arqueológico que permitiera registrar y analizar esas estratigrafías (Utrero 2011: 12), método que se materializó en lo que vino a llamarse lectura de paramentos, englobada dentro de la AA. De igual modo, la ArPa pasó a manejar un concepto de espacio que superó la consideración formalista de espacio como algo dado, como una realidad estática de orden físico y ambiental propia de la Arqueología Espacial procesual, para considerarlo como una construcción social, imaginaria, en movimiento continuo y enraizada con la cultura. Se sustituyó además la categoría abstracta de espacio por otra más contextual de paisaje (Mañana et al. 2002: 17-18; Orejas 1995a: 216).

Ya hemos esbozado arriba que el RA es el objeto material sobre el que focalizamos nuestra actividad, su estudio nos permite acceder al contexto socio-cultural de las sociedades que nos interesan (Criado-Boado 2012: 189). Nos interesaba reflexionar sobre este concepto tanto por su especificidad como por su carácter contextual. Éste es el primer eslabón de la práctica arqueológica, en el sentido de que constituye los restos materiales que han quedado de una realidad a la que queremos acceder y nos va a servir para construir nuestro discurso, por lo tanto, debe ser nuestro primer

\footnotetext{
11 “...el patrimonio arqueológico está constituido por aquellos elementos (todos, una parte o ninguno) del registro arqueológico que a través de un proceso de valoración histórica y patrimonial parezca oportuno sancionar como bienes patrimoniales" (Criado-Boado 2012: 192). Sobre cómo se transforma el RA en PA véase Barreiro 2005: 106-109.
}

recurso. Teniendo en cuenta nuestro ámbito de trabajo, los paisajes y la arquitectura de época histórica, el RA va a suponer el eje sobre el que vamos a articular toda una serie de datos que nos aportan información para enriquecer y precisar nuestro discurso. ¿Qué queremos decir con esto último?

La conceptualización del RA, qué es, cómo se forma y qué representa (Schiffer 1987), es uno de los aspectos en los que se ha incidido desde los distintos posicionamientos teóricos en arqueología, generando un debate que ha venido "reflejando el desarrollo de las estructuras ideológicas, tecnológicas y sociales" (Soler 2007: 43) en las que se produjo y que ha tenido como consecuencia que el significado de registro material se haya ido ampliando y complejizando cada vez más (Hodder 2012; Gordillo 2013), vinculado a distintos posicionamientos teóricos, ${ }^{12}$ parejo a la propia transformación de las técnicas y métodos de excavación pero también a la adopción por parte de la Arqueología de los avances tecnológicos que se han venido desarrollando en otras disciplinas (Soler 2007: 43-44). Precisamente porque es la naturaleza de las fuentes que emplea la arqueología la que determina su especificidad frente a otras ciencias históricas, ya que el discurso arqueológico, tradicionalmente, se ha construido sobre un registro preliterario, frente a otros discursos históricos (Criado-Boado 2012: 181). Aunque esta afirmación es válida para la arqueología prehistórica, cuando nos enfrentamos a la construcción de un discurso sobre sociedades de épocas históricas desde la arqueología, el RA debe convertirse en el eje sobre el que se articulan otros datos de distinta naturaleza, el Registro Escrito y Documental (REyD), por ejemplo. Éste sería el caso de las Arqueologías más acá de la prehistoria, incluyendo la arqueología del presente.

Cabría preguntarnos ¿por qué el eje de la construcción de este discurso debe ser el RA y no el REyD? Creemos que es su carácter contextual el que le confiere esa posición, el RA está anclado en uno o varios contextos: se genera para ser usado, contemplado o habitado en un contexto, y forma parte del mismo; es objeto, acción y resultado de esa acción; nos informa sobre los efectos que otras acciones y el tiempo han producido sobre él, por lo tanto, nos permite acceder a la relación entre la acción social originaria y sus productos (Hodder

\footnotetext{
12 Para un análisis de la relación entre registro arqueológico y posiciones teóricas en arqueología recomendamos Criado-Boado 2012: 183-191 y Lucas 2012
} 
2012), ${ }^{13}$ mientras que el REyD representa un contexto, y lo representa ya en el momento en que se produce la acción social originaria. ${ }^{14}$

Un grabado de la villa de A Guarda, por ejemplo, no es el objeto sino que representa al objeto, aunque nos aporte valiosa información sobre la villa en el momento en que se efectúa el grabado, la materialidad conservada in situ nos aportará información de primer orden, pues es el objeto en sí mismo que, como documento, porta datos sobre un proceso de larga duración, mientras que la representación sólo porta datos de un momento concreto.

En la Figura 2 se presentan dos imágenes de la desaparecida atalaya del puerto de A Guarda, demolida a mediados del siglo XX: una fotografía de 1870 del fotógrafo Ramón Buch y Buet y un grabado de 1880 firmado por T. Avendaño. Si las observamos en detalle, veremos que en la fotografía la atalaya tenía una puerta en el lado derecho y una ventana alta en el izquierdo; sin embargo, en el grabado se representa una puerta en el mismo sitio y una ventana en la parte baja del lado izquierdo de mayores dimensiones que la de la fotografía.

Hoy en día, el conocimiento que tenemos de A Atalaia es gracias a escasos textos que la mencionan y

\footnotetext{
13 Además de a otros aspectos relevantes de la acción social, sus productos y los procesos que le han afectado incluida la recuperación, interpretación y valoración del RA (Criado-Boado 2012: 190-191). Desde los posicionamientos teóricos de la $\mathrm{ArPa}$, se considera que en la formación del RA intervienen tres instancias distintas "una social (pretérita) que produce las formas originales; otra física (o ambiental) que afecta a esas formas una vez producidas; y otra socioinstitucional (o contemporánea) que las hace accesibles a través de una práctica interpretativa realizada en un determinado contexto socioinstitucional" (Mañana et al. 2002: 18).

14 Varios autores han incidido anteriormente sobre la originalidad y especificidad de ese registro, tal como nosotros lo entendemos, Azkarate 2002b: 57.
}

a estas imágenes. Si únicamente contáramos con el grabado, tendríamos una referencia inexacta de sus vanos. El dibujante posiblemente se inspiró en la fotografía, lo cual se deduce del encuadre, los personajes representados, las figuras sobre la atalaya..., pero introdujo algunas variaciones porque hizo una representación personalizada del objeto a través, probablemente, de otra representación del objeto (la fotografía). Por eso, el RA se convierte en información de primer orden frente a otro tipo de registro.

En 1997 en la Punta Xenete del puerto de A Guarda, la Escuela Taller ${ }^{15}$ empieza a construir una réplica de este elemento que el ayuntamiento había demolido a mediados del siglo XX para ampliar el malecón (Figura 3). Esta réplica, destinada a Museo do mar, se sitúa frente a la punta donde se localizaba la original. Presenta ventanas bajas, situadas en una posición similar a las del grabado de Avendaño. La construcción de la réplica era una demanda de la ciudadanía guardesa pues esta construcción siempre había sido un símbolo de la villa, tanto es así que su demolición suscitó importantes críticas en su momento, y su imagen ha estado presente en escudos y sellos de A Guarda desde el siglo XIX. Traemos este ejemplo aquí para introducir el hecho de que el RA es un producto del pasado en el presente y, por tanto, además de estudiarlo para reconstruir ese pasado, debemos gestionarlo en el presente. ${ }^{16}$ Esto es así hasta

\footnotetext{
Existe un proyecto a tal efecto: Ayuntamiento de A Guarda. 1995. Proyecto Escuela Taller. Reconstrucción de la Atalaya y pavimentación de calles del casco viejo. A Guarda.

16 La gestión del RA se complejiza "cuando la práctica arqueológica tiene que reconocer las diferentes dimensiones, problemáticas y expectativas que en la actualidad concurren en el Patrimonio Arqueológico" (Amado et al. 2002: 17).
}
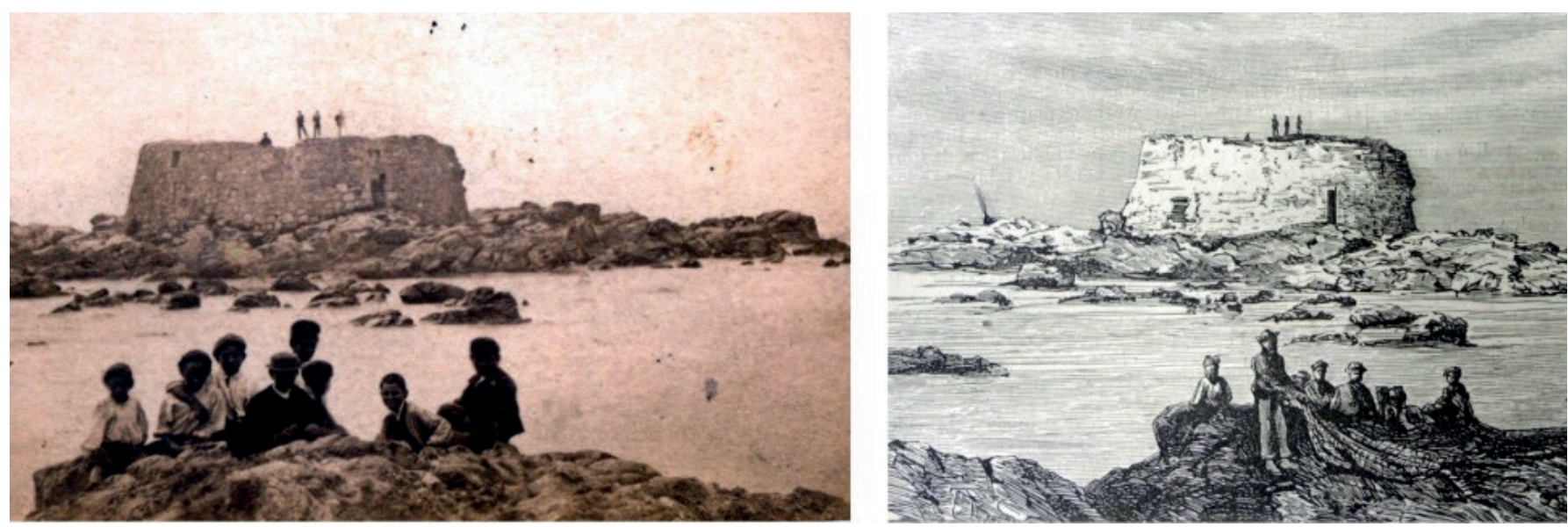

Figura 2. A Atalaia (A Guarda). A la izquierda la fotografía de Buch y Buet (propiedad de A. Martínez Vicente). A la derecha el grabado firmado por T. Avendaño (VV.AA. 1880: 120). 

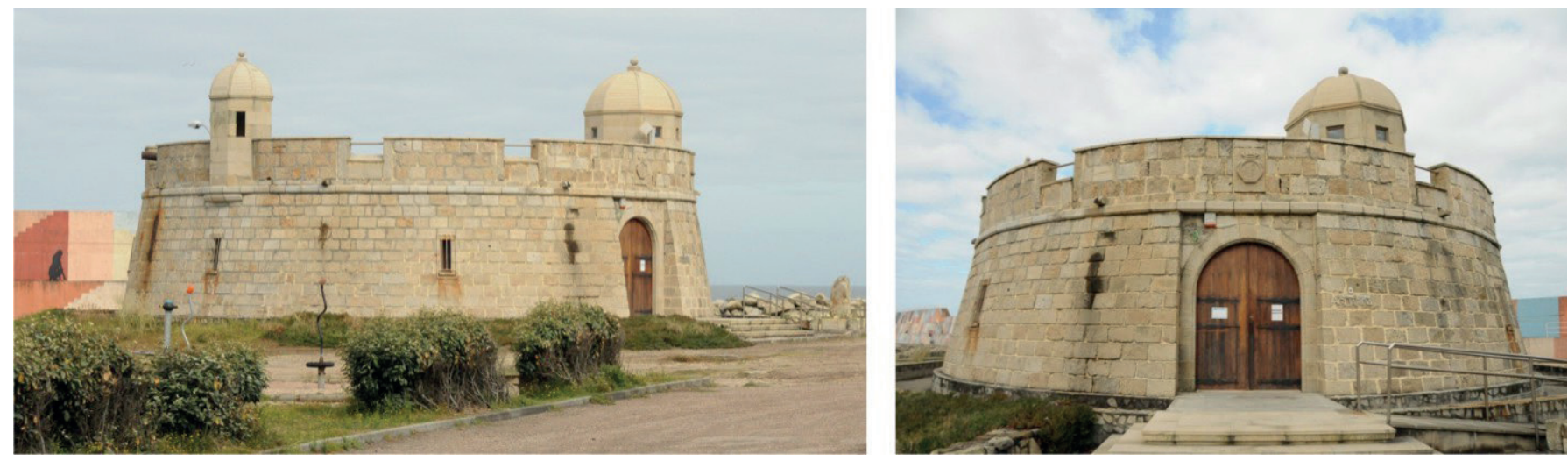

Figura 3. Réplica de A Atalaia construida por la Escuela Taller de A Guarda.

tal punto, que no sólo tenemos que gestionar el RA que nos permite acceder a la memoria del pasado, sino la propia memoria. La reconstrucción de A Atalaia es un buen ejemplo de ello.

Esta visión del RA permite recoger tanto la multidimensionalidad del registro que reconocen los presupuestos teóricos postprocesuales, ${ }^{17}$ como la multivocalidad propuesta desde otros presupuestos teóricos, como hacen la ArPa y la AA cuando reivindican las tres dimensiones del Patrimonio Arqueológico/Arquitectónico ya mencionadas (objetual, documental y recursiva). Atendiendo a todas estas dimensiones y abordando la interpretación del RA desde marcos conceptuales y teóricos explícitos, superaremos aquella preocupación de V. Lull de considerar el RA como realidad arqueológica. Para el autor, la descripción de los restos arqueológicos es sólo el comienzo de la investigación arqueológica (Lull 1988: 6566). Esta idea ha sido ampliada posteriormente por otros autores que aún desde distintos planteamientos teóricos insisten en ver el RA desde un punto de vista mucho más enriquecedor y transversal a los distintos eslabones de la práctica arqueológica (Criado-Boado 2012: 189-190). Concordamos en que la recuperación del RA debe realizarse dentro de un contexto social y disciplinar concreto (Criado-Boado 2012: 190), que debe ser especificado.

Uno de los aspectos importantes dentro de la argumentación que proponemos, es que el RA pasa a ser PA cuando la sociedad lo sanciona como tal, cuando sufre un proceso de valoración (Amado et al. 2002: 33). El PA, y dentro de él la arquitectura y el paisaje, se compone de objetos físicos que tienen su propia existencia que varía a lo largo del tiempo. Si recordamos el ejemplo de $A$ Atalaia, se construye en el siglo XVII; en el siglo XIX

\footnotetext{
17 Las dimensiones tecnológica, social o comunicativa, por ejemplo, de la arquitectura (Mañana et al. 2002: 17).
}

existe, transformada y despojada de su uso primigenio; en el siglo XX desaparece, pero permanece en documentos gráficos y en la memoria de los vecinos; ya en el siglo XXI se recupera, reinterpretada a través de sus representaciones. Lo que la convierte en patrimonio arqueológico es el haber dotado a esta arquitectura defensiva de un significado y relevancia contextual en la actualidad (Quirós 2013: 24-25). Pero además, la multidimensionalidad y multivocalidad de este tipo de PA hace que pase a formar parte de pleno derecho del Patrimonio Cultural (PC). ${ }^{18}$

\section{Sobre arquitectura y paisaje}

Nuestro acercamiento a la arquitectura y paisaje como objetos de estudio arqueológico se basa entonces en tres conceptualizaciones que entendemos comunes a ambas realidades: son materialización de un concepto, ${ }^{19}$ resultado de un proceso y recurso del pasado en el presente..$^{20}$

Esta conceptualización nos permite precisamente abordar las distintas escalas en las que se manifiesta el RA, seleccionar las herramientas de documentación, registro y análisis tanto de la arquitectura como del paisaje, y establecer los límites de la investigación. Nuestro objetivo es aproximarnos a los distintos niveles de significación del RA que nos interesa y a la relación que guardan con la sociedad que inició su proceso constructivo. Intentar acceder

\footnotetext{
18 No es posible dar una definición lo suficientemente flexible y dialéctica sobre Patrimonio Cultural (véase, por ejemplo, la que propone González Méndez 1999: 192). "Este patrimonio no puede ser definido de un modo unívoco y estable. Sólo se puede indicar la dirección en la cual puede ser identificado. La pluralidad social implica una gran diversidad en los conceptos de patrimonio concebidos por la comunidad entera" (Carta de Cracovia, Rivera y Pérez 2000). Para una reflexión al respecto, véase Azkarate 2009: 290-295.

19 Ejemplos de estudios del paisaje y la arquitectura bajo este planteamiento se pueden ver en Leone, Harmon and Neuwirth 2005 o Smith 2003.

20 Sobre la multidimensionalidad del registro arquitectónico véase Mañana et al. 2002: 16-18; también Lefebvre 2013.
} 
a la mayor parte de estos niveles de significación sólo será posible si se hace desde una aproximación múltiple y una mirada interdisciplinaria. Recuperar todos sus niveles de significación, sin embargo, no lo es.

\section{Arquitectura}

La arquitectura se entiende como una tecnología constructiva cuyo objetivo es dar dimensión humana a un espacio (Mañana et al. 2002: 25), pero además ofrece diversos modos de significarse que van desde su propia estructura (el continente), los espacios que ésta crea internamente (el contenido), las relaciones entre interiorexterior (Sennet 1991) o entre lo privado y lo público, su forma de significarse en el paisaje, su representación... ${ }^{21}$ Ámbitos que es imposible estudiar desde una única disciplina, como apunta Parenti (1995: 20). Nos centraremos en tres de las dimensiones donde algunos de estos ámbitos se manifiestan y que resultan de interés para nuestra hipótesis de trabajo (Figura 4).

\section{Arquitectura como materialización de un concepto}

En primer lugar, interesa a nuestra investigación la arquitectura entendida como materialización de un pensamiento

21 Sobre el concepto de arquitectura véase Scruton 1979. social, de un concepto, y en este sentido se intentarán comprender los ámbitos de esta materialización que afectan a la arquitectura como objeto, desde dentro de sí misma, en sí misma y hacia fuera de sí misma. Nos interesa como espacio, como estructura y como parte de un todo que es su entorno inmediato, el territorio en el que se asienta y con el que se mimetiza o en el que se destaca, para pasar a formar parte del proceso de construcción de un paisaje cultural.

En el caso que nos ocupa, se abordó el estudio de la arquitectura entendida como estructura (desde dentro de sí misma y en sí misma) fundamentalmente desde la AA, mientras que el análisis de la arquitectura en su relación con el entorno (hacia fuera de sí misma) se hizo desde la ArPa. Esta aproximación múltiple que aúna los planteamientos teórico-metodológicos de ambas estrategias de investigación, se denominó Arqueología del Espacio Construido (AEC), como veremos más adelante. La AEC se entendió como una forma de abordar de manera conjunta el estudio de la arquitectura y del paisaje, es decir, de la construcción del espacio, no como una subdisciplina arqueológica.

Una manera de dar dimensión humana a un espacio es acotándolo, diferenciándolo de otro espacio mediante el uso de la forma y sus elementos (Ching 1984: 108), y es precisamente la información que estos elementos guardan, que está cargada de significados distintos, ${ }^{22}$ la

\footnotetext{
22 "El ente de la arquitectura no sólo hace visible nuestra existencia, sino que la llena de significación" (Ching 1984: 386).
}

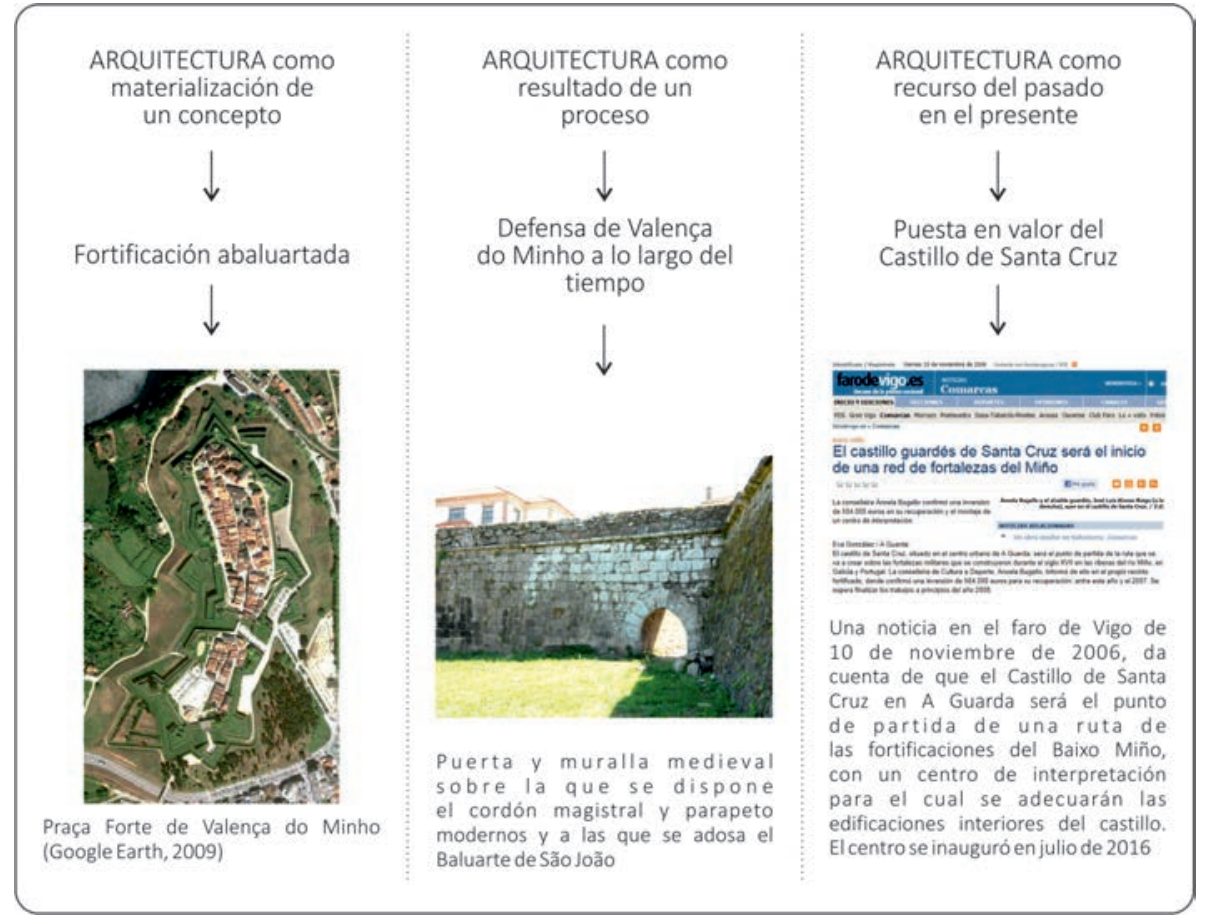

Figura 4. Modelo conceptual de la noción de arquitectura manejada, donde se representan las tres conceptualizaciones que nos interesa valorizar y analizar en este trabajo. 
que nos permite acceder al patrón de racionalidad ${ }^{23}$ que está detrás del hecho constructivo y de su uso. ${ }^{24}$

Estas ideas no son nuevas, han sido ya tratadas por distintos arquitectos que entienden la arquitectura como la expresión de su tiempo, tanto a la hora de proyectar como de interpretar la arquitectura. En su momento Mies van der Roohe buscaba "las relaciones precisas entre la civilización, la cultura y la arquitectura" (Martín Hernández 1997: 19). Desde posiciones más recientes se considera también que la arquitectura conforma un proceso específico de producción e interpretación de la realidad, por lo que no sólo es un elemento representativo de un contexto histórico concreto, sino que detenta un rol como orientación cultural (Rabí 2004), retroalimentando el proceso desde la sociedad a la arquitectura y desde la arquitectura a la sociedad. Con todo ello, podemos afirmar que la arquitectura, como materialización de un concepto, se convierte en una herramienta cultural que construye el paisaje social (Ayán 2006).

Si la arquitectura es reflejo de un pensamiento social, cabría preguntarnos cómo reproduce este pensamiento. Apelando a la semiótica de la arquitectura (Ching 1984: 386), ésta se convierte en un tipo de lenguaje mediante el cual, a través de la construcción de un objeto, las sociedades expresan su forma de habitar y sentir el mundo, es una expresión de su cultura hecha objeto, es cultura material. $\mathrm{Y}$ es este aspecto el que nos interesa focalizar aquí, pues como cultura material es susceptible de ser estudiada con metodología arqueológica. A través de su

\footnotetext{
23 Por "patrón de racionalidad" debe entenderse la forma como una cultura entiende su relación con el mundo, el horizonte intersubjetivo de los individuos. Mientras que el "patrón de subjetividad" se refiere al patrón de racionalidad de un único individuo, a cómo de construye la subjetividad de un individuo a partir del patrón de racionalidad de la sociedad en la que este habita.

24 Para profundizar en este aspecto véase Mañana et al. 2002: 14.
}

análisis podremos llegar a comprender el conocimiento, la tecnología o la concepción del mundo de estas sociedades. Comprender la arquitectura como un objeto que puede ser estudiado desde la arqueología, ha posibilitado el desarrollo de la AA, así como una fructífera reflexión en el campo de la restauración arquitectónica ${ }^{25}$ al entender que el yacimiento arqueológico se extendía más allá del subsuelo y que el edificio formaba parte del yacimiento. Y que en él se aúnan aspectos materiales y simbólicos que debemos decodificar y relacionar adecuadamente (Rabí 2004). Resaltar, nuevamente, que en esta investigación nos aproximamos a la arquitectura desde una perspectiva arqueológica.

Intentaremos ejemplificar nuestra concepción de la arquitectura como materialización de un concepto a través de la óptica del objeto de estudio de este trabajo, volviendo a la Figura 4. En la columna de la izquierda se representa una imagen satélite de la Praça Forte de Valença. En ella se observan dos espacios urbanos encerrados dentro de una estructura amurallada con varias figuras geométricas exteriores, formando todo ello un polígono irregular.

Nos interesa detenernos ahora brevemente en el modelo de fortificación de época moderna. La aparición de las balas metálicas durante la segunda mitad del siglo XV llevó aparejado la introducción de una serie de cambios en la artillería, que obligaron a buscar nuevas soluciones para la arquitectura defensiva: disminución de la altura de las murallas, construcción de un terraplén por el interior sobre el que situar la artillería y sustitución de los matacanes de la parte superior de las murallas medievales por parapetos macizos más resistentes, además del uso de recintos poligonales, como el que observamos en la Figura 5, o del baluarte.

\footnotetext{
25 Doglioni 2002 y 2011; González Moreno-Navarro 1999b; Latorre y Caballero 1995 o Mileto y Vegas 2004; entre otros.
}

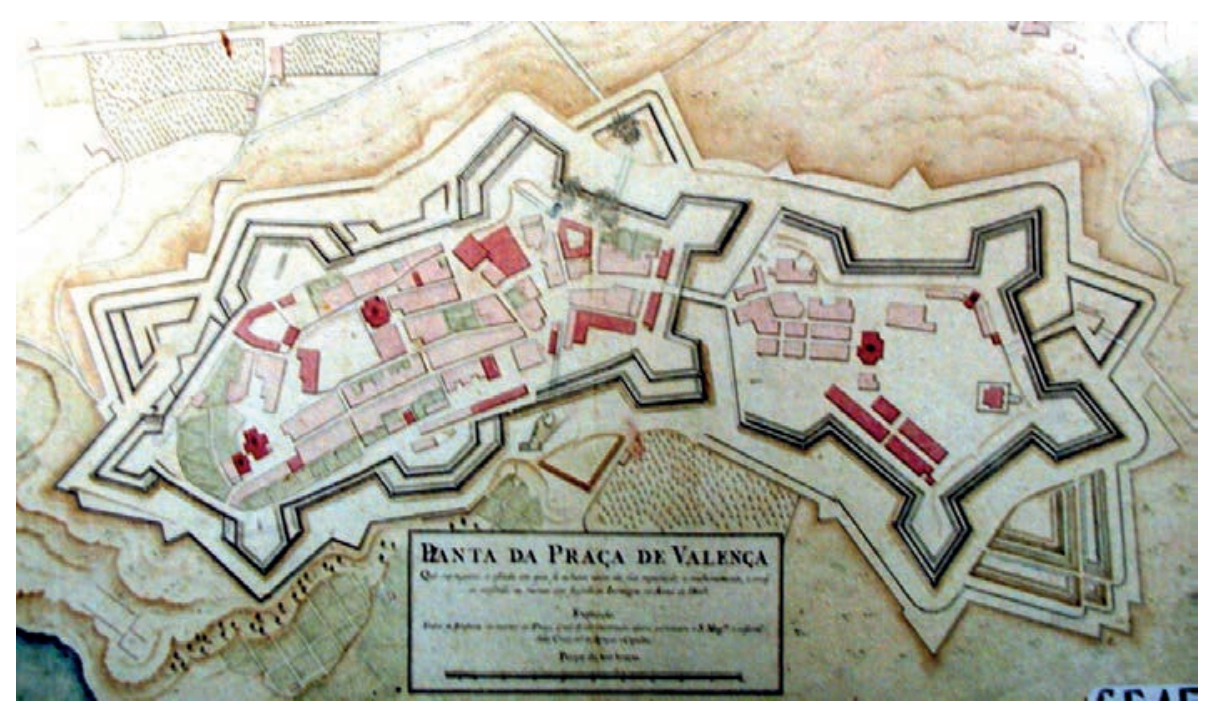

Figura 5. "Planta da praça de Valença que represezenta o estado em que se achava da sua reparação e melhoramento, e em q. se mostrão as ruinas que fizerão os inimigos no anno de 1809" (Ca. 1809) (copia del Archivo Jaime Garrido; original en el archivo del Gabinete de Estudos Arqueológicos de Engenharia Militar de Lisboa -signatura 2755-2A-25A-36). 
A su vez las transformaciones operadas en la parte superior de las murallas obligaron a reforzarlas desde la cimentación, construyéndose ahora por el exterior en talud y avanzando los baluartes. Se introducen también nuevos elementos como los revellines, las medias lunas, la torre con cañones, la cañonera o la casamata.

A esta fortificación, desarrollada en Europa en el siglo XVI, se la conoce como fortificación abaluartada. En los siguientes dos siglos será objeto de diferentes cambios, en la búsqueda de nuevos modelos encaminados a la mejor defensa de las plazas. Este es el caso de la planta de Valença: la ciudad medieval (que corresponde al recinto situado más próximo al río) se abaluartúa, sus murallas se adaptan a las nuevas necesidades defensivas. Se complementa con la construcción de una obra coronada (la parte derecha de la planta de la Figura 5), se dota de foso y de una serie de defensas exteriores. En definitiva la planta de Valença se construye siguiendo las máximas de la fortificación abaluartada de los siglos XVII-XVIII, está materializando un concepto.

\section{Arquitectura como resultado de un proceso}

En segundo lugar, nos interesa destacar también la arquitectura como resultado de un proceso, de hecho es ésta la idea que se ha enraizado fuertemente en la AA y ha permitido su desarrollo generando importantes aportaciones a diferentes campos de la arqueología, la historia, la historia de la arquitectura o la restauración arquitectónica. Autores como Azkarate (2013: 290) definen la arquitectura "como el precipitado final de un denso proceso histórico", por lo que ésta se convierte en depositaria de una memoria que resignificamos en un momento concreto, a través de un proceso de deconstrucción primero y reconstrucción después que nos permite acceder a la huella de esa memoria.

En nuestro ejemplo, recogemos en la columna central una imagen que se corresponde con una parte del recinto amurallado de Valença, situado entre los baluartes de São José e de Nossa Senhora do Carmo. En ella se aprecia una puerta de factura medieval inserta en una muralla de la misma época (Figura 6). En la parte superior de la muralla se superpone un parapeto sobre un cordón magistral y se le adosa por el sur el baluarte de São José (en la imagen de la izquierda de la Figura 6, se corresponde con el muro inclinado), que forma parte de las reformas llevadas a cabo en época moderna para convertir la ciudad amurallada medieval en una plaza fortificada, adaptándola a los nuevos sistemas defensivos de la época. A partir de este momento, la plaza sigue siendo constante objeto de ampliaciones, reformas y mejoras en el sistema defensivo. Es hoy el resultado de un proceso constructivo que muestra los cambios producidos en los distintos sistemas de fortificación desde la Edad Media hasta época contemporánea.
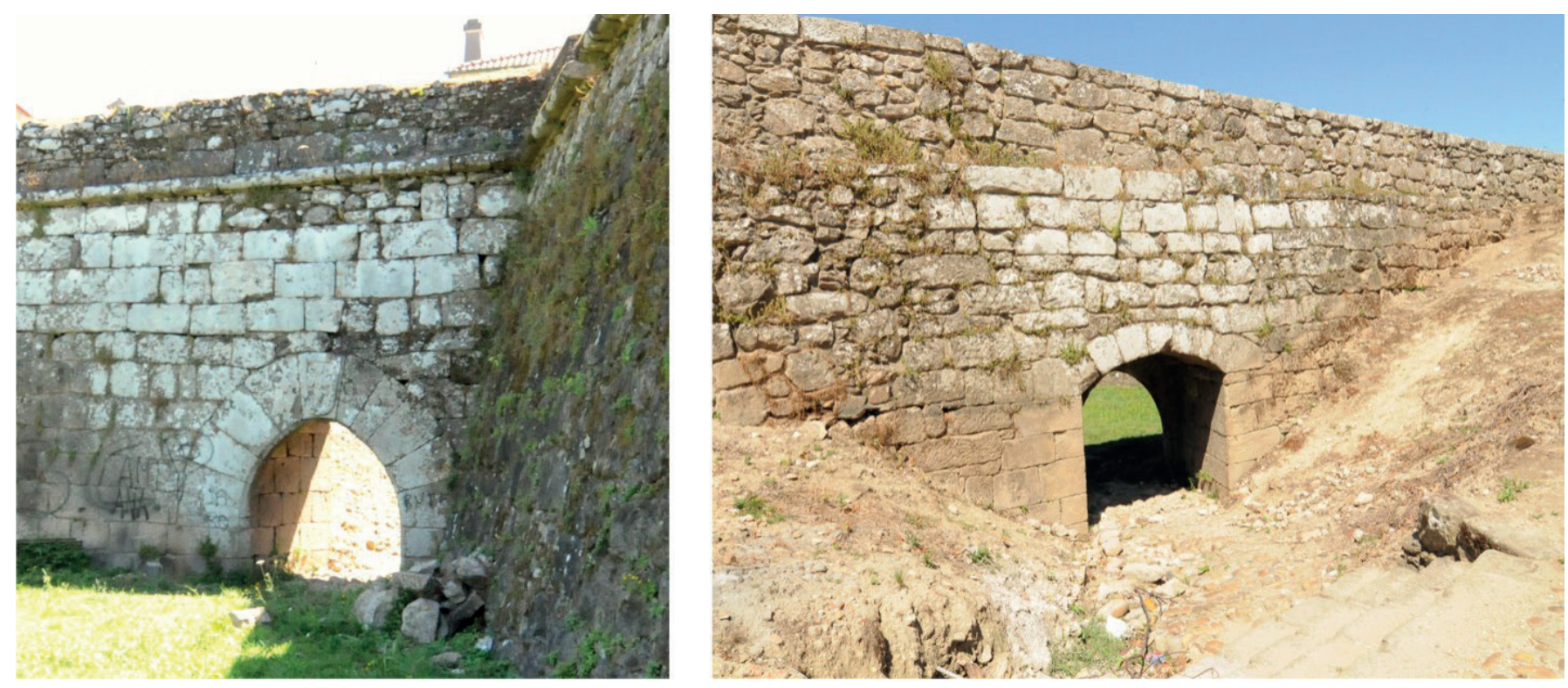

Figura 6. Puerta situada en una de las cortinas del recinto medieval de Valença. Los restos de la fábrica medieval son de sillería irregular dispuesta en hiladas horizontales. Está rematada al exterior por un arco apuntado con clave decorada con escudo, mientras que la interior está rematada por un arco escarzano dovelado. La muralla medieval está alterada tanto por la construcción del parapeto que remata la cortina, como por el flanco del baluarte de São José, de perfil ataludado, ambos realizados en un aparejo de mampostería irregular. 


\section{Arquitectura como recurso del pasado en el presente}

La tercera conceptualización manejada, entiende la arquitectura como un recurso del pasado en el presente. Si tenemos la obligación de estudiar y gestionar el PA en el presente, en el caso de la arquitectura donde su conservación y mantenimiento están ligadas a su uso, esta afirmación se hace especialmente necesaria. El uso (actual) que le demos dependerá de muchos factores, de políticas patrimoniales, de su régimen de propiedad, de su estado de conservación y, ante todo, de su reconocimiento social.
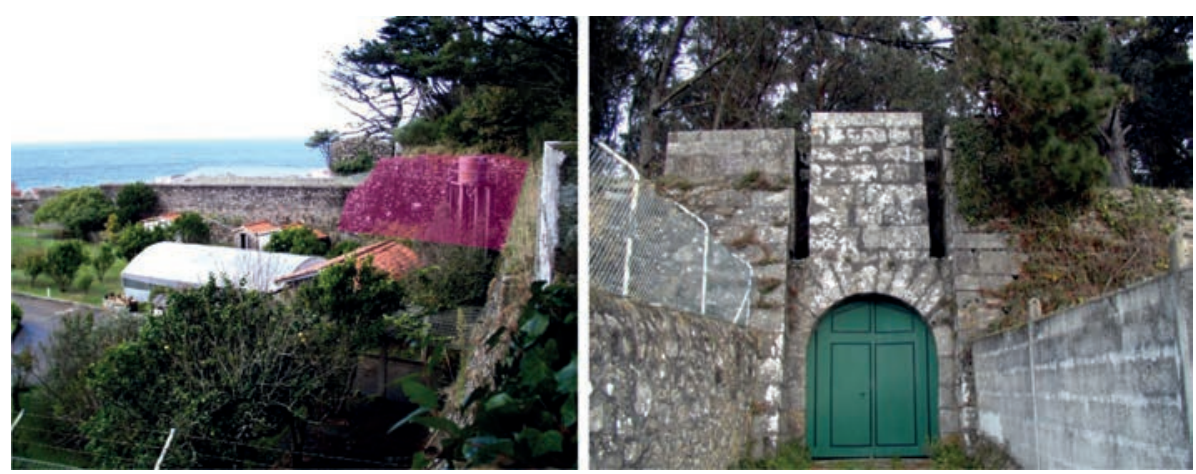

Figura 7. Fotografías del frente suroeste del Castelo de Santa Cruz (2003). En la imagen de la izquierda se pueden observar las fincas particulares que se adosan al frente del castillo, se ha marcado en magenta el Baluarte de la Guía. A la izquierda la Puerta de la Villa a la que se accede a través de un camino situado entre dichas fincas, que han ocupado el espacio en el que se localizaba la media luna de la Villa.

Figura 8. El muro de una de las fincas particulares que ocupan el frente sureste

del Castelo de Santa Cruz se adosa

al ángulo capital del Baluarte de San Sebastián.
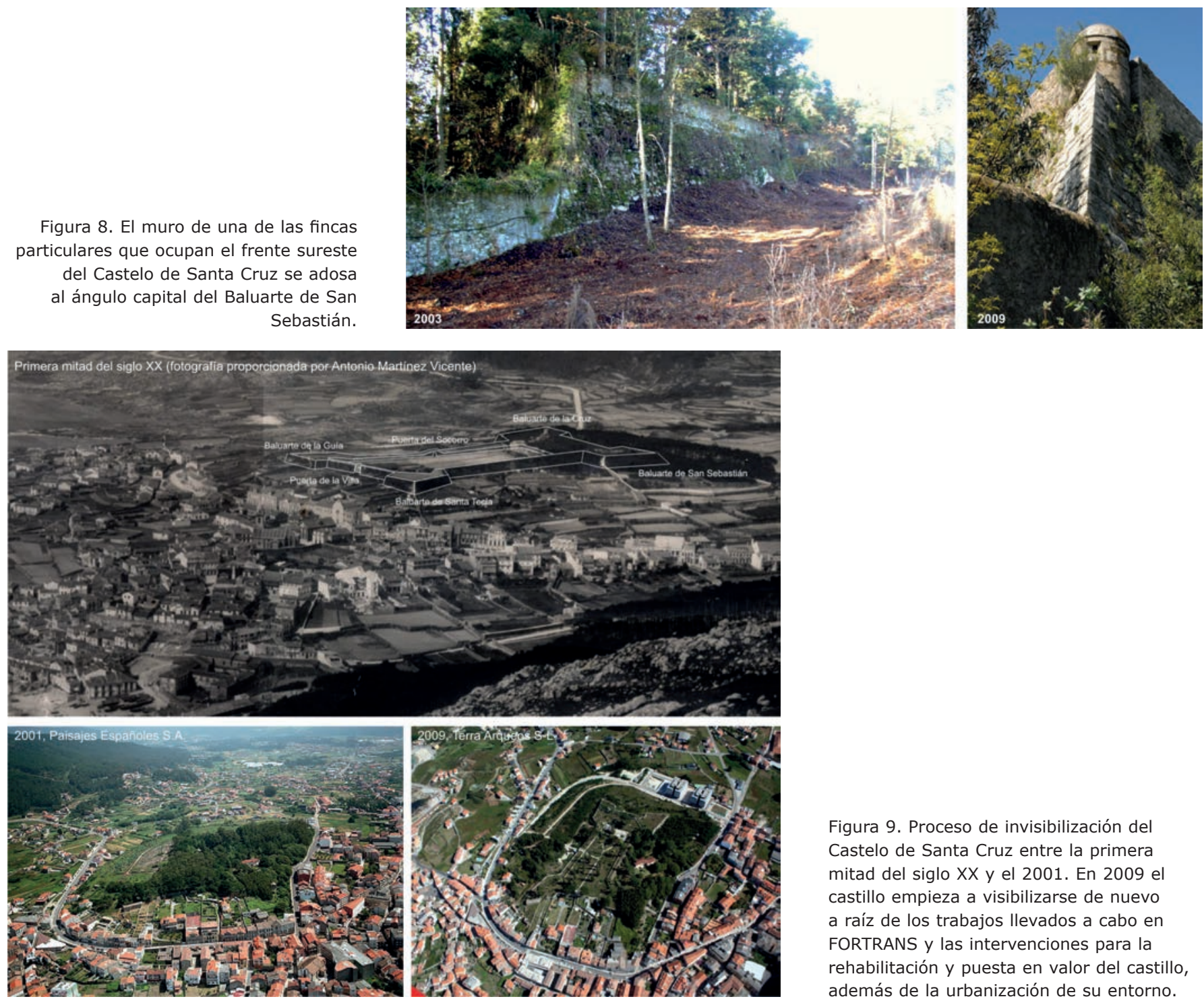

Figura 9. Proceso de invisibilización del Castelo de Santa Cruz entre la primera mitad del siglo XX y el 2001. En 2009 el castillo empieza a visibilizarse de nuevo a raíz de los trabajos llevados a cabo en FORTRANS y las intervenciones para la rehabilitación y puesta en valor del castillo, además de la urbanización de su entorno. 
En nuestro ejemplo, hemos reservado la columna de la derecha de la Figura 4 para representar esta conceptualización. No trataremos aquí la distinta valoración que las comunidades locales, gallega y portuguesa, tienen de cada una de las arquitecturas que conforman el conjunto de la fortificación fronteriza, ni tampoco de su valoración como conjunto, pues existen importantes diferencias en su percepción, conocimiento y valoración que van más allá de los objetivos perseguidos en este artículo. Pero resultaba especialmente llamativo descubrir que en A Guarda el castillo había sido prácticamente invisibilizado y eliminado de la memoria de la vecindad, a pesar de ser una de las fortificaciones permanentes de mayor envergadura del lado gallego de la frontera. Se le habían ido adosando fincas privadas que ocultan parte del perímetro; en su frente sudoeste, únicamente el acceso a la Puerta de la Villa se respetó dejando un camino que discurre entre las fincas y sus respectivos muros de cierre (Figura 7).

Lo mismo sucedió en su frente sureste, donde los muros que delimitan las propiedades mueren, respectivamente, en el ángulo capital de los baluartes de Santa Tecla y San Sebastián (Figura 8). Su frente quedó oculto tras la vegetación arbórea, al igual que en el interior del castillo de propiedad privada, donde las estructuras construidas quedaron ocultas en un frondoso jardín tras abundante vegetación. Todo ello hacía que esta pieza de la fortificación fronteriza se hubiese invisibilizado en el pasado reciente guardés hasta llegar a eliminarse de la memoria de algunos de sus vecinos y vecinas (Figura 9).

Cuando comenzaron los trabajos arqueológicos existía un plan urbanístico para el entorno del castillo que suponía su urbanización, la construcción de pistas y varios edificios de vivienda sobre su glacis. A pesar de los resultados de los estudios previos, este plan siguió adelante como estaba proyectado. Hoy se ha ejecutado parcialmente, se han construido dos de esas torres de viviendas, lo que ha motivado una nueva invisibilización parcial o total del castillo, en función de la ubicación del observador (Figura 10).

\section{Paisaje}

El Convenio Europeo del Paisaje de 20 de octubre de 2000 (BOE núm. 31, de 5 de febrero de 2008, páginas 6259 a 6263) lo identifica como el resultado de la acción humana sobre una matriz espacial, siendo percibido como tal por la sociedad. Esta concepción del paisaje como síntesis (Orejas 1995a: 218-219) ha permitido
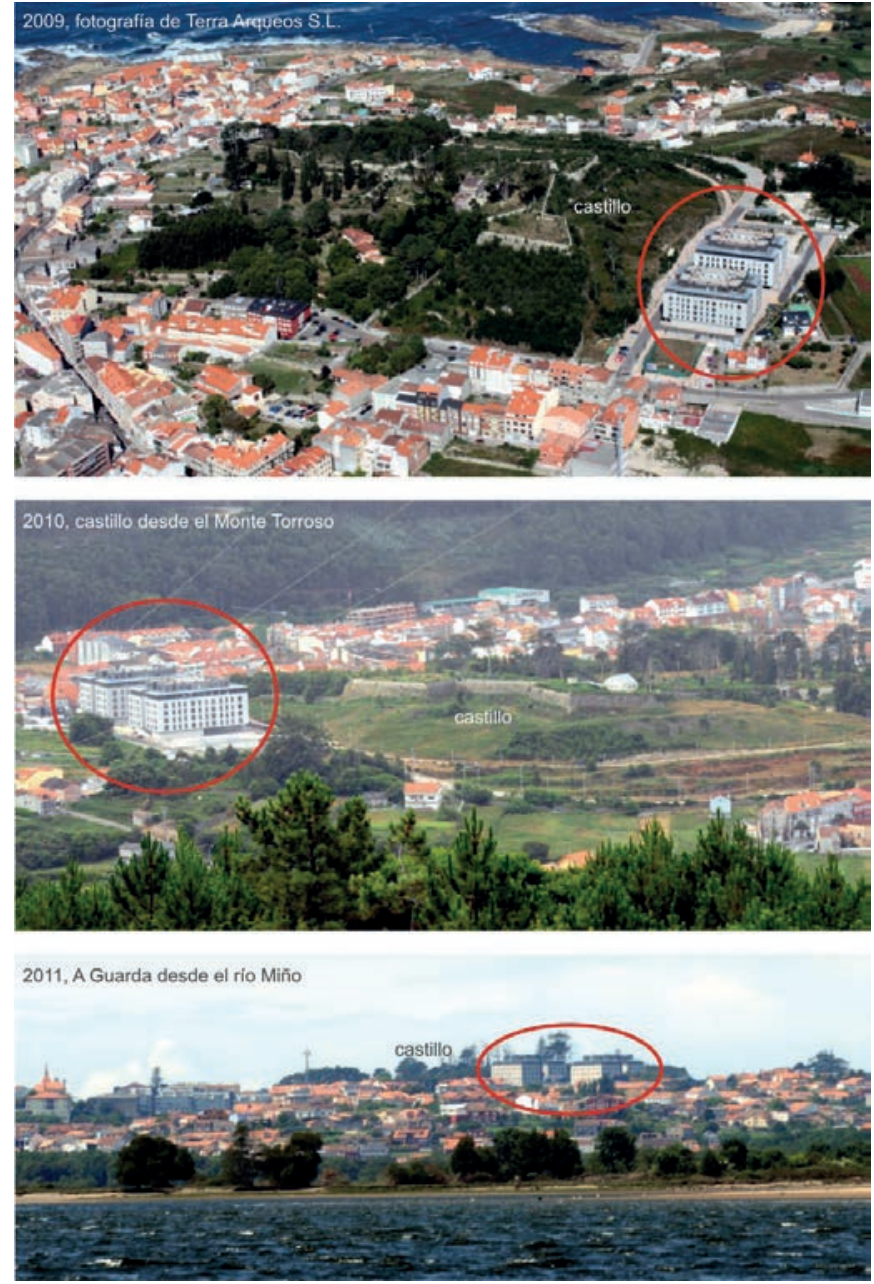

Figura 10. Fotografías recientes del Castelo de Santa Cruz, obtenidas desde distintas posiciones, en las que se puede observar el impacto visual producido por las torres construidas en su glacis.

objetivarlo y estudiarlo, pues materializa aspectos de las sociedades humanas para las que el paisaje constituye una dimensión relevante (Criado-Boado 2012: 20).

Nuestro trabajo parte de la comprensión del paisaje como un producto socio-cultural que objetiva "sobre el medio físico y en términos espaciales" la acción social, "tanto de carácter material como imaginario", donde la acción social está constituida por las prácticas intencionales y no intencionales (Criado-Boado 1999: 5). Este concepto de paisaje intenta superar la consideración formalista del espacio como una realidad estática de orden físico y ambiental, para considerarla una realidad eminentemente social que se construye culturalmente. El paisaje así entendido supuso una reconversión conceptual del espacio que no sólo sería materia sino también imaginación (Criado-Boado et al. 1991: 29; Criado-Boado 1993a: 42). Esta categoría más contextual entiende que 
el espacio es "una construcción social, imaginaria, en movimiento continuo y enraizada en la cultura, existiendo una estrecha relación estructural en las estrategias de apropiación del espacio entre pensamiento, organización social, subsistencia y concepción-utilización del medio ambiente" (Mañana et al. 2002: 18).

El desarrollo de los estudios del paisaje así entendido tuvo lugar como consecuencia del intento por trascender las limitaciones que el registro impone a la interpretación del pasado (Soler 2007: 43), posicionando al paisaje como un elemento principal del RA gracias a su capacidad de integrar diferentes perspectivas (ambiental, histórica, antropológica...), y ser objeto de conocimiento a la vez que medio de transformación social y cultural (Barreiro et al. 2009: 8). No podemos entender este cambio de concepto si no es dentro de una estrategia mayor, en la que la orientación tecno-ecónomo-ecológica de la Arqueología Espacial hacía que el concepto de espacio tuviera una dimensión estrictamente física y empírica y perdiera todo su componente simbólico, político y social. Dentro de esta crítica que surge a mediados de la década de 1980, aparecen una serie de estudios orientados desde la idea de que cuando se trabaja con sociedades el espacio es antes "una construcción política, una realidad social y un producto cultural" que una matriz física. Es aquí donde surge la Arqueología del Paisaje, orientada hacia la descripción de los procesos socio-culturales y simbólicos de construcción de los paisajes pretéritos desde la arqueología (Criado-Boado 1993c: 33-34).

En el debate teórico que tiene lugar en las dos décadas siguientes a $1980,{ }^{26}$ el paisaje adquiere una importancia "inusitada" como evidencia arqueológica (Figura 11). Se intenta superar la realidad física del espacio y se buscan nuevas formas de dotar de mayor sentido las

\footnotetext{
26 Una visión de este debate se puede revisar en Burillo 1998.
}

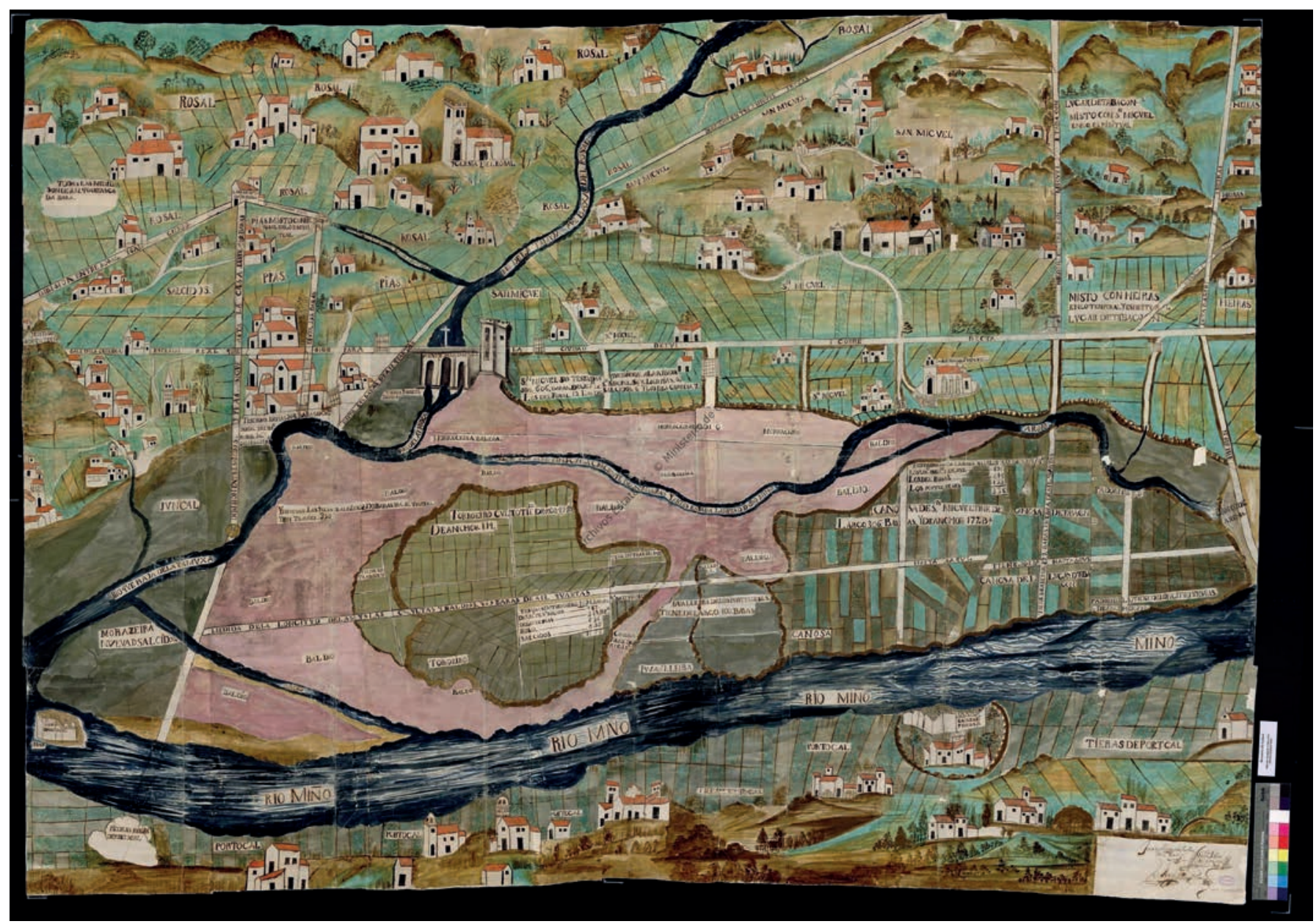

Figura 11. Mapa del municipio de El Rosal con las feligresías de Santa Marina de El Rosal y San Miguel de Tabagón (Pontevedra) cerca de la desembocadura del río Miño de 1733 (Archivo de la Real Chancillería de Valladolid, Signatura PLANOS Y DIBUJOS, DESGLOSADOS, 83). Se representan distintas formas de artificialización del espacio: caminos, parcelaciones, cultivos, construcciones, etc. 
fronteras de la materialidad del registro (Soler 2007: 48). A partir de estos trabajos el paisaje empieza a entenderse en un sentido relacional que transmite la actividad humana material y mental y se convierte en objeto de estudio histórico (Orejas 1995b: 63). La objetivación del paisaje como tal, implicó entender que el uso del espacio genera unas formas concretas en el paisaje y que esta morfología puede ser estudiada con metodología arqueológica (como el análisis fisiográfico, Criado-Boado 1999: 28). A partir de su estudio, era posible acceder al uso que las sociedades hicieron de esos espacios y, por tanto, a las sociedades mismas a través del conocimiento de sus conductas espaciales, integradas en una racionalidad y en unas pautas globales de comportamiento plasmadas en la morfología de ese espacio. Cuando se entiende que las prácticas sociales se objetivan en el espacio, se pasa a hablar de paisaje, se abandona el concepto más neutro de espacio, y se fijan las bases metodológicas para la investigación. El paisaje se convierte así en el espacio usado, diseñado, pensado, apropiado, sacralizado, abandonado... por diferentes sociedades (Orejas 1995a: 217) (Figura 12).

La estrategia de investigación en ArPa se centró en analizar, reconstruir e interpretar los paisajes arqueológicos a partir de los elementos que los concretan, estudiando de manera integral los procesos y formas de culturización del espacio a lo largo de la historia (Mañana et al. 2002: 27). Para ello, se parte de la idea de que las actividades humanas que tienen lugar en relación con el espacio, están organizadas de forma coherente con la representación ideal del mundo que tiene el grupo social que las realiza, o lo que es lo mismo, en el proceso de construcción de los espacios intervienen no sólo los dispositivos mecánicos (físicos) sino que se incluyen también los conceptuales (definen, articulan y nombran) necesarios para poder llevar a cabo la articulación de un espacio. Analizando estos dispositivos mecánicos (las formas), su configuración, los cambios según el distinto tipo de sociedad, etc., se debería poder llegar a acceder, en cierta medida, a los dispositivos conceptuales que los han generado, a su patrón de racionalidad (Criado-Boado 1999: 10). Espacio, pensamiento y sociedad están íntimamente ligados, siendo la construcción del espacio una parte fundamental de la construcción de la realidad de un determinado sistema de saber-poder, herramientas conceptuales que desarrollada la $\mathrm{ArPa}$.

El paisaje así entendido conjuga tres tipos de elementos: físicos, sociales y simbólicos, que a su vez configuran las tres dimensiones presentes en el paisaje: el espacio en cuanto a entorno físico o matriz medioambiental de la acción humana; el espacio en cuanto a entorno social o medio construido por el ser humano sobre el que se producen las relaciones entre individuos y grupos; y el espacio en cuanto a entorno pensado o medio simbólico ${ }^{27}$ en el que desarrollar y comprender la apropiación humana de la naturaleza (Criado-Boado 1999: 6). Atender a estas tres dimensiones es lo permitirá, para este autor, comprender la globalidad del paisaje y es lo que se aborda en una "Arqueología total del paisaje", frente a otras ArPa que se centran únicamente en una u otra de estas dimensiones.

Únicamente añadiremos que el paradigma de paisaje seguido aquí, sigue los presupuestos definidos por Anschuetz et al. (2001), que a su vez toma de Whittlesey (1997), donde éste se define más por lo que hace

\footnotetext{
7 El paisaje existe en cuanto es percibido, experimentado y contextualizado por la gente: Constructed Landscapes, Conceptualized Landscapes and Ideational Landscapes (Knapp and Ashmore 1999).
}

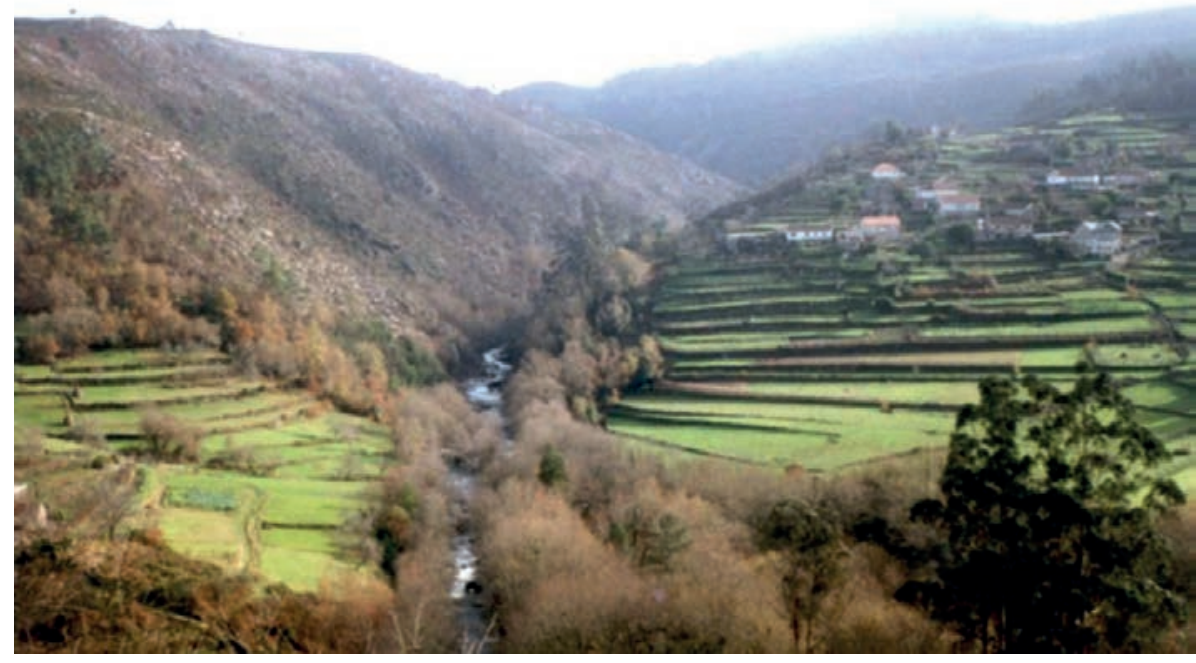

Figura 12. Paisaje aterrazado del valle del Oitavén (Soutomaior, Pontevedra) sobre el que se ha realizado una intensa labor antrópica y se ha constituido un paisaje agrario (fotografía de Paula Ballesteros 2003: 25). 
que por lo que es. Las principales bases del paradigma de paisaje manejado por ambos se rigen por cuatro premisas: "1. Landscapes are not synonymous with natural environments. [...] 2. Landscapes are worlds of cultural product. [...]3. Landscapes are the arena for all of a community's activities. [...] 4. Landscapes are dynamic constructions, with each community and each generation imposing its own cognitive map on an anthropogenic world of interconnected morphology, arrangement, and coherent meaning" (Anschuetz et al. 2001: 160-161).

\section{Paisaje como materialización de un concepto}

Tras esta introducción al concepto de paisaje volveremos a esa triple conceptualización que nos interesa. Nos serviremos esta vez de la observación del paisaje fortificado miñoto para analizar cómo éste se concreta como la materialización de un concepto, para lo cual revisaremos primero la columna izquierda de la Figura 13.

Comentábamos arriba cuáles eran las características básicas de la fortificación abaluartada, y cómo el desarrollo de este tipo de fortificación venía a su vez motivado por el desarrollo de una nueva tecnología armamentística, derivada de la introducción de la pólvora y el consiguiente perfeccionamiento de la artillería. Esta fortificación recibe su nombre del uso del baluarte, "una forma avanzada y dinámica en figura triangular, lo que permitía el empleo de sus dos caras exteriores para la defensa de las cortinas y el apoyo en su enfrentado para lanzar fuego cruzado" (Porras 1995: 53). La descripción que hace Porras del baluarte recoge uno de los más importantes principios del arte de este tipo de fortificación, que dice que cada parte de la fortificación defiende y es defendida por otra parte, de manera que "Una fortaleza ha de constituirse como una máquina perfectamente articulada, que haga posible la mutua visibilidad y defensa de todos los elementos arquitectónicos que la componen" (Martín González 1995: 17).

Detrás de esta idea se encuentra el hecho de que para conseguir una correcta fortificación se intenta alcanzar una figura que responda a la siguiente máxima: "que una pequeña fuerza resista a una más grande, o un pequeño número de hombres a un número mayor"28 (Figura 14). Esta máxima que se aplicaba al diseño de las fortificaciones se puede hacer extensible a una escala aún mayor, pues una fortificación no defendía sólo una plaza, sino una zona y, en casos complejos como el que nos ocupa donde debía defenderse un territorio muy amplio, formaba parte de un sistema defensivo (Martín González 1995: 9).

En el paisaje trasfronterizo miñoto se produce un traslado de las formas características de la fortificación

\footnotetext{
28 Errard-le-duc, de su tratado La fortification demostrée et reduite en art (París, 1594), tomado de Galindo (2002: 63).
}

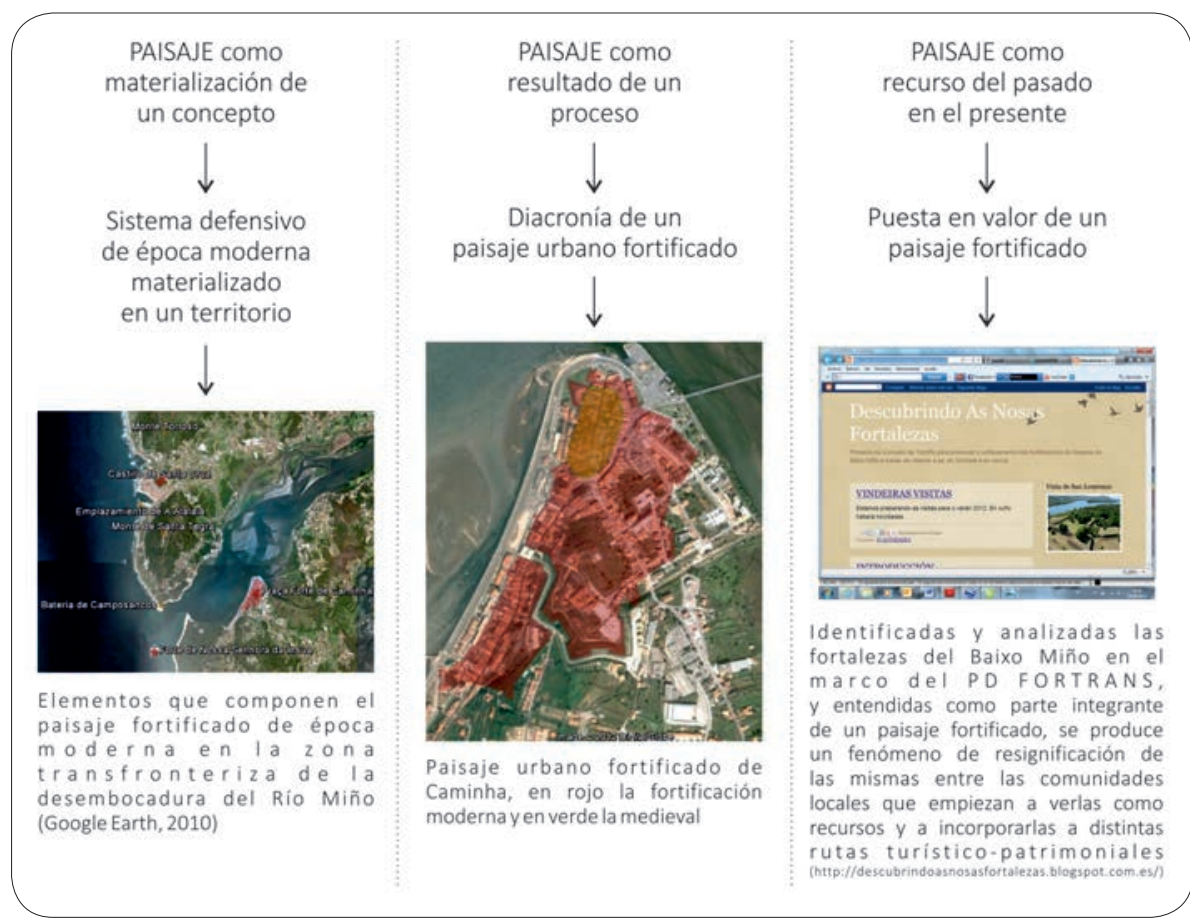

Figura 13. Modelo conceptual de la noción de paisaje manejada. Se representan las tres conceptualizaciones que nos interesa valorizar y analizar en este texto. 

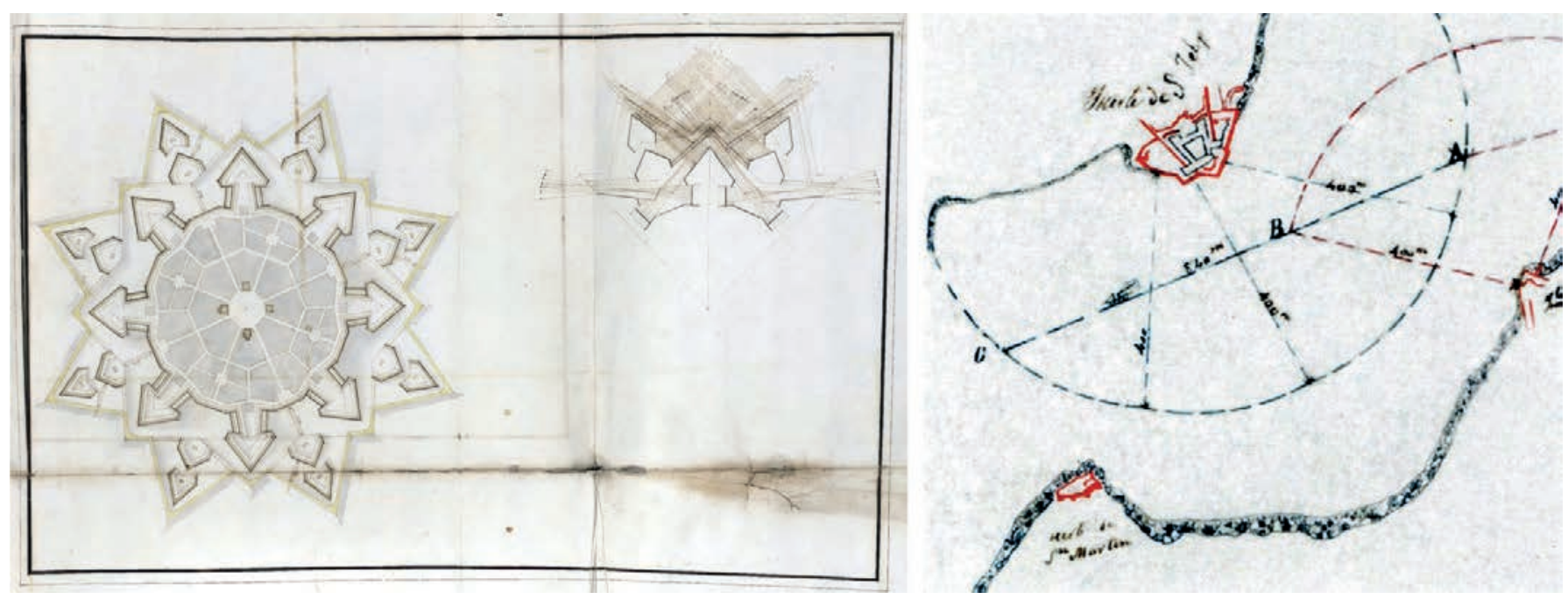

Figura 14. La imagen de la derecha corresponde a un Estudio de Fortificação del Teniente General Nicolao de Langres (Ca. 1661) (Biblioteca Nacional de Lisboa, signatura 7445; http://purl.pt/15387). Representa la planta de una fortificación ideal, con ocho baluartes y cortinas protegidas por revellines. En la parte superior derecha se presenta un estudio detallado de las líneas de tiro desde y hacia cada una de las partes de esta fortaleza. La imagen de la izquierda muestra el emplazamiento de los castillos de San Felipe, La Palma y San Martín, que defienden la zona más angosta de la ría de Ferrol. Se representan los sectores que baten los dos primeros (San Felipe C-A, La Palma B-D, ambos B-A) (imagen extraída de López Hermida 2005; el original se conserva en el Archivo Intermedio de la Región Militar Noroeste). Como vemos, la defensa de las plazas no sólo se tiene en cuenta en cada plaza, sino también entre plazas que forman parte de un mismo conjunto defensivo.

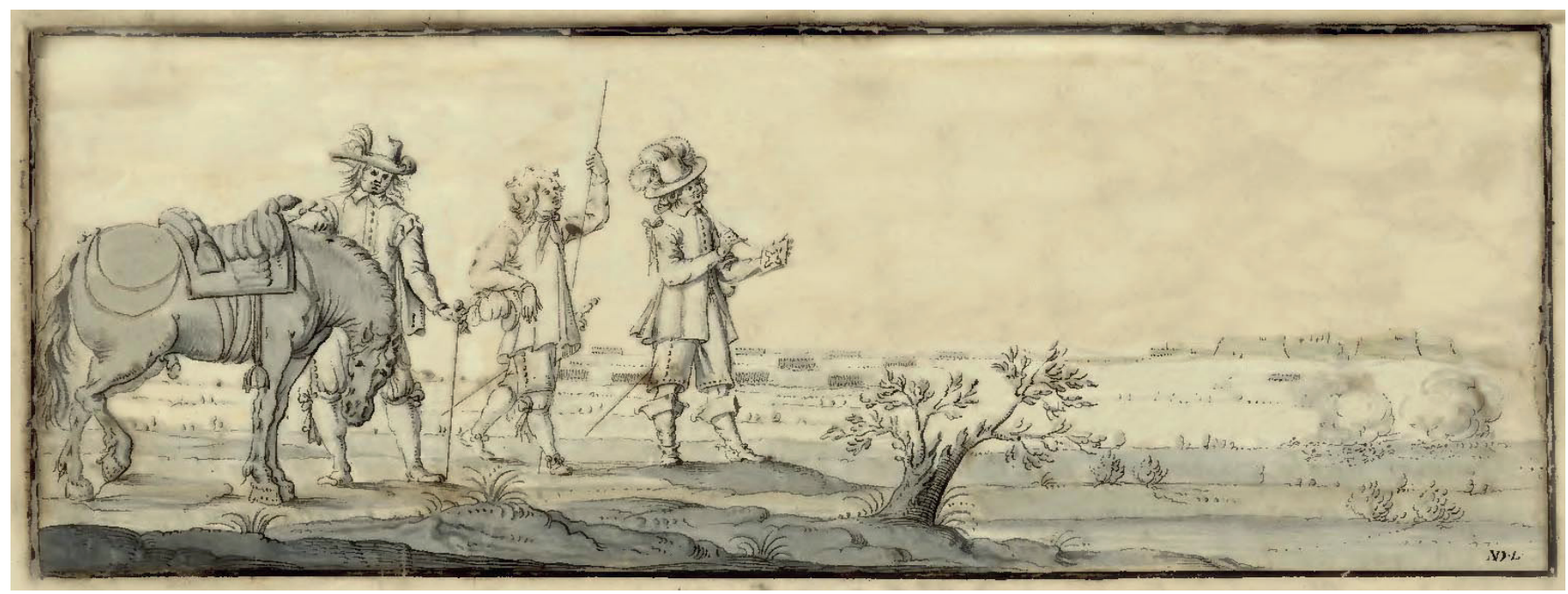

Figura 15. Representación de un ingeniero diseñando una fortificación con dos auxiliares. Dibujo del Teniente General Nicolao de Langres ca. 1661 (Biblioteca Nacional de Lisboa, signatura 7445; http://purl.pt/15387).

abaluartada y de las máximas a las que estas formas responden, a la espacialidad del territorio (Figuras 14 y 16). De la misma manera que debe existir una mutua visibilidad y defensa entre todos los elementos arquitectónicos que componen la fortaleza, esta máxima se aplica también a la relación entre fortalezas, que funcionan como cada una de las partes de una fortificación, siguiendo una planificación y diseño que trate de cubrir todas las partes del territorio, donde unas arquitecturas visibilicen y defiendan a otras. Ello supone que los ingenieros militares deben llevar a cabo previamente un estudio pormenorizado de la topografía y los distintos elementos morfológicos que la componen, a fin de localizar los mejores emplazamientos, adaptar las plantas a ellos y complementar la defensa natural con la disposición de elementos fortificados complementarios de distinta tipología y funcionalidad (Figura 15).

Cada arquitectura se ubica en un espacio estratégico dentro de las zonas que se quieren defender, unas 

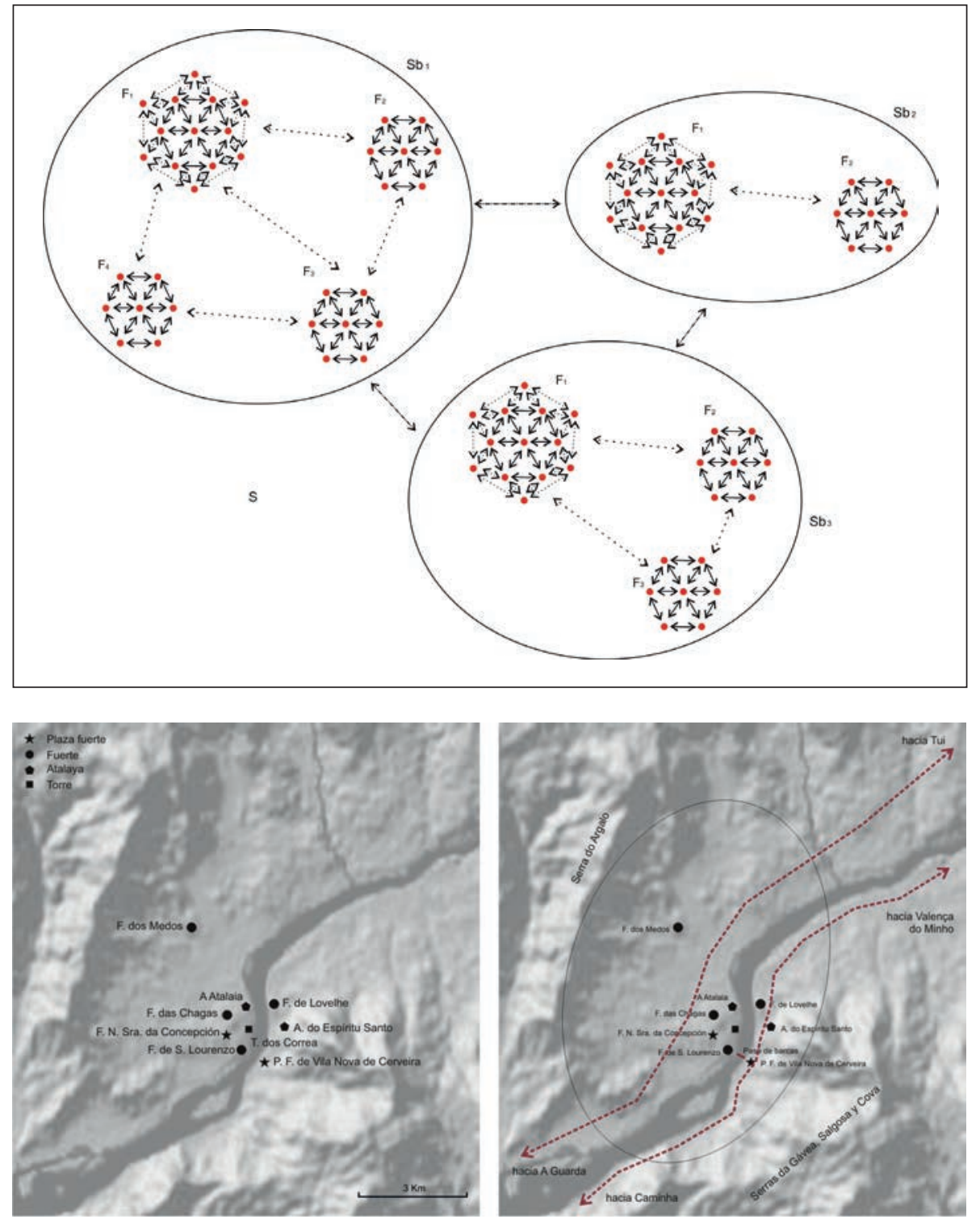

Figura 16. Representación del modelo teórico de un paisaje fortificado, con las relaciones existentes entre los elementos que lo componen. Se representa la interrelación (flechas) entre partes de una fortificación (puntos rojos), entre fortificaciones (F) y entre subsistemas o conjuntos defensivos (Sb). Todo ello forma un sistema fortificado, donde las máximas aplicables al diseño de una fortificación se han hecho extensibles al territorio.

Figura 17. Localización de las fortificaciones que forman parte del subsistema Goián-Vila Nova de CerveiraMedos sobre un Modelo Digital de Elevaciones (MDE). Las fortificaciones se sitúan a ambos lados del río Miño. En la imagen de la derecha, hemos representado con un óvalo la cuenca que controla este subsistema, un espacio enmarcado por la Serra do Argalo en Galicia y las da Gávea, Salgosa y Cova en Portugal, y con una línea roja punteada las vías de tránsito terrestre que discurren paralelas al Miño y que también controlan estas fortificaciones. fortificaciones visualizan y defienden a las otras, de tal manera que se produce una defensa subordinada entre todos los elementos que poco a poco van construyendo el paisaje fortificado, un sistema donde se materializan las máximas de la fortificación abaluartada, especialmente aquella que dice que "toda la Fortificacion exterior esté dominada, defendida y descubierta de la interior". ${ }^{29}$

29 De las máximas que propone Sebastián Fernández de Medrano nos interesan para los aspectos que estamos comentando, la que recogemos arriba (la duodécima) y la undécima "que no aya parte de la Plaça que no estè vista, y defendida de otra" (Fernández de Medrano 1700: 11), las cuales, según el autor, se encuentran dentro de las que se consideran inviolables a la hora de llevar a cabo una fortificación. Para Lecuze por ejemplo, la undécima regla de Medrano debe ser la primera a tener en cuenta. Su máxima quinta dice "La Plaza debe estar igualmente fortificada por todas partes, dominar la campaña vecina, y descubierta hasta el alcance de cañon" (Lucuze 1772: 22).
Un ejemplo de ello podemos observarlo en el conjunto defensivo que hemos identificado como subsistema de Goián-Vila Nova de Cerveira-Medos, donde las fortificaciones se disponen protegiendo tanto el paso de barcas que se localiza en el río Miño como las vías de tránsito que discurren siguiendo el trazado del mismo, a uno y otro lado de la frontera, tal y como se puede ver en la Figura 17.

Las fortificaciones agrupadas situadas en ambas márgenes del río corresponden a dos momentos distintos, ${ }^{30}$ uno de época medieval y otro de época moderna. Será en el siglo XVII cuando en torno a dos poblaciones anteriores, la gallega Barca de Goián y la portuguesa Vila Nova de

\footnotetext{
30 Nos referimos a su momento inicial de construcción.
} 


\begin{tabular}{|c|c|c|c|c|c|c|c|c|c|}
\hline \multirow[b]{2}{*}{ Nombre de entidad } & \multirow{2}{*}{$\begin{array}{l}\text { Tipo de } \\
\text { entidad }\end{array}$} & \multicolumn{2}{|c|}{ Visibilidad } & \multicolumn{6}{|c|}{ Visibilización } \\
\hline & & $\underset{\mathbf{m}}{\mathbf{A} 800}$ & $\begin{array}{l}\text { A } 2 \\
\text { km }\end{array}$ & $\begin{array}{c}800 \text { m } \\
\text { mín. }\end{array}$ & $\begin{array}{l}800 \mathrm{~m} \\
\text { máx. }\end{array}$ & $\begin{array}{l}2 \text { km } \\
\text { mín. }\end{array}$ & $\begin{array}{l}2 \text { km } \\
\text { máx. }\end{array}$ & $\begin{array}{l}\text { Ac. } \\
\text { Mín. }\end{array}$ & $\begin{array}{l}\text { Ac. } \\
\text { Máx. }\end{array}$ \\
\hline Fortaleza de N. Sra. da Concepción & Fortificación & 3 & 8 & 1 & 3 & 1 & 7 & 1 & 19 \\
\hline Forte de San Lorenzo & Fortificación & 4 & 9 & 3 & 5 & 5 & 8 & 6 & 8 \\
\hline Torre dos Ratos & Fortificación & 3 & 9 & 1 & 2 & 1 & 10 & 4 & 17 \\
\hline Torre dos Correa & Fortificación & 6 & 8 & 2 & 4 & 6 & 7 & 6 & 7 \\
\hline Forte das Chagas & Fortificación & 1 & 7 & 1 & 4 & 1 & 9 & 3 & 22 \\
\hline Muelle de Goián & Estructura & & & 5 & 7 & 6 & 8 & 6 & 8 \\
\hline Praça Forte de Vila Nova de Cerveira & Fortificación & 5 & 10 & 2 & 5 & 7 & 10 & 8 & 12 \\
\hline Emplazamiento Fortín de Vila Nova & Estructura & 5 & 10 & 3 & 5 & 8 & 10 & 9 & 12 \\
\hline Muelle de Vila Nova de Cerveira & Estructura & & & 4 & 5 & 8 & 9 & 8 & 10 \\
\hline Forte de Lovelhe & Fortificación & 2 & 9 & 1 & 3 & 3 & 11 & 9 & 23 \\
\hline Atalaia da Mata & Fortificación & 0 & 3 & 1 & 3 & 1 & 10 & 1 & 14 \\
\hline Castelo de Medos & Fortificación & 0 & 0 & 1 & 2 & 1 & 2 & 1 & 29 \\
\hline
\end{tabular}

Significado de las abreviaturas empleadas en la tabla: mín.: número mínimo de entidades que se observan desde una entidad concreta; máx.: número máximo de entidades que se observan desde una entidad concreta; Ac. Mín.: número mínimo de entidades que visibilizan teniendo en cuenta el cálculo de visibilidad acumulada; Ac. Máx.: número máximo de entidades que visibilizan teniendo en cuenta el cálculo de visibilidad acumulada.

Figura 18. Visibilidad y visibilización entre fortalezas y estructuras que conforman el subsistema Goián-Vila Nova de Cerveira-Medos. Se han calculado en un radio de $800 \mathrm{~m}$ y $2 \mathrm{~km}$ y se tiene en cuenta también la visibilidad acumulada entre todos los elementos de la totalidad de la raia húmeda.

Cerveira, se vaya poco a poco articulando un sistema defensivo complejo que protege el paso de barcas del Miño y la vía que discurre por el lado portugués y que comunica Valença, población enfrentada a la ciudad de Tui, y Caminha, situada en el estuario del Miño. En el año 1663 los portugueses ocupan la villa de Goián y comienzan a construir aquí una defensa que funcionará conjuntamente con la que ya existía y se perfecciona a la moderna ahora en Vila Nova de Cerveira (Ericeira 1945, vol. IV: 170 y ss.) habilitando aquí una zona estratégica de dominio portugués en territorio gallego desde donde se efectúan varias incursiones en el país vecino. Los gallegos deciden establecerse entonces en las proximidades, protegidos por el noroeste por la Serra do Argalo, al otro lado de la vía de tránsito que comunica la ciudad episcopal de Tui y la villa de A Guarda en la desembocadura del Miño, construyendo el Forte de Santiago Carrillo en el lugar de Medos.

En la Figura 18, se recogen las visibilidades y visibilizaciones que hemos calculado entre las entidades identificadas en el subsistema Goián-Vila Nova de Cerveira-Medos, es decir, qué número de entidades son visibles desde cada entidad analizada (visibilidad) y desde cuántas entidades es visible la entidad analizada (visibilización). Como se puede apreciar existe una relación visual entre todas ellas. Únicamente no existe relación con el Castelo de Medos, que se corresponde en la Figura 19 con el punto situado más arriba, ya que los radios que hemos usado para el cálculo son de $800 \mathrm{~m}$ y 2 $\mathrm{km}$, pero desde éste se domina la vía de tránsito terrestre gallega, así como otros puntos a larga distancia, pudiendo ser visible, por ejemplo, el movimiento de grandes tropas cruzando el río, tal y como se muestra en la Figura 20.

La ubicación de estas fortificaciones responde a aspectos estratégicos, por una parte, la defensa de las vías de tránsito terrestres o fluvial, por otra, el control de los pasos de barca históricos: en uno de ellos la Praça Forte de Vila Nova de Cerveira se enfrenta al actual Castelo de San Lourenzo, ${ }^{31}$ aquí se emplazaba hasta hace pocos años el Ferry que comunicaba Goián con Vila Nova; el otro, situado

\footnotetext{
31 Este fuerte se construye con posterioridad a la finalización de la Guerra de la Restauração, pero se hizo sobre otro de menores dimensiones conocido como Forte da Barca que fue destruido por los portugueses una vez conquistada la villa. Por lo tanto, el análisis que hacemos de la relación entre ambas fortificaciones corresponde al de las defensas originales de aquel periodo de guerra.
} 


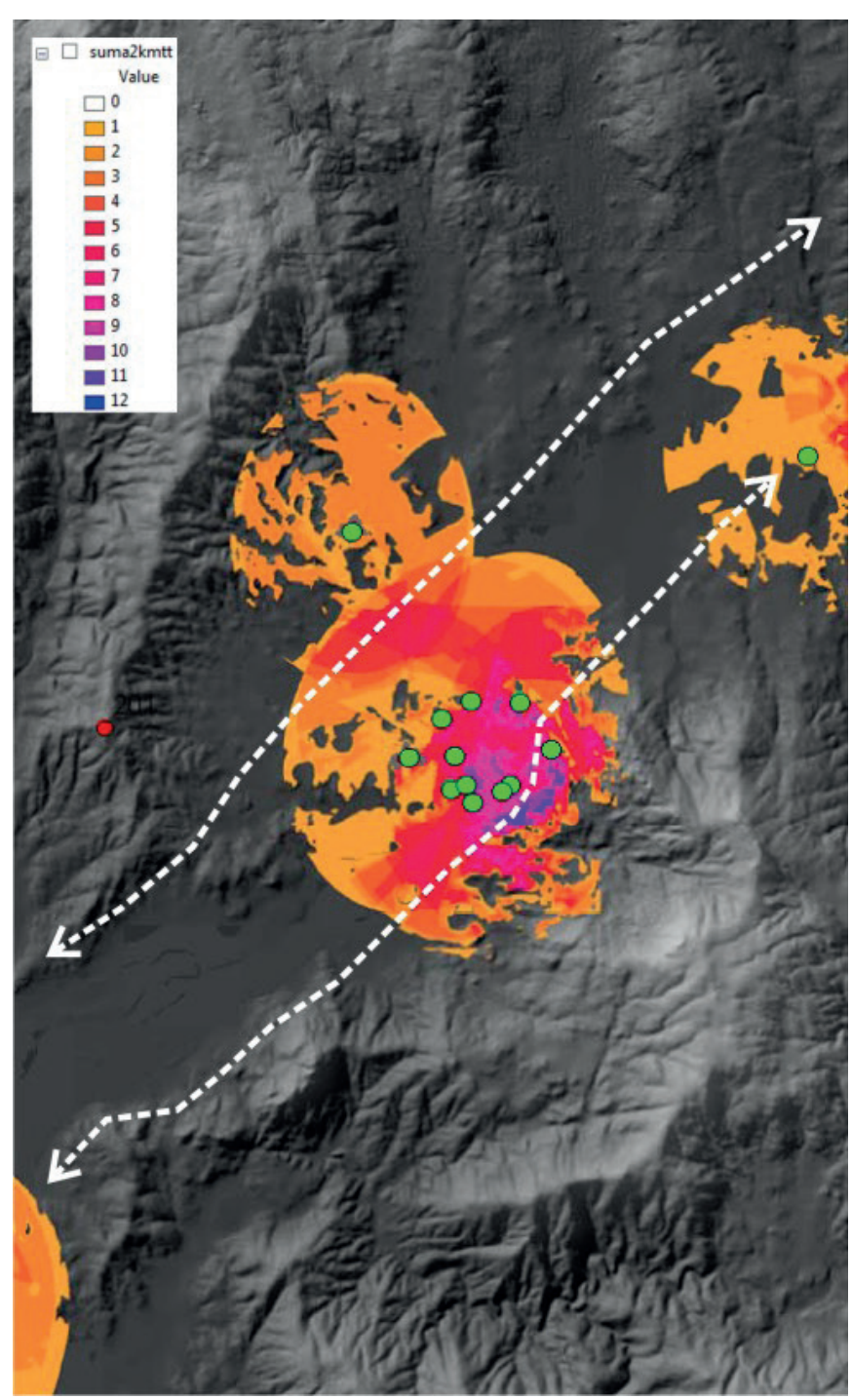

Figura 19. MDE de la zona en la que se emplaza el subsistema Goián-Vila Nova de Cerveira-Medos con la representación de las visibilidades en un radio de $2 \mathrm{~km}$. Como se puede apreciar las zonas que concentran un mayor control visual son aquellas en las que se localizan las vías de tránsito, tanto en el lado gallego (al que corresponde la parte superior de la imagen) como en el portugués.

en el lugar donde se emplazan el Forte de São Francisco de Lovelhe en Portugal y A Atalia o Torre dos Ratos en Galicia, hoy está ocupado por el puente internacional que comunica las poblaciones de Goián y Lovelhe. ${ }^{32}$

\footnotetext{
32 No existe un paso documentando en la planimetría de la época entre Lovelhe y A Atalia, sin embargo, debió ser una zona portuaria en épocas anteriores ya que a ambos lados del río se documentaron sendos yacimientos durante la construcción del puente internacional, el del lado gallego identificado como de época romana y el del lado portugués como un "cais de acostagem fluvial”, una estructura portuaria de la Alta Edad Media (Almeida 2002). En una publicación posterior se adscribe a época prerromana y romana (Ramos y Branco 2010: 16-17).
}

Estos aspectos materializan en el paisaje las máximas de la fortificación abaluartada por las que se rige el arte de la guerra de época moderna. Vemos cómo las relaciones entre las partes de una fortificación se trasladan al territorio, existiendo también relaciones entre fortalezas. Pero además, también existen otros elementos en este territorio que permiten comunicar un subsistema con otro.

Para el caso gallego ${ }^{33}$ conocemos la existencia de fachos, por la documentación histórica y bibliográfica, ${ }^{34}$ por su representación en distintos documentos cartográficos (Figura 21) o por la toponimia. A partir de esta documentación, hemos localizado algunos a lo largo del Baixo Miño (se corresponden con los puntos rojos de la Figura 22). Estos se emplazan en zonas de mayor altitud que aquellas en las que se ubican las fortificaciones, normalmente en la línea de montañas que cierra por el norte el valle del Miño. Desde estos puntos hemos realizado el cálculo de visibilidad en un radio de 2 y $5 \mathrm{~km}$, con lo que pudimos comprobar que complementan, a mayor distancia, las visibilidades de las entidades que confirman los subsistemas y que, además, se encadenan con estas y con las del facho anterior y posterior (Figura 22).

\section{Paisaje como resultado de un proceso}

La segunda conceptualización se refiere al paisaje entendido también como resultado de un proceso constructivo que, en este caso, conllevó su adaptación al nuevo arte de fortificar, transformando los espacios urbanos medievales, que estaban ceñidos por una cinta amurallada con sus correspondientes torres, en espacios de mayor amplitud delimitados por una o varias líneas defensivas que a medida que avanzaban hacia el exterior del recinto urbano descendían en altura. Buen ejemplo de ellos son los núcleos fortificados que se construyeron en torno a ciudades medievales anteriores como Caminha, Vila Nova de Cerveira, Tui, Valença, Salvaterra do Miño, Monção o Melgaço.

\footnotetext{
33 Para el territorio portugués no hemos conseguido documentar ningún facho como estructura pero sabemos que debían existir, por lo que se recoge en Antunes (1996: 3): "Tentamos então [...] fazer um ponto da situação relativamente às obras de defesa projectadas, delineadas, construídas e utilizadas sob o espectro das Guerras da Restauração, com os dados que possuímos até meados do século XVIII. Relegamos, por uma questão de método e de tempo, o estudo dos fachos e atalaias que pontuavam a nossa defesa raiana ou que com ela estavam articulados, para um trabalho de maior enverfadura e de enquadramento temporal diverso". Y por la presencia de algún topónimo facho en la zona. 34 “Os portugueses mailos galegos andaron sempre en guerra. E en Goián había un castelo onde se defendían do ataque. Para avisar do inimigo, nos outeiros que arrodean o castelo acendían fogueiras ou fachos. Desta forma os da fortaleza estaban preparados para a defensa. Por iso os portugueses non conseguiron vencer ós do castelo" (Gude 2009: 28).
} 

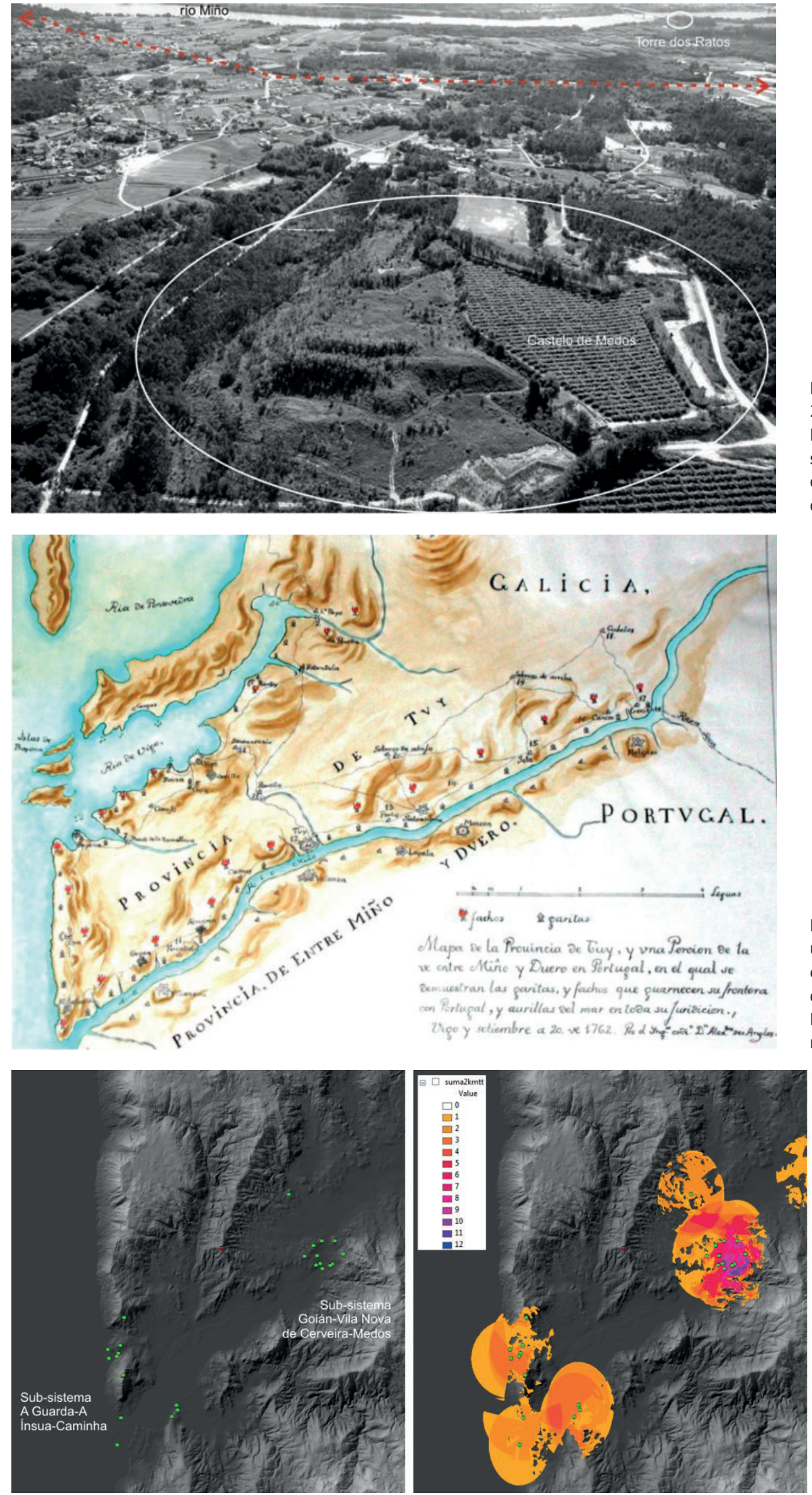

PORTVGAL.
Figura 20. Vista aérea del fuerte de Medos de 2009 (proporcionada por Terra Arqueos S.L.). En primer término se localiza el fuerte, en segundo término la vía de tránsito que une Tui con A Guarda y, al fondo, el río Miño y la Torre dos Ratos.
Figura 21. Mapa de la Provincia de Tuy, y una Porcion de la de entre Miño y Duero en Portugal [...] del Ingeniero Alexandro des Anglés de 1762 (copia en el Archivo Privado Jaime Garrido). Los fachos aparecen representados como una luminaria roja.

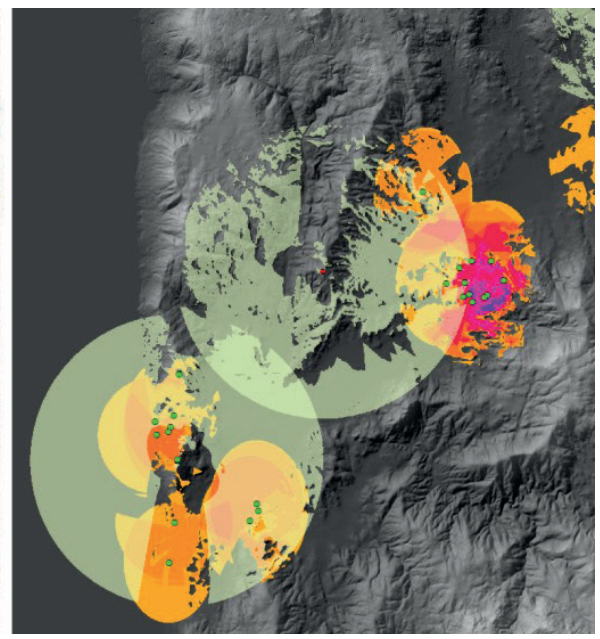

Figura 22. MDE con las entidades que componen los subsistemas de A Guarda-A Insua-Caminha y Goián-Vila Nova de Cerveira-Medos. En la imagen central, visibilidades en un radio de $2 \mathrm{~km}$ de estas entidades. En la imagen de la derecha, las visibilidades anteriores se complementan con las de los fachos en un radio de $5 \mathrm{~km}$. 


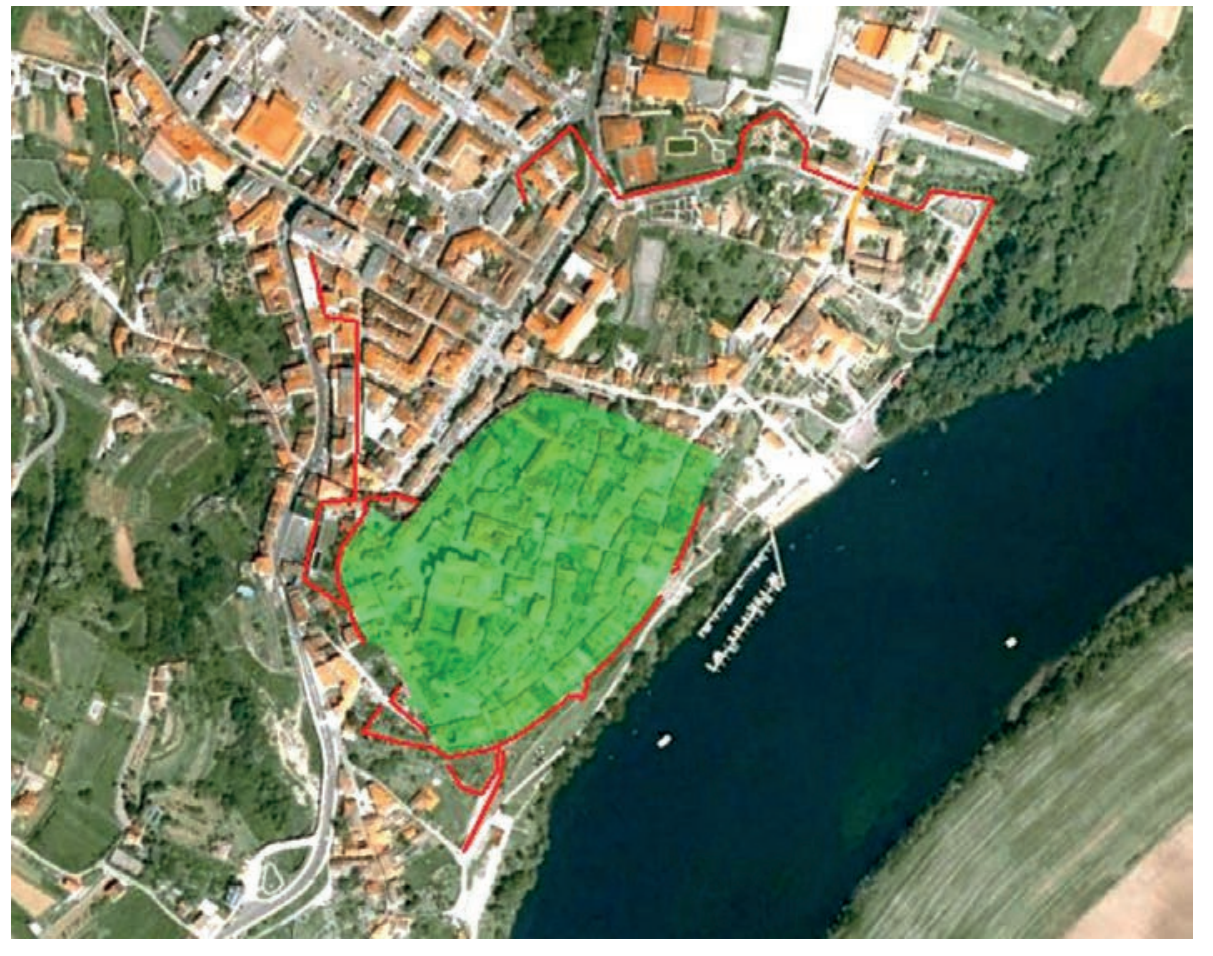

Figura 23. Imagen satélite de la ciudad de Tui (2006, (c) Google Earth), sobre la que se ha dibujado en verde el recinto medieval y en rojo los restos de la fortificación moderna o su trazado en aquellos lugares en el que el crecimiento urbanístico ha respetado dicho trazado.
Pero al igual que sucedía con la aplicación del concepto defensivo de una plaza a la totalidad del territorio, en este caso también se produce el mismo proceso y poco a poco sobre un paisaje anterior, se va conformando a lo largo del periodo de guerra una nueva estructura morfológica que responde a otras lógicas defensivas y constructivas (Blanco-Rotea 2011: 145-148). Un paisaje fortificado que seguirá completándose en los dos siglos siguientes (Figura 24). En este proceso se conjugan dos aspectos, por una parte, la reutilización de fortificaciones previas que o bien se mantienen sin que exista una transformación de sus elementos constructivos (como en el caso de Lapela, donde no hubo una alteración significativa del castillo medieval, Figura 25), o bien se conservan pero son envueltas por estructuras modernas (como en el caso de Tui, Figura 23) o bien se emplean como soporte de las estructuras modernas (como mostrábamos en la Figura 6 para el caso de Valença). Por otra parte, estarían las construcciones realizadas ex novo, escogiendo los emplazamientos que responden a los principios comentados anteriormente y siguiendo ya las máximas de la fortificación abaluartada, como el Castelo de Medos (Figura 21).
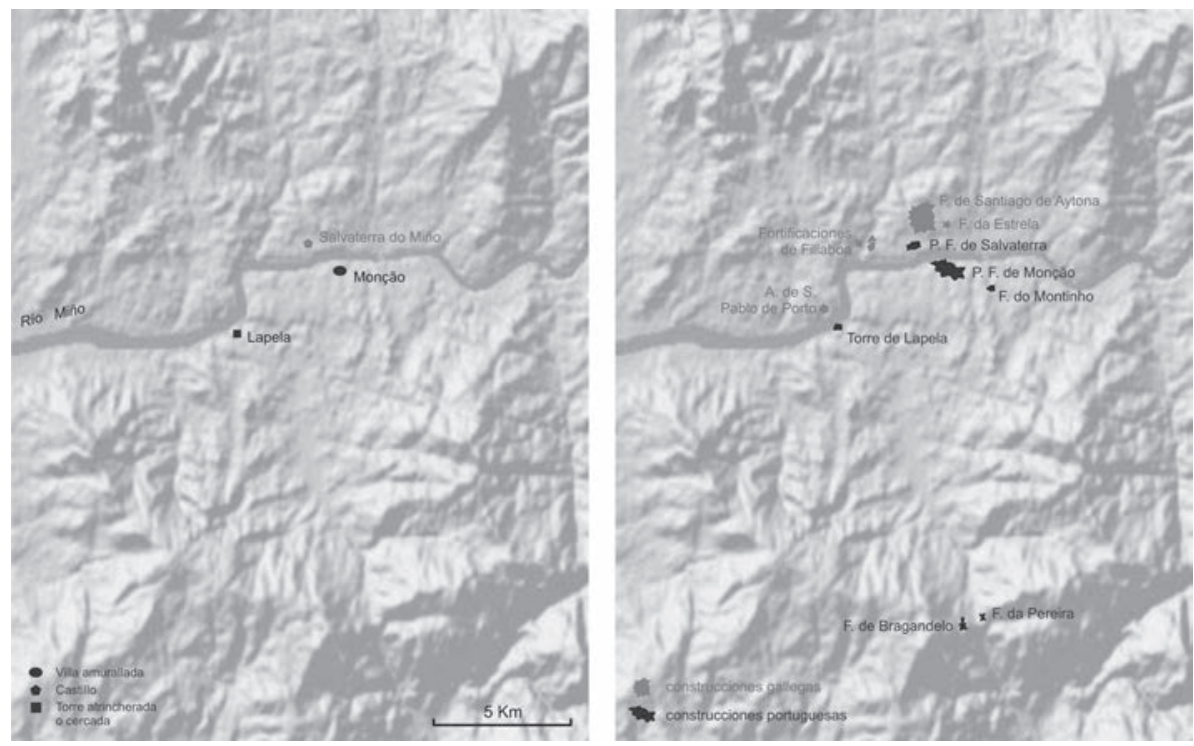

Figura 24. MDE de la zona de SalvaterraMonção y Extremo, en el que se han indicado las poblaciones medievales, a la izquierda, y las construcciones realizadas una vez conquistada Salvaterra do Miño en 1643 por los portugueses, a la derecha. Además se han situado los fuertes de Extremo (Forte de Bragandelo y Forte da Pereira) dispuestos en dos altos que jalonan la vía de tránsito que desde Monção se dirige hacia el interior de Portugal por Arcos de Valdevez. 


\section{Paisaje como recurso del pasado en el presente}

Algunas de las construcciones que componen el paisaje fortificado miñoto se están convirtiendo en un recurso cultural. El Castillo de Santa Cruz en A Guarda fue recientemente restaurado y rehabilitadas sus construcciones como centro de interpretación de las fortalezas transfronterizas, ${ }^{35}$ pero existen otros ejemplos similares a ambos lados de la raia.

Uno de los aspectos que nos interesa destacar de la iniciativa de llevar a cabo un plan director de las fortalezas transfronterizas de esta zona en 2003 era precisamente su interés por conocerlas, comprenderlas y revalorizarlas como conjunto y como paisaje, sirviendo de base "para a construción de novos equipamentos e dotacións de calidade e para a recuperación de valores culturais materializados na raia húmida" (Vecoña 2006: 5). Alguno de los objetivos de este plan director eran "Poñer en relación as fortalezas co contexto territorial e socio económico do Baixo Miño" o "Elaborar unha estratexia conxunta e formular usos e propostas viables" (Vecoña 2006: 5). Precisamente la documentación y valorización de estas fortificaciones y los elementos asociados a ellas, y la divulgación de su conocimiento entre el público en general y las poblaciones locales en particular, permitió poner en marcha distintos procesos de resignificación entre los que se engloban diferentes iniciativas que inciden en la puesta en valor de los diferentes conjuntos defensivos $y$, con ello, del paisaje fortificado transfronterizo. Una de ellas es el diseño de unas rutas realizadas a pie, en bicicleta y en canoa que tienen como objetivo promover el conocimiento de las fortificaciones del subsistema que se emplaza en el ayuntamiento de Tomiño, bajo el título de "Descubrindo as Nosas Fortalezas". ${ }^{36} \mathrm{O}$ el diseño de una "Ruta de puesta en valor de las fortalezas transfronterizas del Miño" ${ }^{37}$ por parte del Estudio Crecente Asociados. ${ }^{38}$

Este tipo de iniciativas son una muestra de cómo el paisaje se está empleando como recurso, contribuyendo a la puesta en marcha de los últimos eslabones de la cadena

\footnotetext{
El castillo fue abierto al público en diciembre de 2013 y el centro de interpretación, que cuenta con una exposición permanente sobre esta temática (https://minerva.usc.es/xmlui/handle/10347/14903), en julio de 2016.

$36 \mathrm{http} / / /$ descubrindoasnosasfortalezas.blogspot.com.es/search/label/00\%20 INTRODUCCI $\% \mathrm{C} 3 \% 93 \mathrm{~N}$

37 http://www.crecenteasociados.com/es/proyectos/31/ruta-de-puesta-envalor-de-las-fortalezas-transfronterizas-del-minyo/

38 Algunas de las actuales iniciativas para la puesta en valor de este paisaje, se basan en otras anteriores a la elaboración del Plan Director Fortrans, que se centraron en el diseño de rutas para esta zona de temática más amplia, como la que se recoge en Santos Solla (1999) bajo el título "Guía da Raia".
}

de valor del patrimonio, que ha sido posible gracias precisamente a la elaboración de aquel Plan Director y al trabajo de difusión que de él hicieron tanto los miembros del equipo como las distintas administraciones implicadas. El caso de "Espazo Fortaleza" (http://www.espazofortaleza.com/), resultado del proyecto de recuperación del entorno del Forte de San Lourenzo en Goián (Tomiño) realizado recientemente, es un ejemplo de la relación entre la arquitectura y el paisaje como recurso, ya que, por una parte, hace hincapié en la revalorización y resignificación de esta fortaleza, centrándose en un único bien, pero también como punto de partida y lugar de enlace con otros elementos fortificados de la zona a través de una ruta por otras fortificaciones menos conocidas (y visibilizadas) del entorno, que se han englobado bajo el nombre de "patrimonio oculto" dentro de una iniciativa de Turgalicia. Ahora queda por ver la implicación y aceptación que tiene la sociedad local por este tipo de iniciativas y si se identifica o no con ellas.

\section{Pensando en una doble dirección}

Siguiendo nuestro argumento inicial, volviendo a la fuerte relación entre paisaje y arquitectura que apuntábamos al principio y revisando lo visto en los dos apartados anteriores, podríamos decir, siguiendo a Derrida (1986) en su Metáfora Arquitectónica, y trasladando su pensamiento también al paisaje, que arquitectura y paisaje son una espacialización del tiempo y el pensamiento. Si el paisaje es "el espacio de las relaciones sociales" (Orejas et al. 2002: 306), la arquitectura es una porción de ese espacio acotado (Ching 1984: 108), por tanto, paisaje y arquitectura están unidos espacialmente, materializados temporalmente y significados simbólicamente.

Unificar el estudio de ambas entidades del registro arqueológico era importante puesto que partíamos de la idea de la existencia de una interacción entre ellas, ya que las arquitecturas defensivas y todas las estructuras asociadas a las mismas (de control, viarias, de interrelación, etc.) conformaban unos espacios construidos, unos conjuntos o subsistemas $^{39}$ defensivos, y no debían estudiarse, analizarse y

\footnotetext{
39 En trabajos anteriores empleamos el término "subsistema" para referirnos a cada uno de los conjuntos construidos para fortificar una zona concreta del Miño y que guardaban una serie de relaciones que hacían que los entendiéramos precisamente como un conjunto (Blanco-Rotea 2011). El término subsistema se empleó ya que formaban parte de un sistema defensivo más complejo que era la defensa de la raia entre Galicia y Portugal (Cobos-Guerra 2011). En este trabajo decidimos emplear el término "conjunto" como sinónimo de "subsistema" ya que es el que optamos por usar en la web "La construcción de una frontera" que acompaña a este texto, por tratarse de un término de mejor comprensión que "subsistema" para un público más amplio.
} 
valorizarse como entidades aisladas. Conjuntamente con el espacio físico articulan un paisaje cultural, un sistema defensivo complejo, el paisaje fortificado transfronterizo del Baixo Miño en Galicia y Alto Minho en Portugal.

Si el estudio en detalle de la arquitectura y del paisaje, por separado, ha permitido en las últimas décadas abordar otras dimensiones del registro arqueológico que no estaban antes presentes y acceder así al mayor número de elementos (materiales y simbólicos) que conforman ambas realidades, intentar introducir dentro del proceso de análisis e interpretación del registro arqueológico al paisaje y la arquitectura conjuntamente, nos permitirá acceder a un mayor número de significados. Nuestra propuesta pasará por abordarlas como parte integrante de un mismo espacio construido, con distintos niveles de significación, donde la arquitectura construya paisaje y el paisaje signifique la arquitectura.

Trataremos ahora de identificar las herramientas teóricas con las que intentar deconstruir primero y reconstruir después esos espacios pensados, materializados y transformados en la frontera galaico-portuguesa.

\section{MARCOS. ARQUEOLOGÍA DE LA ARQUITECTURA Y ARQUEOLOGÍA DEL PAISAJE}

Comentábamos anteriormente, que este texto pretende desgranar el marco conceptual y teórico empleado a la hora de trabajar con el paisaje fortificado de época moderna en la frontera miñota. Valorándolo con distancia, este marco se ha ido ensanchando a medida que nuestras necesidades de investigación se ampliaban y que nuestra visión sobre la arquitectura y el paisaje y la relación existente entre ambos se iba enriqueciendo. Visto con cierta perspectiva, se puede llegar a pensar que, tal vez, sea un marco estrecho y que la AA y la ArPa sean insuficientes para captar todos los matices que los espacios construidos nos proporcionan. Pero lo cierto es que adoptar ambas estrategias de investigación nos ha permitido, precisamente, aunar, ampliar, abrirnos y buscar sinergias con otras disciplinas. Creemos que ambos enfoques al haber adoptado (y contribuido a construir) los conceptos de arquitectura y paisaje a los que nos hemos referido más arriba, nos permitieron generar aproximaciones al patrimonio construido mucho más abiertas, dinámicas y, al final, transdisciplinares que las que habríamos conseguido con otros enfoques más tradicionales. Se puede ampliar más el marco, pero nuestra propuesta pretende aunar ambas perspectivas sin renunciar a la potencialidad de cada una de ellas, a través no del desarrollo de nuevas arqueologías, que sólo seguirían contribuyendo a la fragmentación del discurso arqueohistórico (Mañana et al. 2002: 23), sino para servir a nuestro propósito de articular estrategias de investigación en torno a proyectos o programas que focalicen sus objetivos sobre el patrimonio, desarrollando perspectivas de investigación y métodos de trabajo realmente adecuados al objeto, y no a intereses disciplinares o curriculares concretos.

Por otra parte, ya tratamos en otra ocasión el porqué de la introducción de la AA dentro del grupo de investigación en el que se desarrolló este trabajo (Mañana et al. 2002: 12-13), en el cual se diseñó un plan de investigación centrado en el estudio de los paisajes construidos durante la Prehistoria en el noroeste de la Península Ibérica a través del análisis de la concepción territorial, la forma de conceptualización del espacio y construcción del paisaje generados por las diferentes sociedades que habitaron nuestro país en ese periodo (Mañana et al. 2002: 12). El estudio de estos paisajes se había llevado a cabo desde una escala macroespacial, aportando aspectos sobre la ubicación de los espacios habitacionales, los patrones de emplazamiento, los sistemas de ocupación del espacio y las condiciones medioambientales y de subsistencia; pero era necesario contrastar los modelos a escala macro con otros que permitieran completar y matizar la visión de los paisajes prehistóricos, por lo que se propuso abordar el estudio a escala microespacial del registro arqueológico, lo que nos llevada directamente al análisis de la arquitectura. Inicialmente, este estudio se centró en dos tipos de arquitectura, la funeraria y la doméstica (Mañana et al. 2002: 12), pero la introducción del análisis del registro arquitectónico conllevó además ampliar el periodo cronológico en el que se había centrado el plan de investigación que mencionamos arriba, para trabajar también con arquitecturas de períodos postclásicos, lo cual conllevó, además, analizar construcciones con otras funcionalidades, como las vinculadas a la arquitectura de poder (arquitecturas eclesiásticas y fortificaciones) y, por extensión, con la caracterización de los paisajes en que éstas se ubican y contribuyen a construir. Trabajar con el registro arquitectónico suponía acceder a otras claves para la comprensión de las formaciones socioculturales estudiadas, pues aportaba una importante información que permitía "ver de diferente forma los factores de orden individual, social, políticoeconómico, subsistencial y simbólico que prevalecían en las comunidades del pasado" (Mañana et al. 2002: 
12). A partir de estos planteamientos y de la adopción del estudio de la arquitectura desde la AA, se diseñó un programa de investigación integral centrado en la arquitectura y los espacios construidos que se acabó articulando en cuatro sublíneas de investigación: monumentalidad megalítica, espacios domésticos de la Edad del Hierro, arquitectura histórica y espacios agrarios.

El objetivo entonces de la introducción de la AA fue, por una parte, atender al cambio de escala macroespacial a una microespacial $y$, por otra parte, a la ampliación de nuestra óptica arquitectónica para abarcar el estudio de nuevos periodos y de estructuras con otras funcionalidades. La base conceptual inicial de aquella propuesta fue la ArPa (Criado-Boado 1999), pero era necesario introducir otras estrategias de investigación que completaran una aproximación macro al espacio construido.

\section{ARQUEOLOGÍA DEL PAISAJE}

Se entiende la $\mathrm{ArPa}$ como un modelo interpretativo del registro arqueológico, donde los elementos que lo conforman, sea cual sea su escala, se analizan "como objetos implicados en el paisaje y participantes del mismo" (Parcero-Oubiña 2000: 20), y también como una estrategia de investigación derivada de ese modelo, tal y como proponen Barreiro et al. (2009: 4). Entender la ArPa como tal implica, al mismo tiempo, manejar una determinada concepción de paisaje, donde éste es tanto un contexto como un objeto de estudio susceptible de ser analizado e interpretado con una metodología arqueológica (Parcero-Oubiña 2000: 20) ${ }^{40}$ como hemos visto.

Este marco interpretativo pretende superar, tal como apuntamos, una perspectiva espacial determinista (Mañana et al. 2002: 25). En la ArPa se integran numerosas corrientes que conforman un variopinto panorama, pues el estudio del paisaje es de interés a numerosas disciplinas, en él "confluyen intereses, puntos de vista, tradiciones académicas y de investigación y técnicas diferentes" (Orejas 1995a: 222).

Dentro de este interés, la arqueología se ha mostrado como una de las más activas, en parte por ser "precursora en la problematización e investigación del concepto de paisaje cultural, de gran fortuna en la

\footnotetext{
40 "La Arqueología del paisaje [...] es ante todo una propuesta metodológica para la investigación de las sociedades antiguas desde su espacialidad" (Orejas et al. 2002: 306).
}

actualidad. Este concepto surge, sobre todo, en ciertas aproximaciones de la Arqueología, la Geografía y el Urbanismo, desde hace 25 años (aunque ya había sido acuñado por el geógrafo Carl O. Sauer, de la escuela de Berkeley, en los años veinte del siglo pasado), y sólo más tarde se incorpora en otras disciplinas (como la Historia del Arte, la Arquitectura o la Historia)" (Barreiro et al. 2009: 8).

Para Orejas en los orígenes de la ArPa deben tenerse en cuenta dos aspectos relacionados entre sí. Por una parte, el contexto científico que ha motivado que en el campo de la Arqueología, durante la década de 1980 la ArPa fuera suplantando paulatinamente a la Arqueología Espacial y agrupando los análisis territoriales sobre el mundo antiguo, lo que "responde a una nueva realidad científica y social desde que en los primeros años de la década pasada, se sentaran las bases de la superación tanto de los enfoques fenomenológicos como de los derivados de la arqueología procesual" (Orejas 1995a: 216). Por otra, el contexto social desde el que aparece una idea de patrimonio en la que ya no se subraya la yuxtaposición de elementos, sino el "reflejo de la dinámica social que dio lugar a su construcción y uso" (Orejas 1995a: 216). En esta idea encajaría una ArPa que "supone integrar, interpretar y comprender en un doble sentido: la lectura (o las lecturas) que nosotros hacemos hoy de un paisaje del pasado y la (o las) que de él hicieron las comunidades que lo construyeron" (Orejas 1995b: 62).

Uno de los aspectos necesarios para que se produjera este desplazamiento de la Arqueología Espacial por parte de la $\mathrm{ArPa}$, es que tuvo lugar dentro de un determinado contexto historiográfico (Bernardi 1992; Rossignol and Wandsnider 1992; Ashmore and Knapp 1999) en el que se introdujo una nueva perspectiva sobre la práctica arqueológica y su objeto de estudio, que quedó reflejada en el marco conceptual propuesto para definir los términos básicos manejados por la ArPa (Mañana et al. 2002: 26), nos referimos a los términos arqueología, registro arqueológico y, sobre todo, paisaje, sobre los que ya hemos abundado en el apartado anterior.

De acuerdo con aquel nuevo marco teórico y conceptual la ArPa se definió como la inclusión de la práctica arqueológica dentro de coordenadas espaciales, a través de las cuales se trata de pensar el registro y la cultura material arqueológica desde una matriz espacial y, al mismo tiempo, convertir el espacio en el primer objeto de la investigación arqueológica para no solo reconstruir los ambientes del pasado, sino también intentar elaborar 
modelos sobre las interrelaciones entre espacio imaginado, utilización del espacio y organización social en las comunidades (pre)históricas (Mañana et al. 2002: 26).

La propuesta desarrollada por el equipo dirigido por Felipe Criado-Boado, intentaba diseñar un Programa de Investigación en Arqueología del Paisaje y Paisajes Culturales, que trataba de estudiar el paisaje entendido como una dimensión relevante de las sociedades humanas, puesto que no sólo constituía la base en las que éstas se desarrollaban sino también su resultado y, como tal, representa a la formación sociocultural (CriadoBoado 2012: 20). ${ }^{41}$

Sobre esta base conceptual, el objetivo cognitivo de este Programa de Investigación y de la ArPa sería deconstruir los paisajes sociales, "descomponer los mecanismos mediante los cuales las tecnologías espaciales y arquitectónicas producen el espacio doméstico reproduciendo el sistema de poder" para mostrar después "que el espacio construido es el producto de una serie de mecanismos de representación" de un determinado sistema de saberpoder (Criado-Boado 1999: 2), gracias a un ejercicio de reconstrucción (a partir de la deconstrucción) de los paisajes arqueológicos como "medio para penetrar en la prehistoria del pensamiento" (Criado-Boado 2012: 2021). En la reconstrucción de los paisajes históricos que aquí nos interesan tenemos la ventaja de que contamos con otro tipo de información que podemos sumar a la información que nos proporcionan los paisajes como RA. Constituye un ejercicio que nos permite inferir conclusiones desde informaciones, herramientas y disciplinas que pueden actuar conjuntamente. Estamos de acuerdo con Orejas et al. cuando dicen que los procesos de formación de un paisaje son tremendamente complejos, por ello, documentarlo e investigarlo requiere una aproximación flexible e interdisciplinar que combine varios métodos, e interpretarlo requiere tener en cuenta una gran variedad de factores (Orejas et al. 2002: 303 y 305).

Uno de los aspectos por los que deberíamos preguntarnos a continuación es cómo podemos llevar a cabo el estudio de estos paisajes (deconstrucción) y su interpretación (reconstrucción), pero no es el objetivo de este texto tratar el proceso metodológico, ${ }^{42}$ sino el

\footnotetext{
${ }_{41}$ "“[...] el estudio del paisaje parte de la idea de que el análisis de las sociedades antiguas es posible desde el estudio de los productos de sus acciones e imaginaciones. Pero entendiendo el paisaje no como un mero reflejo de estas acciones, sino como parte de las mismas sociedades, ya que el espacio, al igual que el tiempo, no son coordenadas externas, sino que forman parte de una sociedad" (Orejas et al. 2002: 305)

42 Este aspecto será tratado en otro trabajo. Véase, por ejemplo, Mañana et al 2002 y Blanco-Rotea 2011.
}

marco teórico. Sin embargo, podemos indicar que muchos de los esfuerzos desarrollados dentro de la ArPa se encaminaron a llevar a cabo un desarrollo metodológico que insistía en abordar nuevos aspectos el registro, no tratados hasta la fecha, y en incorporar determinadas técnicas de análisis, centrándose en elementos más perceptivos del paisaje, en definir de forma más precisa el registro arqueológico y en ofrecer explicaciones más globales (Soler 2007: 43; Tilley 1994; Knapp and Ashmore 1999). En el caso del paisaje, la aplicación de técnicas como la fotointerpretación, los análisis de ${ }^{14} \mathrm{C}$, la dendrocronología, los análisis polínicos, la teledetección, la informatización del registro arqueológico, el uso del GPS, de los SIG (Sistemas de Información Geográfica) $\mathrm{o}$, más recientemente, los datos LiDAR, supuso reconocer que es necesario contar con un mayor número de información y que ésta sea de mejor calidad, de manera que permita profundizar en aspectos no registrados desde perspectivas de investigación anteriores. El uso de estas técnicas transformó la visión de la naturaleza de los datos arqueológicos y su interpretación, enriqueciendo significativamente la disciplina arqueológica (Soler 2007: 44).

Diseñar una metodología específica en ArPa está directamente ligado al concepto de paisaje manejado (Orejas 1995a: 217), como sucede también con la arquitectura, de ahí la importancia de su definición previa. En todo caso, la autora apunta que los paisajes antiguos son resultado de racionalidades antiguas que no deben analizarse desde la nuestra, tener esto en cuenta conlleva implicaciones metodológicas, siendo necesario incorporar la comprensión pretérita del paisaje, junto a su explicación: "el espacio sólo adquiere sentido cuando va acompañado de una lectura del individuo o de la comunidad, que genera determinados comportamientos, actitudes y formas de percepción" (Orejas 1995a: 218-219).

Orejas propone que para entrar de lleno en el estudio del paisaje y el territorio es necesario superar el análisis de los mapas de punto y de las relaciones planas entre ellos para analizar las relaciones espaciales tridimensionales y temporales, para acceder así a las articulaciones de las diversas formas, su origen y evolución (Orejas 1995a: 219). Este aspecto ha tenido implicaciones prácticas a la hora, por ejemplo, de desarrollar un sistema de registro arqueológico desde ArPa. "La Arqueología del Paisaje repiensa el yacimiento como área, y como consecuencia de ello prioriza no sólo la importancia de localizar y de definir el yacimiento, sino también de delimitarlo y zonificarlo" (Amado et al. 2002: 22). 
En el marco en el que se desarrolla esta propuesta teórica, la ArPa se concibió como una propuesta que "apunta hacia una necesaria transdiciplinariedad, vertebrada en torno al paisaje, concepto que, cada vez más, se va revelando como clave para ahondar en los procesos de conocimiento y ordenación del territorio" (Barreiro et al. 2009: 8), porque además: "Cualquier intervención propuesta [desde el presente] es un nuevo elemento en la dinámica de los paisajes, al investigar sobre ellos los repensamos, les damos un nuevo sentido y los incorporamos a nuestro presente" (Orejas 1998: 18).

\section{ALGUNAS CUESTIONES SOBRE ARQUEOLOGÍA DE LA ARQUITECTURA}

En cuanto a la AA, nos centraremos en varios aspectos que consideramos importantes: por una parte, la redefinición del concepto de arquitectura que tuvo lugar en los orígenes de esta estrategia de investigación; por otra, su heterogeneidad (entendida en un sentido positivo) en su posterior desarrollo; finalmente, en su contribución a la "transición epistemológica y renovación metodológica" que la disciplina arqueológica viene atravesando desde la década de 1990 e incluso antes (Azkarate et al. 2002a: 9). No haremos, sin embargo, un análisis pormenorizado de la misma, más allá de estos aspectos, puesto que éste se realizó en varios trabajos durante las últimas dos décadas (Quirós 2002 y 2006; Utrero 2011; Azkarate 2013; entre otros).

Más allá de las definiciones que hagamos de la AA, ésta, como categoría conceptual, ha sido identificada como disciplina de pleno derecho, ${ }^{43}$ pero también como un universo de experiencias de naturaleza diversa, que ha ido adquiriendo un perfil específico en la década de 1980-1990 y que sigue siendo objeto de un proceso de construcción y experimentación enriquecido de forma constante con distintos enfoques (Azkarate 2013). En este sentido, la AA ha seguido un proceso de consolidación que, en ciertos aspectos, guarda muchos paralelismos con la ArPa, empezando por el propio cambio en la concepción de su objeto de estudio y en la aproximación a su análisis desde la arqueología y con herramientas metodológicas propias de ésta. Es por ello que creemos que aquella afirmación que hacíamos sobre la $\mathrm{ArPa}$ puede hacerse extensiva a la AA, entendiéndola como un modelo interpretativo del registro arqueológico de

43 Nosotros mismos así lo hemos hecho en varias ocasiones: Blanco-Rotea 1997, 1998a, 1998b, 1999. naturaleza arquitectónica y también una estrategia de investigación derivada de ese modelo.

La AA es ciertamente joven y, por lo tanto, todavía se encuentra en construcción. Pero no por ello podemos decir que esta estrategia de investigación esté poco extendida, todo lo contrario, al analizar la evolución que ha tenido en las últimas décadas (desde la de 1990 cuando Mannoni (1990a, 1990b) acuñó el término Arqueología de la Arquitectura), sobre todo en ciertos contextos europeos como el italiano y el español, observamos que ha gozado de una importante implantación y desarrollo en ámbitos relacionados, por una parte, con la investigación de edificaciones y conjuntos históricos y, por extensión, de las sociedades que los construyeron, transformaron y habitaron, por otra, con la restauración y rehabilitación arquitectónica. Si bien es cierto, en la década de 20002010 los contextos de aplicación, las metodologías y el ámbito geográfico se han ido ampliando poco a poco, tal y como apuntan distintos autores (Quirós 2002: 31 y 2006; Utrero 2011: 17-19; Azkarate 2013), “...la AA se está convirtiendo en un campo de juego abierto a cuantos les interesa el espacio construido como herencia del pasado, pero también como recurso para el futuro, como depósito de memorias históricas, archivos estratigráficos, como elenco de técnicas constructivas, compendio de dimensiones simbólicas y significantes, reflejo de conflictos y vivencias sociales, en definitiva como topografía de las complejas 'constelaciones cotidianas' de la sociedad" (Azkarate 2013: 272).

Es precisamente en esta década, en la que han aparecido varios trabajos en España que recogen con bastante precisión el nacimiento, desarrollo e implantación de la AA en diferentes contextos europeos (Quirós 2002 y 2006; Utrero 2011), con un interesante análisis sobre las causas que están detrás del progreso diferenciado de la misma entre distintos países, como Inglaterra, donde se pusieron las bases en la década de 1970 para el desarrollo tanto metodológico como de nuevos sistemas de registro que posibilitarían la extensión del método estratigráfico al análisis de la arquitectura (Utrero 2011: 12), o Italia, donde se llevaron a cabo "las primeras sistematizaciones teóricas y aplicaciones al análisis de las construcciones históricas entendidas como secuencias de unidades estratigráficas" y donde realmente la AA se consolidó como disciplina (Utrero 2011: 13-18), sobre todo a partir de la década de 1990 cuando, como decíamos, Mannoni acuña este término que aglutinaba experiencias heterogéneas que resultaban de la aplicación de instrumentos, conceptos y problemáticas de la 
disciplina arqueológica al estudio de la arquitectura ${ }^{44}$ (Quirós 2006).

También en esta década se lleva a cabo un análisis más profundo de la situación y perspectivas actuales en AA, que si bien ya habían sido tratadas en los trabajos arriba mencionados (Utrero 2011), es Azkarate (2013) quien hace especial hincapié en una doble tendencia que se viene notando de forma más reciente. Esta tendencia se hace eco, por un lado, de la necesidad de potenciar nuevos enfoques en el estudio de la arquitectura para desarrollar la investigación de los espacios construidos con propuestas que proceden de distintos campos de investigación (arquitectura, semiótica, historia del arte, antropología....). ${ }^{45}$ Estos enfoques entienden que el espacio es un concepto fundamental en arquitectura y han desarrollado estudios que inciden tanto en el análisis del espacio tridimensional como perceptivo, pero asumen además el concepto de Norberg-Schulz (1980: 13-15) de espacio existencial, que entiende que la espacialidad de la arquitectura está integrada dentro de la racionalidad que la generó. Una vez asumida esta concepción, tiene sentido el análisis de los aspectos geométricos y perceptivos del espacio a los que nos referíamos arriba (Mañana et al. 2002: 27). Estos enfoques se han desarrollado, fundamentalmente, en contextos de aplicación anglosajones donde ya existía una importante tradición en este sentido. En nuestro país es todavía escasa su difusión, aunque cada vez tienen una mayor representatividad en publicaciones especializadas en AA.

La segunda tendencia a la que hace alusión Azkarate, se refiere a la implantación de la AA en otros ámbitos internacionales donde se están produciendo múltiples experiencias con problemas de investigación, enfoques y métodos muy heterogéneos, como sería el caso de Latinoamérica: ${ }^{46}$

\footnotetext{
44 Son varios los autores que han incidido en la existencia de una tradición anterior en arqueología que se centró en el estudio de la arquitectura (Latorre y Caballero 1995, Quirós 2006, Azkarate 2013), pero frente a aquella tradición basada en una historia de las formas, de los estilos y de las técnicas que Mannoni denominó "la arquitectura en la arqueología" (Quirós 2006) y que se basaba en métodos estilístico-comparativos (Azkarate 2013), la AA que comienza en los años 70 del siglo XX y se materializa en los 90, se dota de nuevos instrumentos de análisis y se plantea nuevos problemas de investigación, que motivan, precisamente, la búsqueda de otros nuevos instrumentos, de manera que ambos aspectos se retroalimentan.

45 Algunos ejemplos de este tipo de análisis de los espacios construidos se pueden ver en: Sánchez 1998; Mañana et al. 2002; Ayán 2003 y 2008; Mañana Borrazás 2003; Criado-Boado y Mañana 2003; Gutiérrez y Cánovas 2009 o Bermejo 2009.

46 Azkarate 2013: 288. En el fondo esas experiencias heterogéneas que se aglutinan bajo esta denominación, no dejan de recordar a aquellas primeras experiencias llevadas a cabo en contextos europeos, si bien es cierto que en el caso de Europa la estratigrafía tuvo un gran peso y se convirtió en el eje fundamental de la AA, mientras que el análisis estratigráfico se está implantando de manera desigual en el cono sur americano.
}

"La labor arqueológica en centros urbanos ha venido enriqueciéndose a partir de la introducción de los métodos que la Arqueología de la Arquitectura emplea para el estudio de alzados. Esto ha traído consigo una gradual transformación en la conceptualización de estos contextos, que aún se abre paso entre los investigadores, para la comprensión de las construcciones como totalidades de varios niveles de materialización cultural" (Rodríguez y Hernández 2005: 4). Algunas de estas experiencias latinoamericanas ya están siendo publicadas en revistas especializadas en contextos europeos, aunque su difusión en ellos es todavía muy escasa (véase, por ejemplo, Rolón y Rotondaro 2010: 213222). Desde nuestro punto de vista esta escasa difusión está motivada por dos cuestiones distintas pero relacionadas, en primer lugar, la fuerte tradición estratigráfica de la AA europea (mediterránea sobre todo) y, con ella, del método estratigráfico como herramienta casi exclusiva de análisis de la arquitectura; en segundo lugar, la diferente concepción de arquitectura de la que se parte en ambos contextos, fundamentalmente entre la AA anglosajona y latinoamericana y la del sur de Europa, donde el estudio del espacio en arquitectura no ha sido asumido de la misma manera. En este sentido, creemos que es importante apostar por una postura abierta como la que propone Azkarate cuando dice que deberíamos "aprender de la historiografía anglosajona en la que, desde hace ya algunas décadas, se habla con toda naturalidad de archaeology of architecture para referirse a experiencias distintas nacidas de enfoques también muy diversos" (Azkarate 2013: 272).

\section{Revisando los inicios, focalizando objetivos, buscando una definición}

Ese compendio de experiencias que desde la arqueología focalizaron su interés en el estudio de la arquitectura, cogió cuerpo no sólo en el momento en que Manonni las aglutina bajo una única denominación, sino sobre todo porque se consolidó una tradición que defendió que un edificio histórico era ante todo un documento que aportaba información sobre sociedades pasadas (Azkarate 2013), era cultura material y podía ser estudiado como tal con una metodología arqueológica. Este cambio de visión de la arquitectura desde la arqueología, permitió que ésta pasara a entenderse no sólo como una estructura, un contenedor de espacios y funciones, sino como un objeto cargado de contenido, como un documento que había que decodificar. En parte, esta nueva concepción no hizo sino ampliar los pasos que dio el postprocesualismo cuando reconoció el carácter multidimensional del registro arquitectónico y se concibió la arquitectura 
como una herramienta de construcción de la realidad social (Mañana et al. 2002: 24-26), convirtiéndose así en un potente medio para el conocimiento de los contextos productivos y sociales que la generaron (Azkarate 2002b: 57). Si a esta concepción del contexto construido como documento se unía la conservación de muchos de ellos, sobre todo de periodos postclásicos, e incluso su reutilización en el presente (Figura 25), se hacía necesario articular nuevas aproximaciones de estudio al patrimonio construido que permitieran su conocimiento exhaustivo y previo a la práctica restauradora y rehabilitadora de los mismos.

De forma muy general la AA se define como la estrategia de investigación que estudia la arquitectura con una metodología arqueológica cuyo principal objetivo es el conocimiento histórico de los contextos construidos y de las sociedades que los generaron y su finalidad última contribuir a su gestión integral. Ahondando un poco más, podemos recurrir a los criterios básicos que, para Quirós (2002: 28-29), ayudan a definir la AA, y que están relacionados tanto con la investigación básica como con la aplicada. Por una parte, para este autor se trata de una estrategia que se inserta dentro de la disciplina arqueológica y por lo tanto, histórica, que utiliza un bagaje instrumental de naturaleza fundamentalmente arqueológica. Pero su sentido no es reconstruir únicamente la historia del edificio, sino el conocimiento de la sociedad a través de los restos materiales arquitectónicos, y por ello considera que debe propugnar el desarrollo de modelos interpretativos que superen los modelos de la historiografía de la arquitectura.
Por otra parte, en su vertiente más aplicada, la AA tiene un compromiso con el estudio y la gestión del patrimonio edificado, pues siendo documento de las sociedades pasadas, es también recurso de las sociedades actuales. Ocupa, además, una incómoda posición disciplinar intermedia que debe superar los límites entre distintas disciplinas que se dedican al estudio y gestión de este patrimonio, como la propia arqueología, la arqueometría, la restauración o la arquitectura. Este último aspecto es importante porque a pesar de encuadrarse dentro de la arqueología, toma muchas de sus herramientas de otras disciplinas y guarda fuertes sinergias con ellas. El problema es que en vez de haberse visto esta relación como una fortaleza, tal y como apunta Quirós (2002), desde algunos sectores se ha visto la AA como un intrusismo profesional en aspectos que eran competencia exclusiva de sus feudos disciplinares, imposibilitando la colaboración entre disciplinas y la construcción de conocimiento nuevo desde nuevas ópticas. Afortunadamente, esta tendencia se ha visto rota la mayoría de las veces desde las propias necesidades de los proyectos (y de los contextos construidos) que, por sí mismos, demandaban esta colaboración, siendo el propio objeto de estudio el que ha propiciado muchas veces la construcción de esta estrategia de investigación, o al menos ésta ha sido nuestra experiencia.

Ya hemos comentado que la AA hunde sus raíces en experiencias anteriores, pues la preocupación de los arqueólogos y arqueólogas por la arquitectura no es un fenómeno reciente. Sin embargo, lo que diferencia los

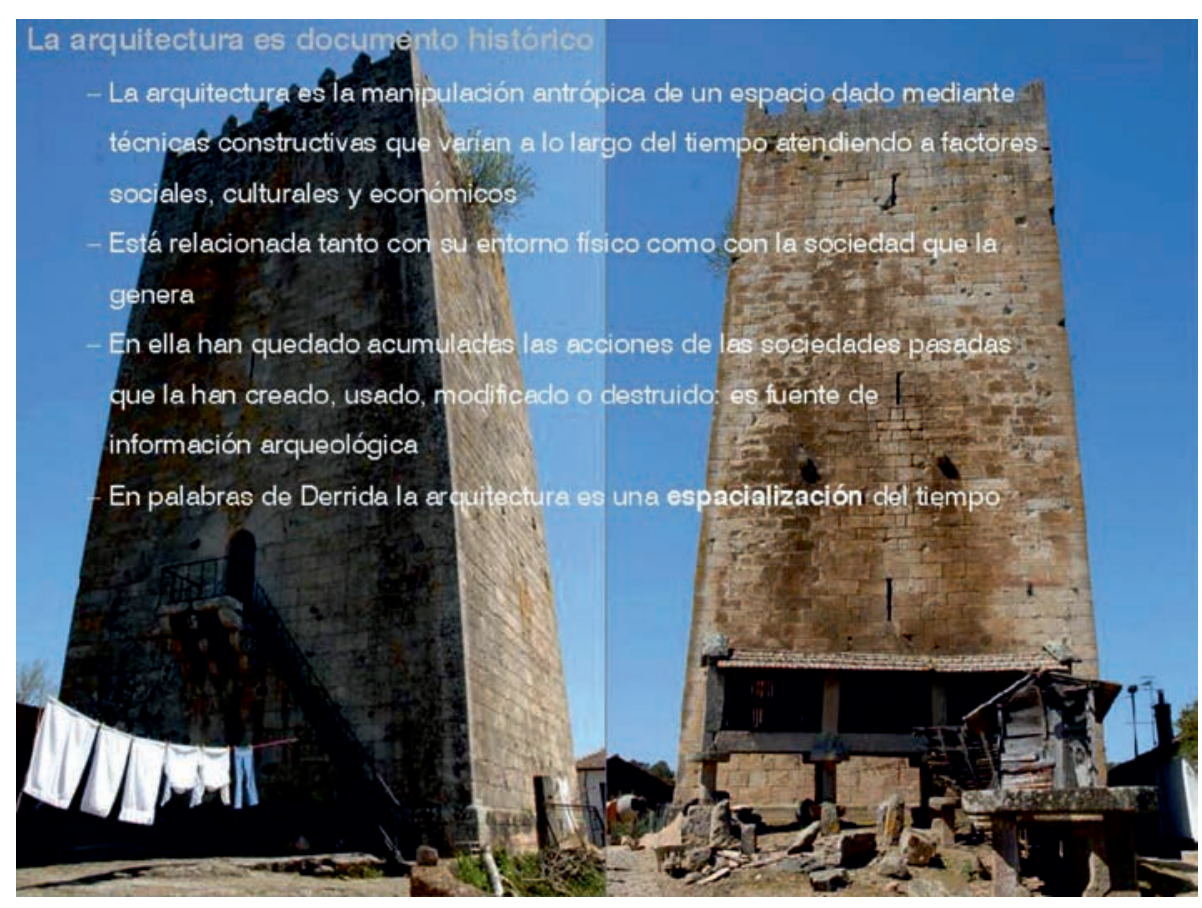

Figura 25. La torre de Lapela (Monção) es uno de los pocos restos que hoy se conservan del castillo de Lapela. Esta torre homenaje, construida en el siglo XIV y despojada de su funcionalidad primigenia, se ha convertido hoy en testigo de los procesos que ha vivido desde su origen. 
anteriores estudios arqueológicos sobre arquitectura de esta disciplina, es el empleo de ciertos instrumentos de análisis en su estudio, el desarrollo de nuevos problemas y ámbitos de investigación y de una práctica arqueológica orientada a la investigación aplicada (Quirós 2002: 28). Su "nacimiento" tiene una clara vinculación con la aplicación del método estratigráfico al estudio las construcciones históricas ${ }^{47}$ (éstas pasaron a entenderse como objetos pluriestratificados que había que estudiar conjuntamente con el yacimiento soterrado, ya que existía una clara vinculación entre ambos) en contextos anglosajones en la década de 1970 (Harris 1991 y 1993), evidentemente con la arqueología urbana que se practica a partir de entonces (Quirós 2005: 124-126) y con la arqueología medieval que adoptará éste y otros métodos ${ }^{48}$ para abordar el estudio de las arquitecturas desde una renovación instrumental. ${ }^{49}$ Frente a experiencias

\footnotetext{
47 "Sin duda, esta clase de estudios no hubieran podido llevarse a cabo sin disponer del método propuesto por E. C. Harris a partir de 1975, que nos indicó cómo poner orden a un registro que, por entonces, ya era estratigráfico, en nuestro caso de acuerdo con las enseñanzas de Lamboglia y sus epígonos, pero que no acababa de aportar toda la objetividad posible en la recogida y la interpretación de los datos de campo" (López Mullor 2002: 159).

48 "L'ampliamento delle ricerche archeologiche dalle civiltà antiche al medioevo età posteriori era ovvio che aumentasse gli interessi degli archeologi per gli elevati delle costruzioni ancora esistenti, creando trasferimenti da un settore all'altro di metodi e strumenti di lavoro di varia origine" (Mannoni 1994: 65). 49 "La AA nace, por tanto, (a) al calor de la renovación estratigráfica procedente del mundo anglosajón y (b) en el caldo de cultivo de una arqueología medieval que, frente a la tradición idealista anterior, priorizará las nuevas técnicas de estudio sobre el terreno y un estudio integral de la cultura material" (Azkarate 2013: 274).
}

anteriores, la AA introducirá "una visión crítica, una rigurosa renovación metodológica y una ampliación de sus objetivos y de sus campos de estudio habituales" (Azkarate et al. 2002a: 7-8).

Es precisamente en el ámbito de la arqueología medieval donde se llevan a cabo las primeras experiencias en Italia, cuyos inicios en la investigación arqueológica de esta época desde la AA vinieron de la mano de los arqueólogos, quienes experimentaron la aplicación de los instrumentos propios de la excavación arqueológica al análisis de los edificios en pie, considerados "como 'depósitos verticales' de información histórica estratificada que debía individuarse, registrarse e interpretarse en estrechísima relación con todo lo que se estudiaba en el 'depósito horizontal' " (Parenti 2001: 41) (Figura 26). Los primeros criterios de registro adoptados venían directamente de los trabajos de excavación, siendo estas primeras experiencias parte integrante de las mismas (Parenti 2001: 42)..$^{50}$

A partir de estas primeras experiencias tiene lugar lo que Parenti denomina como una "segunda fase italiana", en la que se comienza a experimentar y verificar las posibilidades que ofrece el análisis estratigráfico fuera del ámbito de la excavación arqueológica, aunque

\footnotetext{
50 “...el edificio forma parte de un contexto, por lo que no es posible limitarse a analizar solamente las estructuras situadas por encima de la cota cero. Hay en primer lugar una continuidad estratigráfica entre los depósitos en alzado y en el subsuelo, y esta continuidad no se puede fragmentar, sino que hay que primar la unidad de la intervención arqueológica...” (Brogiolo y Quirós 2002: 208-209).
}

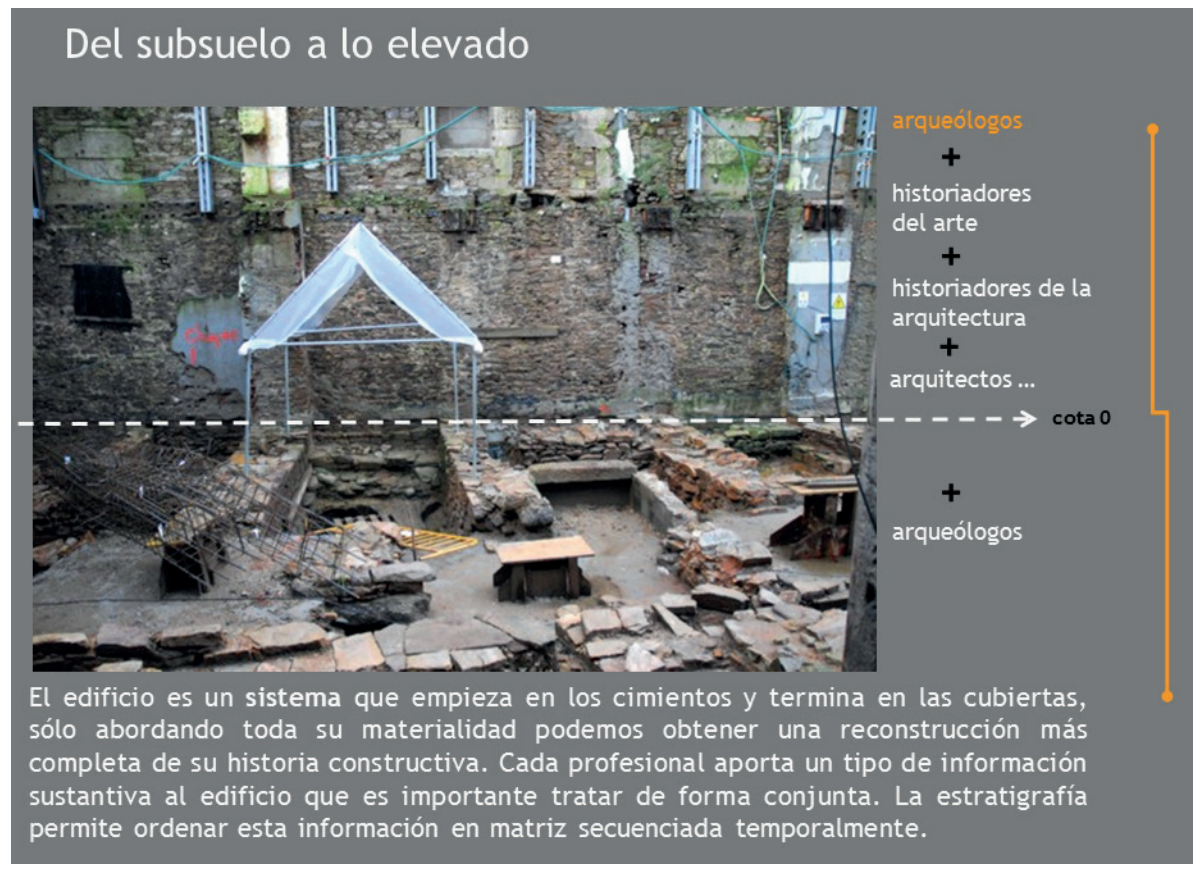

Figura 26. Cambio de perspectiva en el estudio del edificio (Preguntoiro 23, en Santiago de Compostela. Fotografía (C) Sonia García Rodríguez). Hasta la introducción de la AA los arqueólogos se centraban, casi con exclusividad, en el estudio del subsuelo, mientras que arquitectos, historiadores de la arquitectura o historiadores del arte lo hacían de lo que se conservaba por encima de la cota cero. La AA dotó al arqueólogo de herramientas para abordar también el estudio de la arquitectura por encima de esta cota cero, pasando a entender el edificio como un sistema y haciendo el yacimiento extensible a la totalidad del mismo. 
inicialmente se aplicó exclusivamente a edificios monumentales. En este momento se diversifican los trabajos, cruzando y verificando datos procedentes de distintos tipos de fuentes como la documentación histórica, la iconografía, la cartografía o los análisis de las características de los materiales constructivos con los resultados de los análisis estratigráficos de los edificios. En estas primeras fases, que Parenti califica de experimentación, los objetivos prioritarios de la disciplina eran determinar las fases de la historia de los edificios y describir sus técnicas constructivas, sobre todo en grandes contextos monumentales y para períodos medievales. Será después cuando se amplíe el campo cronológico y constructivo, analizando toda clase de edificaciones y no únicamente las monumentales. Para Brogiolo la AA en Italia se posicionará entre dos perspectivas: de un lado, la oportunidad de perseguir objetivos de conocimiento histórico investigando sinergias y colaboraciones con otras disciplinas que se ocupan también de lo construido; del otro, la necesidad de mantener una relación con aquellos que trabajan en la transformación de la arquitectura para asumir una responsabilidad común en su salvaguarda (Brogiolo 2002: 24-25).

Desde Italia, la AA se difunde a otros ámbitos europeos donde en las últimas décadas se ha asistido a una profunda renovación de los estudios arquitectónicos realizados desde la arqueología, surgiendo distintas líneas de trabajo como la Archéologie du bâti o Archéologie des élévations en Francia, la Baufordchung y la "Arqueología de la Construcción" en Alemania o la Archaeology of Buildings o Building Archaeology en Gran Bretaña. Pero, a pesar del común origen de todas ellas en un mismo contexto social y científico no se puede hablar de una disciplina única en Europa, ya que su génesis, desarrollo y ámbito e instrumentos de aplicación son muy distintos (Quirós 2002: 28). Para este autor, es la experiencia italiana la que cuenta con una masa crítica de estudios más afirmada, además de una codificación y normalización de instrumentos más sólida teniendo como criterio fundamental de análisis de la arquitectura, la estratigrafía (Quirós 2002: 28).

Efectivamente, en las distintas reuniones celebradas en la última década en España (el Seminario Internacional de Arqueología de la Arquitectura celebrado en Vitoria-Gasteiz en 2002 o el encuentro Arqueología aplicada al estudio e interpretación de edificios históricos. Últimas tendencias metodológicas, celebrado en Madrid en 2009) se sigue reclamando la necesidad de una normalización conceptual e instrumental (Azkarate et al. 2002a: 7; Vega 2011: 7). ${ }^{51}$ La revista Arqueología de la Arquitectura (CSIC-UPV-EHU) que nació de aquel seminario ha contribuido precisamente a crear uno de esos campos de debate, reflexión e intercambio que se reivindicaba, gracias a la importante demanda y difusión que tiene a través, sobre todo, de la red. A pesar de la heterodoxia de todas las experiencias que se siguen llevando a cabo bajo el paraguas de la AA, creemos que precisamente esta heterodoxia ha contribuido a su enriquecimiento, tal y como apunta Azkarate (2013).

No podemos, sin embargo, obviar la importancia que la estratigrafía tuvo (y debe tener) dentro de estas experiencias. Por una parte, la incorporación de instrumentos estratigráficos al estudio de la arquitectura propició el comienzo de un nuevo campo de investigación generando una importante renovación metodológica y no menos importante reflexión teórica. Por otra, se sigue considerando que la AA está determinada por su carácter estratigráfico, donde el diagrama o matrix $^{52}$ se convierte en el "eje principal de análisis y decodificación de la historia del edificio" en el que insertar la información obtenida gracias a otros instrumentos de análisis ${ }^{53}$ "de carácter tipológico, formal, estructural, arqueométrico o el recurso a fuentes escritas son absolutamente imprescindibles para lograr un afianzamiento de nuestra disciplina y un acercamiento más sólido a la historia constructiva de nuestros edificios históricos" (Azkarate et al. 2002a: 8).

Sin embargo, esta importancia central de la estratigrafía en el estudio de los contextos construidos desde la AA ha jugado a veces en su contra porque, por una parte, ha invisibilizado la propia AA, llegando a equipararse o confundirse ésta con el análisis estratigráfico, $\mathrm{y}$, por otra, ha hecho que muchas veces la investigación de estos contextos se quede en el edificio sin ir más allá.

\footnotetext{
51 Luis Caballero denunciaba en 2009 la existencia de una Torre de Babel en este campo: "Termino planteando algunas cuestiones que denomino como nuestra 'Torre de Babel', la tendencia por diferenciar grupos cerrados que amenazan por escindir una metodología común; o por considerar como importantes cambios de base lo que son variantes metodológicas o terminológicas, que deben ser entendidas como instrumentales dentro de un modelo profesional común" (Caballero 2011: 115).

52 La representación de la secuencia que se obtiene del estudio de las construcciones mediante análisis estratigráfico.

53 "Nuestro método está mejor preparado para fechar y comprender el edificio como un documento histórico - incluyendo en lo histórico desde el aspecto cronológico a la interpretación social y estética, pero ello no debe hacer que invalidemos los otros métodos. Lógicamente aquellos caerán en desuso [...], si es que son menos útiles que los nuevos instrumentos, pero, aún así, es posible que algunas de sus habilidades sigan siendo válidas. Por otra parte, aquellos métodos son nuestros predecesores y en su historiografía debemos ver reflejados nuestros inicios" (Caballero 1997: 307).
} 
Desde las primeras fases de su desarrollo, distintos autores reivindicaron que el estudio del edificio debía ser el instrumento base que permitiera generar investigaciones sobre temas más generales (Brogiolo 2002: 24), que la AA fuese una disciplina histórica, que contribuyese a la elaboración de una historia social de nuestro pasado a través del registro arqueológico, impulsando nuevos problemas históricos y la creación de nuevos ámbitos de investigación (Azkarate et al. 2002a: 8). Pero precisamente la observación de la arquitectura desde una óptica estratigráfica, permitió ver cada edificio no como un modelo de estudio que representaba a un determinado estilo arquitectónico, sino como un resultado único de distintos modos de construir, funciones, usos y representaciones simbólicas, "La historia de la arquitectura se convierte así en una historia de los modos de construir más que de lo construido. Es necesaria, pues, la adopción de nuevas propuestas epistemológicas que complementen las propuestas que hasta ahora se han seguido en los estudios de la arquitectura" que permitan comprender los procesos sociales que se encuentran detrás de una secuencia estratigráfica, para pasar de hacer estratigrafía a hacer arqueología "explorando las múltiples posibilidades que ofrece la arquitectura, más allá de su consideración como contenedora de objetos o soporte de estilo" (Azkarate et al. 2002a: 8).

Existe un último aspecto importante que está relacionado con la formación y consolidación de la AA en determinado contextos $\mathrm{y}$, muy especialmente, en la península ibérica. La AA trabaja fundamentalmente con un tipo de registro, el patrimonio edificado, que se encuentra todavía en uso o que está sujeto a constantes procesos de intervención restauradora o rehabilitadora. Ya hemos visto como este patrimonio, tras un proceso de re-conceptualización, está siendo objeto de estudio de la AA a través de una importante renovación metodológica y del planteamiento de nuevos modelos interpretativos del registro construido. Pero hay que añadir que la AA nace comprometida socialmente (Azkarate et al. 2002a: 9), como parte integrante de la disciplina arqueológica ha heredado sus presupuestos epistemológicos, y comparte aspectos como los que apunta Criado-Boado sobre la arqueología en general, "como intervención intenta restablecer el sentido original de esos objetos en un universo actual, tendrá que ser siempre una empresa intelectual, cognitiva, y la gestión de los recursos arqueológicos una práctica interpretativa realizada desde códigos concretos y en niveles diferentes. La Arqueología, sea Pública, Comercial, Académica o Divulgativa, se tiene que basar siempre en un modelo coherente de registro arqueológico. Su formación y, en concreto, la formación del PA (que es una parte privilegiada de aquél), depende de prácticas sociales actuales, determinadas por circunstancias contextuales concretas, y que constituyen un tipo de trabajo especial que, en realidad, adopta siempre el modo de una interpretación o valoración" (Criado-Boado 1996a: 28). La AA adquiere entonces un compromiso social con el conocimiento, la protección y la gestión del patrimonio edificado (Azkarate et al. 2002a: 9). Es precisamente esa implicación una de las razones que ha coadyuvado a su importante impulso en el marco de intervenciones de restauración y rehabilitación (Quirós 2002: 28) que, al mismo tiempo, han contribuido a la construcción de su corpus teóricometodológico al tener que dar respuesta, precisamente, a los desafíos generados por la intervención en patrimonio edificado.

Como sucede para el contexto general europeo, en España la AA tiene también en la actualidad una concepción y un campo de actuación muy heterogéneo que va desde las lecturas estratigráficas de alzados hasta los análisis espaciales, pero que incluye también el análisis de la cadena operativa de los materiales constructivos, los análisis arqueométricos, las lecturas basadas en criterios analógicos y estilísticos, la excavación de las bóvedas de iglesias, las propuestas de instrumentos de datación, el estudio de procesos sociales a partir del documento arquitectónico o el análisis crítico de documentación planimétrica histórica (Quirós 2002: 27). ${ }^{54}$ No vamos a hacer aquí un análisis sobre su origen y desarrollo en España, ese tema ha sido abordado tanto en las publicaciones a las que nos referíamos anteriormente como en otras (Azkarate 2008 y 2013; Quirós 2002 y 2006; Utrero 2011).

\section{FINALIDAD MÚLTIPLE. HACIA UNA GESTIÓN INTEGRAL DEL PATRIMONIO CONSTRUIDO DESDE EL CONOCIMIENTO}

Sí nos interesa, sin embargo, focalizar sobre cuáles son los principales campos de investigación y aplicación a los que la AA se ha orientado y en los que se ha consolidado desde sus comienzos.

\footnotetext{
54 Ejemplos de muchos trabajos con estos y otros enfoques han sido publicados en la revista Arqueología de la Arquitectura.
} 


\section{Herramienta para el conocimiento histórico}

Parenti se refiere a la información histórica "legible" en las superficies arquitectónicas como "la autenticidad de la construcción arquitectónica" (Parenti 2001: 44), o lo que es lo mismo, la arquitectura y las huellas que la actividad humana y los procesos naturales han ido dejando sobre ella, son la primera fuente documental sobre la historia del edificio y la sociedad que lo ha generado. De ahí la necesidad de estudiarlas adecuadamente, de entenderlas como Cultura Material y de su potencial para la Historia.

Con la introducción de la AA se produce un salto respecto a prácticas anteriores en el estudio de los espacios construidos. Simplificando mucho, las aproximaciones que se hacían a la arquitectura desde la arqueología se quedaban muchas veces en la mera descripción de sus materiales o de sus formas, para definir sus características principales y clasificarlas, encuadrarlas en un momento histórico concreto o en determinado estilo arquitectónico, establecidos desde disciplinas como la Historia del Arte o la Historia de la Arquitectura. Si bien la AA atiende también a la materialidad de la arquitectura, no se limita a identificar los materiales con los que está realizada, sino que intenta entender y explicar por qué se emplean unos materiales, unas formas arquitectónicas o unas técnicas constructivas y relacionarlo con la sociedad que los ha utilizado, trata de introducir todos estos y otros aspectos en unas coordenadas espacio-temporales y sociales, ${ }^{55} \mathrm{a}$ partir del cambio conceptual al que hemos hecho mención por el que la arquitectura se entiende como "potente medio de conocimiento de los contextos sociales y productivos que la generan" (Azkarate 2002a: 57). Para este autor esta idea es la mayor aportación de la AA puesto que la condición primigenia del monumento es la dimensión documental, por la riqueza informativa que nos suministra, a través del análisis de lo material, sobre el edificio y su contexto social, ${ }^{56}$ porque una sociedad "mientras construye edificios, en realidad construye la sociedad misma"

\footnotetext{
55 Estos cambios en la disciplinas no son exclusivos de la AA o de la Arqueología en general, sino que también se muestran en la propia Arquitectura cuando algunos autores reivindican, por ejemplo, el paso de una teoría procedimental a una teoría sustantiva: "Mientras que la teoría procedimental describe cómo hacer arquitectura, la teoría sustantiva explica por qué la arquitectura debería ser hecha de cierto modo', en clara referencia al mundo socio-cultural en lugar de procesos auto-referidos" (Rabí 2005).

56 Azkarate se refiere aquí a una de las tres dimensiones que posee un monumento arquitectónico según recuerda A. González (Azkarate 2002b: 57): la dimensión documental, la arquitectónica y la significativa.
}

(Criado-Boado 2002: 92). ${ }^{57}$ Por ello el análisis histórico debe ser imprescindible dentro de cualquier proceso de intervención en conjuntos construidos, permitiendo a partir de él restituir la memoria colectiva (Brogiolo y Quirós 2002: 209), la memoria social (Criado-Boado 2002: 91).

Se podrían poner muchos ejemplos para mostrar como la AA se ha convertido en una potente herramienta de conocimiento histórico, pero quizás dos de los más paradigmáticos en nuestro contexto peninsular sean, por una parte, los trabajos liderados por Luis Caballero Zoreda del Grupo de Investigación en Arqueología de la Arquitectura del CSIC, para las iglesias altomedievales de la península y, por otra, los desarrollados por el Grupo de Investigación en Patrimonio Construido de la UPV-EHU, dirigido por Agustín Azkarate, en la Catedral de Santa María de Vitoria-Gasteiz, a los que ya nos hemos referido en varias ocasiones.

Otro aspecto a destacar es que, a pesar del enorme potencial de la AA para el estudio de la arquitectura de cualquier período al que nos enfrentemos, no debemos olvidar que ésta es un elemento sumamente complejo, cuya formación y transformaciones responden a diferentes aspectos, que se pueden escapar a su estudio exclusivo desde esta estrategia de investigación si tiene un foco de mira muy reducido (Caballero 2002: 98). Por ello, consideramos que los planes integrales que focalizan sus objetivos en el conocimiento de nuestro patrimonio construido se tienen que articular en torno a una importante multiplicidad de disciplinas, que realmente se integren entre sí, ${ }^{58}$ para estudiar, conocer y valorar éste de la forma más completa posible. En este sentido, nuestra propuesta intenta abordar la investigación en patrimonio construido desde dos estrategias de investigación, como hemos dicho, AA y ArPa, atendiendo así a varios niveles espaciales y de significación en los que se manifiesta la arquitectura. Como apunta Caballero, todas estas disciplinas, aplicadas a las construcciones históricas bajo objetivos convergentes, nos ofrecen informaciones de distinto carácter, que no son excluyentes ni determinantes, pero sí complementarias. Aplicar este tipo de perspectivas a todos los proyectos arqueológicos en los que participemos, no es siempre posible, dependerá de la casuística de cada proyecto, pero nuestro objetivo debería ser intentar que esta mirada transdisciplinar lo sea,

\footnotetext{
57 Creemos que es dentro de estas coordenadas como ha de entenderse la filosofía que había detrás del proyecto Catedral de Vitoria o de otros llevados a cabo por el mismo grupo de investigación (Azkarate 2002b: 57-58).

58 Respondan, como decía Azkarate (2004: 45) a una mirada interdisciplinar e incluso si es posible transdisciplinar.
} 
fusionando o vertebrando incluso este tipo de intervenciones en planes de investigación de mayor envergadura.

\section{Herramienta para la praxis restauradora}

La práctica restauradora en los últimos años del siglo XX y primeros del XXI se mueve entre dos planteamientos que si bien son complementarios chocan en algunos aspectos por las propias contradicciones que conllevan a la hora de llevarlos a la práctica. Por un lado, hablamos de la necesidad de conservar nuestro patrimonio construido y su memoria para las generaciones futuras $y$, por otro, de la necesidad de seguir habitando ese patrimonio, lo que supone intervenir sobre él.

Muchos son los debates que tratan el tema de la conservación, restauración y rehabilitación del patrimonio arquitectónico. Podemos encontrar opiniones en las que, en materia de ciudades históricas, se ve la intervención como la búsqueda de un equilibrio entre la protección, la revalorización y la revitalización de los espacios patrimoniales, y la necesidad de introducir nuevos elementos que mantengan a la ciudad viva (Gallego 2000: 9-10); u otras donde la intervención-restauración tiene una lectura doble y contraria, como vehículo de la evolución o como baluarte contra la evolución (Manieri 2002: 23-24). Opiniones que reflejan esta dualidad y que confrontan la protección y la transformación de las ciudades históricas. El problema en este punto es cómo encontrar un justo equilibrio entre ambos extremos, donde la práctica restauradora es sinónima, por un lado, de intervención que introduce cambios que permiten seguir usando los espacios construidos aportándoles nuevos usos o recuperando otros viejos; y, por otro, se entiende como vehículo para la conservación de nuestro patrimonio construido, tanto de sus valores materiales como inmateriales. ${ }^{59} \mathrm{Y}$ es aquí donde la AA juega un importante papel.

Es innegable la relación que existe entre la práctica restauradora y la AA. Si valoramos nuestra propia práctica, los proyectos en los que hemos intervenido, con escasas excepciones, estaban relacionados con la intervención en patrimonio construido, bien para

El cortometraje "O Castelo da froita", https://www.youtube.com/ watch? $\mathrm{v}=\mathrm{BbPdF}$ tkstjw, fue presentado recientemente en el I Festival de Curtametraxes sobre o Patrimonio Arqueolóxico da Provincia de Pontevedra Telearqueoloxía 2016. En él se muestra la percepción que parte de la vecindad de la villa de A Guarda tiene del Castelo de Santa Cruz y su reciente recuperación patrimonial. Y no todas hacen la misma lectura de esta trasformación. restaurarlo, rehabilitarlo o ponerlo en valor, desde proyectos focalizados en monasterios o fortalezas que se iban a convertir en hoteles, restos de murallas sobre las que se pretendía construir viviendas de obra nueva $\mathrm{o}$ edificaciones rurales abocadas a desaparecer. Y a cada uno de ellos corresponde una relación distinta que podría ser representativa de los modos de relación socio-profesional entre arquitectos-as e historiadoresas/arqueólogos-as.

Basándonos también en nuestra práctica, diríamos que existen algunos planteamientos que deberían tenerse en cuenta a la hora de intervenir en un edificio histórico y que deben tener presente tanto su irrepetibilidad como su propiedad compartida.

En primer lugar, destacar la irrepetibilidad del patrimonio. ${ }^{60}$ Cada objeto patrimonial, cada arquitectura, posee unos valores propios e intrínsecos, por tanto, no existen recetas universales para la actuación en materia de patrimonio construido ni tampoco para su estudio y comprensión. Pueden, por un lado, aplicarse herramientas consensuadas desde las que identificar determinados patrones que se repiten tanto sincrónica como diacrónicamente, determinadas técnicas constructivas, determinadas iconografías o relaciones espaciales que son replicadas y adaptadas en distintas arquitecturas, tal y como propone la AA. Por otro, pueden tratar de interpretarse estos espacios construidos desde distintos modelos interpretativos. O también se puede plantear la intervención restauradora, acudiendo a la experiencia acumulada sobre el uso de materiales, la recuperación de antiguas técnicas, el conocimiento sobre las relaciones y diálogos entre lo contemporáneo y el pasado... ${ }^{61}$ Cada uno de estos aspectos se manifiesta de manera individual en cada arquitectura motivado por factores sociales, técnicos, medioambientales o de disponibilidad de materiales y solamente la conjunción (y comprensión) de todos ellos al unísono tendrá como resultado un producto final, que no otro, que es el edificio, la construcción histórica o el paisaje arquitecturizado.

\footnotetext{
60 "Cada comunidad, teniendo en cuenta su memoria colectiva y consciente de su pasado, es responsable de la identificación, así como de la gestión de su patrimonio. Los elementos individuales de este patrimonio son portadores de muchos valores, los cuales pueden cambiar en el tiempo. Esta variabilidad de valores específicos en los elementos define la particularidad de cada patrimonio. A causa de este proceso de cambio, cada comunidad desarrolla una conciencia y un conocimiento de la necesidad de cuidar los valores propios de su patrimonio" Carta de Cracovia (Rivera y Pérez 2000).

61 Son muchas las propuestas en este sentido, por ejemplo, algunas de las que recogen Mileto y Vegas (2004) o Doglioni (2002 y 2011).
} 
Teniendo en cuenta lo anterior, y aceptados los principios que se recogen en la Carta de Cracovia, ${ }^{62}$ el proceso de conocimiento previo del edificio es una fase irrenunciable para cualquier intervención, no sólo porque nos permite acceder a aspectos de la biografía del edificio, sino porque a través de ese conocimiento comprenderemos las soluciones que se adoptaron en el pasado y ayuda a la toma de decisiones en el presente. Sin embargo, todavía no existe una reflexión crítica ni una conciencia suficiente sobre la consubstancialidad entre el "conocimiento de un monumento" y el "acto de su restauración" (Azkarate 2002b: 59).

No podemos olvidar tampoco la propiedad del patrimonio, puesto que pertenece a la sociedad $\mathrm{y}$, como depositaros que somos, debemos reivindicar que la intervención en patrimonio construido se realice bajo criterios consensuados democráticamente por la totalidad de la sociedad a la que toca intervenirlo en un momento concreto de su historia, aspecto que no suele tenerse en cuenta.

Un ejemplo concreto que ilustra la potencialidad de la AA dentro del proceso restaurador, se encuentra en los trabajos realizados en la catedral de Santa María de Vitoria-Gasteiz por los arquitectos Cámara y Latorre (Cámara y Latorre 2002), a través del cual se analizó el comportamiento de las estructuras construidas de la catedral. Los autores nos muestran cómo debían comprender a qué período correspondía tal o cual comportamiento estructural, y qué soluciones se habían adoptado en aquel momento para corregirlo. Esto no hubiera sido posible sin un estudio previo del edificio. Del mismo modo se muestra que los resultados del estudio estructural pudieron ayudar en muchas ocasiones a resolver otro tipo de preguntas históricas. Las conclusiones de estos y otros análisis se tuvieron en cuenta a la hora de tomar decisiones en el proceso global de restauración del edificio. ${ }^{63}$

La relación AA/Restauración también ha tenido consecuencias negativas para el patrimonio edificado, pues no han sido pocas las ocasiones en las que la una ha justificado a la otra y viceversa. Existen numerosos ejemplos en los que un importante gasto en estudios

\footnotetext{
62 La Carta de Cracovia hace una mención explícita a los proyectos de restauración del patrimonio edificado: "Semejante conservación requiere un apropiado 'proyecto de restauración' que defina los métodos y los objetivos. En muchos casos, esto además requiere un uso apropiado, compatible con el espacio y significado existente. Las obras en edificios históricos deben prestar una atención total a todos los periodos históricos presentes".

${ }_{63}$ Recomendamos las conclusiones de su ponencia en el Seminario celebrado en Vitoria-Gasteiz en el año 2002 (Cámara y Latorre 2002: 154).
}

previos llevados a cabo bajo los planteamientos metodológicos de la AA y de otras disciplinas, han permitido intervenciones posteriores mutiladoras y transformadoras del patrimonio bajo la justificación de que había sido previamente estudiado. En otras ocasiones los estudios previos son muy deficientes, pero simplemente se consideran válidos por llevar el apellido "análisis estratigráfico" o "arqueología de la arquitectura". En ese sentido, compartimos la idea de Antoni González "la lectura estratigráfica debe ser un medio y no un fin en sí mismo" (en Brogiolo y Quirós 2002: 209).

\section{Herramienta para la conservación}

Las y los profesionales que nos dedicamos a la gestión del patrimonio debemos tener como un objetivo fundamental su conservación (Carta de Cracovia, Rivera y Pérez 2000).

Hemos visto que el conocimiento histórico debe ser consubstancial al acto de restauración y que en este acto debía haber un proceso previo en el que no sólo identificásemos la historia del edificio, sino todo aquello relativo a su materialidad, como información necesaria para la elaboración del proyecto de restauración (Mileto y Vegas 2004: 155). Lograr este conocimiento se puede hacer desde muchos ámbitos disciplinares. La experiencia acumulada en las últimas décadas en aquellos proyectos que se han dedicado a abordar el estudio del patrimonio edificado desde la AA, demuestra que esta estrategia de investigación genera, además de una interpretación sobre el espacio construido analizado, un importantísimo volumen de datos que van desde la documentación geométrica del patrimonio hasta la información relativa a las unidades estratigráficas identificadas, tanto desde su georreferenciación en el edificio hasta aspectos de tipo descriptivo e interpretativo, o a la evolución de sus espacios. Toda esta información corresponde, lógicamente, al momento previo de intervención en el edificio, intervención que también deberá documentase puesto que pasará a constituir una nueva etapa en el mismo, ${ }^{64} \mathrm{y}$ constituye un material importantísimo que contribuye a la conservación de la memoria de los espacios construidos.

Este proceso de documentación se puede llevar a cabo desde varios planteamientos teórico-metodológicos, pero lo cierto es que la AA, gracias al corpus metodológico que

\footnotetext{
64 "No se trata de congelar el edificio, sino más bien de concebir la intervención como una fase más de la estratificación" (Mileto 1999: 14).
} 
ha desarrollado en las últimas décadas, se ha convertido en una potente herramienta para la conservación. Por todo lo que hemos visto, es importante incorporar dentro de cualquier proceso de intervención en espacios construidos un riguroso programa de estudio desde el que se empleen las herramientas más adecuadas en cada caso. Esto implica también diseñar y planificar las intervenciones en todas sus fases que, lógicamente, deben contemplar una fase previa de documentación. Somos conscientes de que durante el proceso restaurador, ciertos aspectos de la biografía del edificio pueden llegar a perderse ante la propia y necesaria salvaguarda de la totalidad del mismo, o ante la decisión consensuada de priorizar ciertos elementos del edificio sobre otros ante la imposibilidad de conservar todos ellos (motivo por el cual debemos documentar todo el proceso y aprovechar la oportunidad única que para el conocimiento supone esta práctica). Esa fase previa irrenunciable de conocimiento de los espacios construidos permite obtener infinidad de datos que hay que interpretar y conservar para futuras investigaciones, intervenciones o para su disposición pública. La AA se ha mostrado como una de las estrategias de investigación más rigurosas, productivas y eficaces, porque intenta comprender las construcciones históricas de forma sincrónica y diacrónica a través de su materialidad y desde dentro de sí mismas.

No entendemos por qué, después de dos décadas largas de desarrollo de la AA en España en las que se ha demostrado su potencialidad y se ha teorizado sobre la fragilidad del patrimonio construido, sobre su irrepetibilidad, sobre la necesidad y obligatoriedad de llevar a cabo proyectos de restauración respetuosos con este patrimonio y con los valores materiales e inmateriales de los que es portador, todavía en 2016, las legislaciones estatal y autonómicas, en su mayoría, no presentan las mismas cautelas a la hora de intervenir en patrimonio construido que, por ejemplo, en patrimonio arqueológico "convencional". Si no es posible llevar a cabo en muchas comunidades un proyecto de construcción de una autopista sin que haya una evaluación previa de impacto ambiental y arqueológico que conlleve el estudio de cada uno de los elementos arqueológicos que vayan a ser afectados por este proyecto, ¿cómo es posible, sin embargo, actuar sobre nuestros cascos históricos, monasterios, fortalezas o paisajes construidos sin que haya una documentación previa exhaustiva de los mismos? En la mayor parte de los casos, su documentación dependerá de la mayor o menor sensibilidad de los técnicos que formen parte de dirección general de patrimonio que corresponda, cuando este aspecto tendría que estar legislado. ${ }^{65}$ Este es un aspecto que todavía no hemos reivindicado lo suficiente. No puede ser que la conservación de cierto tipo de patrimonio siga dependiendo de la sensibilidad de un investigador, un técnico, un gestor o un político. ${ }^{66}$

La información resultante del estudio de un espacio construido desde la AA puede resultar muy heterogénea, va desde los resultados de la lectura estratigráfica, su interpretación y el establecimiento de las fases del edificio, hasta su representación gráfica con anterioridad a la intervención o como resultado de las interpretaciones de las lecturas o de la aplicación de otro tipo de análisis, empleando, por ejemplo, reconstrucciones de los diferentes momentos de uso, pasando por el vaciado documental, el estudio de las tipologías edilicias o de las técnicas constructivas. Pero toda ella contribuye a la creación de archivos documentales del patrimonio construido que ayudan a su conservación, convirtiéndose así en un instrumento de primer orden en este sentido.

Esta conservación se puede llevar a cabo de muchas maneras, pero es también fundamental su transmisión y reversión a la sociedad, desarrollando los últimos eslabones de la Cadena de Valor del Patrimonio. Por ello, diferentes autores han reivindicado siempre, como una de las fases del proceso de estudio, la elaboración de archivos documentales en los que se ponga a disposición pública la información obtenida de este tipo de estudios y la publicación de los resultados (Caballero 1995: 44). Ésta es una parte fundamental en todo el proceso de revalorización de patrimonio.

\footnotetext{
65 "La Arqueología de la Arquitectura, al no estar reglamentada, resulta «invisible» para la Administración. Para que ésta encargue su aplicación, tiene no sólo que ser consciente de su existencia, sino de su necesidad y del trámite que puede seguir para gestionarla. Como este camino no está normativizado, es necesario que lo siga un intermediario, al que hemos llamado «responsable», una persona interesada, que normalmente puede ser el arqueólogo [...] o el arquitecto encargado de la intervención o un técnico responsable con funciones administrativo/políticas conocedor del método y atraído por su introducción" (Caballero 2004: 129).

${ }_{66}$ Un ejemplo reciente de este debate se puede ver en el artículo de Álvaro de Cózar y José Marcos "La ciudad descatalogada", publicado el 14 de abril de 2013 en El País, que hace referencia a nueva ley autonómica de patrimonio madrileña: "La arqueología es, según denuncian los críticos, una de las grandes perdedoras con la nueva Ley de Patrimonio. 'Con la nueva ley el valor arqueológico queda difuminado y casi eliminado. La labor arqueológica queda bastante defenestrada', asegura Diana Díaz, presidenta del Colegio de Arqueólogos de Madrid. La ley elimina la obligatoriedad de realizar informes arqueológicos preventivos en los proyectos de construcción. Sin esos informes, las excavadoras pueden arrasar yacimientos sin que nadie se diera cuenta. 'La ley no va a afectar a yacimientos como el de Titulcia, declarado BIC el pasado agosto. Pero para llegar a esa declaración, antes de todo eso tuvieron que ir arqueólogos, descubrir los yacimientos que había y documentarlos', concluye la arqueóloga”.
} 


\section{Herramienta para la gestión}

Recordemos que una de las mayores aportaciones de la AA a la arqueología y la historia fue comprender que las arquitecturas eran un potente medio de conocimiento de los contextos sociales y productivos que las generaron (Azkarate 2002a: 57). Pero, "sería un grave error estratégico y metodológico (también deontológico) preocuparnos únicamente del conocimiento histórico, ignorando la situación que vive el patrimonio edificado" (Azkarate 2002a: 58). Y efectivamente, de nada nos valdría seguir aumentando el conocimiento sobre nuestra arquitectura, ampliando o completando estudios anteriores, si no somos capaces de gestionar este patrimonio, y en la gestión entran todos los aspectos anteriores, el propio conocimiento, la restauración o la conservación, pero también otros como la reversión del conocimiento a la sociedad, su divulgación y difusión, la toma de decisiones sobre el presente y futuro de ese patrimonio, la participación de la sociedad en esa toma de decisiones, etc.

Uno de los aspectos que más interesaba desarrollar en la propuesta de la que deriva este texto era contribuir a generar un modelo de gestión integral del patrimonio construido o, al menos, identificar determinados procesos que se puedan adaptar a generar modelos de gestión integral que se adecúen a cada caso, si bien es cierto, este aspecto no se trata en este texto, pues presentar ese modelo no es su objetivo. Simplemente queremos incidir en que es en el campo de la gestión del patrimonio construido donde la AA presenta un grandísimo potencial, no sólo por la contribución que precisamente ha realizado a la gestión integral de ese patrimonio (análisis, documentación, restauración, rehabilitación, puesta en valor, socialización, conservación, etc.), sino porque en la mejora de esa gestión se han desarrollado diferentes técnicas que han permitido la renovación de la disciplina arqueológica, contribuyendo a generar una estructura retroalimentada entre los procesos técnicos y la investigación (Azkarate 2002b: 61).

Es precisamente desde la comprensión de la diferentes dimensiones del patrimonio y de su potencialidad como multi-recurso, donde surgen proyectos que en su planteamiento intentan atender a todos los eslabones de la cadena de valor del patrimonio y, evidentemente, a su gestión desde los ámbitos más diversos (científico, cultural, social, político, económico...). Sólo desde estas perspectivas se pueden entender proyectos como el de la Catedral de Santa María (Azkarate et al. 2002b) o Salinas de Añana ${ }^{67}$ (Plata Montero 2008 y 2009). ${ }^{68}$

\section{Para concluir, breves aportaciones de la AA}

Recientemente se apuntaba que nadie puede negar una evolución desde los momentos iniciales de la AA "en los que los testimonios arquitectónicos no eran para los arqueólogos sino contenedores de contextos estratigráficos que permitían su secuenciación histórica, a otros más recientes en los que se enfatiza también su capacidad para acceder a dimensiones simbólicas y sociales o se reconoce su potencialidad para participar activamente en proyectos interdisciplinarios relacionados con la documentación, conservación y socialización de los paisajes culturales" (Azkarate 2013: 11). Hemos reseñado algunos proyectos que ejemplifican este hecho.

Sin embargo, todavía queda mucho por hacer para regularizar, normativizar y democratizar la disciplina. En la reunión organizada en el Instituto del Patrimonio Cultural de España en 2009 se apuntaba hacia este hecho, y en 2016 los que participamos en aquella reunión todavía no hemos realizado un documento en este sentido. Sigue siendo además necesario apostar por programas de formación en AA dentro de los planes específicos de arqueología, pero también de restauración arquitectónica, de arquitectura y de historia del arte. Es necesario normativizar una exigencia por parte de las administraciones públicas de documentar los espacios construidos antes de ser intervenidos (insistimos en la idea de Azkarate de que el conocimiento es un acto

\footnotetext{
67 La investigación llevada a cabo en este valle salinero ha desencadenado una serie de procesos sociales, culturales y económicos que ponen de manifiesto la rentabilidad en términos patrimoniales y sociales de la aplicación de la cadena de valor del patrimonio (https://www.gourmets. net/salon/index.php? route $=$ actividades $\% 2$ Fexpositores $\% 2$ Fdetalle \&expos itor_id=483576, http://www.elcorreo.com/vizcaya/v/20130409/alava/colaboracion-valle-salado-anana-20130409.html, son algunos ejemplos de esta rentabilidad).

68 Aunque estos son dos de los proyectos más identificativos del actual Grupo de Investigación en Patrimonio Construido, esta misma filosofía $\mathrm{y}$ enfoque hacia la gestión integral del patrimonio construido se ha aplicado a otras proyectos desarrollados más recientemente, como el que el grupo lleva a cabo en el Fuerte Sancti Spiritus (Puerto Gaboto, Santa $\mathrm{Fe}$, Argentina) y su entorno (Azkarate et al. 2012), con presencia en las redes sociales (https://www.facebook.com/Proyecto.Fuerte.Sancti.Spiritus. Argentina). Existen otros muchos proyectos arqueológicos llevados a cabo por otros grupos y planteados desde la gestión integral del patrimonio, pero hemos acudido a estos ejemplos porque nos interesaba hacer hincapié aquí en trabajos desarrollados para este fin desde la AA, o al menos con una fuerte presencia de esta estrategia de investigación en sus planteamientos teórico-metodológicos.
} 
consubstancial a la restauración). Algunas de las prácticas que se han llevado a cabo en nombre de la AA, desde diferentes ámbitos sin la formación necesaria, simplemente por considerarse que muchas de las metodologías que se aplican al estudio de los edificios históricos no son destructivas, sin tener en cuenta que las consecuencias de esos informes sí pueden llegar a serlo, tienen que dejar de producirse o al menos conllevar una reflexión profunda sobre sus consecuencias. Independientemente de que nuestras interpretaciones sobre los espacios construidos puedan ser o no cuestionadas, el acto de registrar la información que nos proporcionan los documentos construidos y los contextos en lo que se ubican, es un acto fundamental en arqueología y de una tremenda irresponsabilidad no llevarlo a cabo adecuadamente.

Finalmente, nos gustaría remarcar algunos aspectos ya comentados que hacen hincapié en la importancia que la AA está teniendo en la renovación arqueológica de las últimas décadas. En primer lugar, un aspecto a destacar es el alto grado de publicación que ha tenido desde el comienzo de su desarrollo en Europa, ya que desde momentos muy tempranos contó con el suplemento Archeologia dell'Architetura dentro de la revista Archeologia Medievale (http://www.bibar.unisi.it/riviste/archeologia-dellarchitettura), o con la publicación de monográficos en revistas o de actas de distintos cursos, congresos y encuentros que iban mostrando los avances en la disciplina, ${ }^{69}$ lo cual contribuyó a su rápida difusión que, a su vez, ayudó a paliar la importante carencia de formación específica en AA que existía (y existe) en la mayoría de las universidades españolas, sobre todo en los primeros años de su implantación en la península.

Por otra parte, cabe destacar también que desde su inicio la AA tuvo una vertiente muy aplicada, tanto en el desarrollo metodológico, como en la transferencia de conocimiento, gracias sobre todo a su vinculación con el campo de la restauración desde el que se abrieron nuevos caminos para la misma. Es el caso, por ejemplo, de la importante labor desarrollada por el Servei del Patrimoni Arquitectònic Local de la Diputación de Barcelona de la mano de Antoni González Moreno-Navarro (González Moreno-Navarro 1999a y 1999b; González Moreno-Navarro et al. 1990) donde se consolidó un equipo dedicado a la restauración arquitectónica en el que se primaba la interdisciplinariedad y donde la

\footnotetext{
69 Archeologia dell'Architettura 2; Caballero y Latorre 1995; Caballero y Escribano 1996; Fontenla 1997 y 1998; Azkarate 2002 y 2003; Ayán et al. 2003; por ejemplo.
}

arqueología comienza a formar parte del proceso de restauración, logrando codificar un protocolo de intervención estratigráfica integral de los edificios analizados (López Mullor 1993, 1999, 2002 y 2011). Y gracias a la vertiente social de muchos de los proyectos planteados (volvemos a remitirnos tanto a los trabajos que se llevaron a cabo desde el Servei del Patrimoni Arquitectònic -López Mullor 1993- como desde el Grupo de Investigación en Patrimonio Construido de la UPV-EHU).

No han faltado tampoco aquellos grupos e investigadores que han empleado la AA como herramienta para la revisión de modelos interpretativos anteriores y la construcción de nuevos modelos, tal es el caso del trabajo de Luis Caballero y su equipo sobre las iglesias altomedievales de la península ibérica (Caballero y Utrero 2005), o de Juan Antonio Quirós y el Grupo de Investigación en Patrimonio y Paisajes Culturales que dirige, sobre la Alta Edad Media.

Pero, como decíamos, aún quedan pasos por dar hasta lograr, sobre todo, la regularización y normativización de la disciplina. Es, tal vez, momento para la reflexión sobre qué camino queremos construir en el futuro y cuáles con las necesidades fundamentales para que la AA consolide su papel dentro de la historia de la arqueología. Y creo que puede ser de la mano de otras compañeras, como la ArPa, como pueda maximizar sus potencialidades.

\section{OTRAS MIRADAS. UNA PROPUESTA INTEGRADORA A MODO DE CONCLUSIÓN}

Estos fueron los conceptos y marcos teóricos desde los que se abordó la investigación sobre paisajes fortificados que comentábamos al inicio de este texto. En el primer caso, intentamos revisar dos conceptos clave en nuestra aproximación, los de arquitectura y paisaje, observándolos desde la matriz que representa la ontología del Patrimonio Arqueológico (PA) empleada por Criado-Boado (2012: 193-194). A partir de esta matriz presentamos ambos elementos patrimoniales como $\mathrm{ma}^{-}$ terialización de un concepto, resultado de un proceso y recurso del pasado en el presente. Esta conceptualización común nos permitió estudiarlos desde una misma perspectiva y dentro de una misma matriz espacial. Unificar el estudio de ambas entidades era importante puesto que partíamos de la idea de la existencia de una interacción entre ellas, las arquitecturas defensivas, todas las estructuras asociadas a ellas y el territorio en el 
que se insertan conforman un paisaje construido, por lo que su valorización y caracterización como entidades aisladas no creíamos que fuese la estrategia adecuada a nuestro fin de caracterizar este paisaje.

El estudio en detalle y por separado de la arquitectura y el paisaje, permitió en las últimas décadas abordar otras dimensiones del registro arqueológico y acceder a un mayor número de elementos materiales e inmateriales que conforman ambas realidades; pero intentar introducir dentro del proceso de caracterización y valorización del registro arqueológico al paisaje y la arquitectura conjuntamente, nos permite acceder a un mayor número de significados. Nuestra propuesta aboga por abordarlas como parte integrante de un mismo espacio construido, con distintos niveles de significación, donde la arquitectura construya paisaje y el paisaje signifique la arquitectura.

Detrás del planteamiento de aquella investigación no sólo estaba abordar su estudio conjunto, sino proponer también un modelo de trabajo. Nuestra intención era plantear una estrategia o programa de investigación arqueológico (PIA) en Paisajes Fortificados (PF). Un PIA necesita "proveerse de una formulación teórica pertinente que incluya reflexiones y dispositivos que le permitan dar cuenta de aquel segmento de la realidad que investiga" (Id: 178), en nuestro caso, los paisajes culturales. El autor analiza los aspectos que debe incluir un PIA ${ }^{70}$ (Criado-Boado 2012: 178-179): una ontología, una epistemología, una base teórica, una propuesta metodológica, una metodología, un método, unos modelos interpretativos y una dimensión crítica. Haremos aquí simplemente una reflexión sobre el modelo de trabajo que construimos para abordar el estudio de los PF.

\section{Desde la arquitectura y el paisaje hacia el espacio construido}

Tras haber analizado los conceptos de arquitectura y paisaje e identificarlos como básicos en nuestra investigación, era inevitable que emergiese el de espacio como sustancial en nuestro trabajo. El Espacio es una de las dimensiones fundamentales de la investigación arquitectónica, y de determinada investigación arqueológica, y de su concepción dependen las técnicas analíticas a emplear en su estudio. Una parte imprescindible de

\footnotetext{
70 Nosotros hablamos de Programa de Investigación Arqueológica, realmente el autor se refiere a un contexto más amplio, a un programa de investigación científica.
}

nuestra estrategia de investigación deriva directamente del concepto teórico de espacio, de su interpretación en el campo de la arquitectura y de cómo acaba contribuyendo a la investigación de las arquitecturas pretéritas. Haremos un breve recorrido por estas temáticas antes de llegar a la conclusión que nos interesa.

Recordemos que la arquitectura es ante todo una tecnología constructiva cuyo objetivo es dar dimensión humana a un espacio (Mañana et al. 2002: 25). Analizando la configuración formal de una construcción se puede, por un lado, encontrar ciertas pautas de regularidad que la hacen coherente dentro de un patrón de racionalidad y, por otro, identificar recurrencias estructurales que indiquen un determinado modo de concebir el espacio en esa cultura. En la arquitectura fortificada de época moderna, el baluarte constituye un elemento que se repite y confiere una forma característica a este tipo de fortificación (polígonos estrellados); pero más allá de ser un elemento representativo de la arquitectura que analizamos, formalmente hablando, también lo es de los principios que la generan, de su patrón de racionalidad. El baluarte es una figura que evoluciona a partir de los cubos de la muralla medieval para intentar paliar los efectos que en ésta produjo la introducción de la artillería; los cubos evolucionan hacia formas triangulares, primero el bastión y, más tarde, el baluarte. Éste tiene forma de punta de flecha, con dos caras, dos flancos y una gola. Supone "una forma avanzada y dinámica en figura triangular [...] que permitía el empleo de sus dos caras exteriores para la defensa de las cortinas y el apoyo en su enfrentado para lanzar fuego cruzado. $\mathrm{Su}$ propia defensa partía de los flancos y orejones" (Porras 1995: 53). Es decir, es una figura que materializa una de las máximas de la fortificación abaluartada "MAXIMA $N^{\circ} 1$ / Todas las partes de la fortificación deben ser vistas y flanqueadas las unas de las otras" (Lucuze 1772, en Porras 1995: 48). El mismo argumento podríamos usar para el concepto paisaje, que veíamos cómo también suponía la materialización del patrón de racionalidad que está detrás de la fortificación del período que nos ocupa, al llevar al territorio los mismos principios que regían la arquitectura. La conceptualización final del PF moderno que surgió de nuestra investigación, y que veremos más adelante, apoya esta afirmación.

Teniendo en cuenta las conclusiones obtenidas en nuestro trabajo, proponemos dar un salto hacia una noción simbiótica de ambos conceptos que nos permita estudiarlos de forma conjunta, sin renunciar a las especificidades de cada uno de ellos y a su individualización 
cuando sea necesario, de manera que podemos caracterizarlos y valorizarlos tanto por separado como conjuntamente, según el enfoque que hemos presentado en las páginas anteriores. Nos referimos a la introducción del concepto de espacio construido.

\section{El concepto de Espacio ${ }^{71}$}

La mayor parte de las acciones humanas encierran un aspecto espacial; por un lado, los objetos están distribuidos según relaciones espaciales (lejos-cerca, interiorexterior, etc.), por otro, el ser humano para poder llevar a cabo sus acciones debe comprender esas relaciones y unificarlas en un concepto espacial.

El espacio, considerado como una de las dimensiones existenciales fundamentales del ser humano (Norberg-Schulz 1980: 9), ha sido objeto de estudio y reflexión de la filosofía y las ciencias desde muy antiguo. La última revolución del concepto en ambos campos llegó con Einstein, que sintetizó los conceptos de espacio existentes en física a tres categorías principales (Ven 1981: 67-72): el concepto aristotélico de espacio como lugar; el concepto de espacio como contenedor; y el concepto de espacio como campo cuatridimensional, el espacio relativo. A partir de aquí, el antiguo concepto de un único tipo de espacio se complejiza: espacios físicos concretos (micro, ordinario y macro) y espacios matemáticos abstractos, inventados por el hombre para describir con mayor o menor grado de aproximación los anteriores. La teoría de la relatividad nos lleva más allá de esta dicotomía entre espacio y tiempo, "sustituyendo la idea de trozos de materia situadas en un espacio tridimensional, por una serie de acontecimientos en un espacio-tiempo de cuatro dimensiones" (NorbergSchulz 1980: 9-10).

Fuera del ámbito de las ciencias, la idea de espacio adquiere también otras dimensiones. La noción tradicional de espacio está reducida a un problema natural, geográfico, como un mero lugar de residencia o un sitio de explotación. A partir del siglo XIX y bajo la racionalidad burguesa, se considera al espacio como naturaleza que explotar, reduciéndolo a su dimensión de territorio: un espacio dominado que se puede parcelar, medir o vender. ${ }^{72}$ Además, dentro del sistema de saber moderno, el espacio ha estado en descrédito en relación

\footnotetext{
71 Este apartado y el siguiente están basados en nuestro trabajo previo Mañana et al. 2002: 25-29.

72 Es un concepto que sirve para justificar el uso que se hace del espacio a partir de este momento, en consonancia con la propia racionalidad burguesa.
}

con el tiempo (Criado-Boado 1993b: 15 y ss.): tal y como indica Foucault, el primero es considerado como lo inmóvil, lo muerto, mientras que el tiempo era rico, fecundo, dejando al espacio en un segundo plano, supeditado al tiempo.

Pero en todos estos conceptos de espacio, quedan muy empobrecidos aspectos de la vivencia espacial, como la relación emocional y simbólica con el medio ambiente. Englobando estos aspectos esenciales C. Norberg-Schulz (1980: 9-12) al hacer un estudio sobre la noción de espacio distingue entre varios conceptos: espacio pragmático, espacio perceptivo, espacio existencial, espacio abstracto, espacio cognoscitivo del mundo físico, espacio abstracto de las puras relaciones lógicas, espacio expresivo o artístico y espacio arquitectónico. ${ }^{73}$ Aunque están encadenados unos con otros (Mañana et al. 2002: 26) nos interesan aquí los dos últimos, el primero porque acoge al segundo, el segundo porque se puede definir como una concretización del espacio existencial del hombre.

En este breve recorrido por los distintos ámbitos teóricos en los que se reflexiona sobre el concepto de espacio, se observa que éste ha pasado de ser una noción con un único significado (lugar, espacio tridimensional, etc.), a valorarse de forma multidimensional, considerando tanto su concepción como matriz física como la percepción que el ser humano tiene sobre él y el significado cultural que lleva implícito. Este espacio multidimensional está directamente relacionado con el patrón de racionalidad ${ }^{74}$ de la sociedad que lo genera y vive, siendo además la arquitectura (y el paisaje) el medio más evidente de concretar los conceptos espaciales de esta racionalidad. Quizás sea el estudio de la espacialidad de una sociedad pretérita uno de los medios más satisfactorios de acceder a su racionalidad, como lenguaje que permanece.

\section{El espacio en Arquitectura, espacio y paisaje, espacio construido}

En las últimas décadas del siglo XIX nace la arquitectura moderna para romper con el eclecticismo decimonónico dominante; en ella destacan la fusión de ornamentación y construcción como unidad y el hecho de ser el primer movimiento que visualizó la nueva conciencia de la

\footnotetext{
73 Sobre el concepto de espacio véase también Scruton 1979: 43-52 y Sennet 1991.

74 El pensamiento de Lévi-Strauss.
} 
abstracción espacial, surgiendo por primera vez la idea de espacio en cuanto idea arquitectónica ${ }^{75}$ (Ven 1981, en Mañana et al. 2002: 26). Es entonces cuando arquitectos e historiadores del arte empiezan a considerar el espacio como un concepto fundamental en arquitectura, gracias a influencias como las del filósofo Lao-Tsé. En lo que se refiere al espacio, fue fundamental la expresión en su teoría ( $c a .550$ a. C.) de la superioridad de lo contenido en un espacio arquitectónico, del espacio interior. Este pensamiento ejerció una gran atracción entre los arquitectos, "quienes perciben el contenido intangible de la forma arquitectónica como lo que verdaderamente impulsa a la arquitectura" (Ven 1981: 23). Esta es la primera tentativa escrita de interpretación de la línea fronteriza como continuidad del espacio, poniendo énfasis no tanto en el espacio interior como en aquellas partes del edificio que transmiten lo interior hacia el espacio exterior (los umbrales).

En el estudio del concepto de espacio en Arquitectura destacan las teorías de varios historiadores del arte y arquitectos. Schmarsow considera que la arquitectura se genera a partir del cuerpo humano y defiende su carácter funcionalista. Distingue tres modalidades de espacios: el táctil, el móvil y el visual, con lo que incorpora los sentidos en simultáneas y sucesivas experiencias en el espacio y el tiempo. Hildebrand, sin embargo, percibe el espacio a través de la visión pura (imágenes en reposo) y la visión cinética (imágenes recibidas con el espectador en movimiento). Las teorías cubistas que a partir de la teoría de la relatividad de Einstein añaden el concepto de la cuarta dimensión, que se adquiere con el movimiento del cuerpo ${ }^{76}$ (frente a la tradicional dimensión euclidiana estática), fueron también fundamentales para el estudio del espacio en arquitectura. Uno de los mayores representantes de la arquitectura moderna, Le Corbusier acabó adoptando también esta cuarta dimensión llamándola "espacio inefable" o "estado emocional por el que se experimentan espacios definidos por series armónicas" (Ven 1981: 91), lo que deriva en una gran consideración en la disposición del volumen y al orden

\footnotetext{
75 “...fue a mediados del siglo XIX cuando la palabra 'espacio' comenzaba a ser utilizada por algunos críticos, sobre todo en el ámbito alemán donde 'espacio' y 'habitación' son lingüísticamente similares” (Martín Hernández 1997: 165).

76 En las vanguardias de principios de siglo, se emplean modelos arquitectónicos directamente relacionados con los planos superpuestos característicos del cubismo, en los que la transparencia del material permite la visión a través y simultánea de los diversos planos interior/exterior. "En esa influencia recíproca de espacios, que se producía a través de un material real pero 'invisible', radicaba la concepción espacio-temporal entendida como el nuevo paradigma de la arquitectura de este siglo [XX]" (Martín Hernández 1997: 166).
}

de la circulación en los edificios. En todas estas teorías, la percepción de los espacios, se perfila como fundamental en el estudio de la arquitectura, siendo una de las claves el movimiento.

De este modo, en la arquitectura moderna se propusieron diversos supuestos respecto al espacio. Uno de los autores fundamentales en esta actualización fue S. Giedion (1980 y 1988), para quien el proceso por el cual una imagen espacial puede ser transpuesta a la esfera emocional es expresado por el concepto espacial: "Proporciona información acerca de la relación entre el hombre y lo que lo rodea. Es la expresión espiritual acerca de la realidad que se halla frente a él. El mundo situado ante él es modificado por su presencia; le obliga a proyectar gráficamente su propia posición si desea relacionarse con él" (Norberg-Schulz 1980: 13). Este aserto coincide con el identificado en la Arqueología del Paisaje, en el que se considera que a través del estudio de los conceptos de espacialidad, de su modelo estructural, se puede acceder al esquema de racionalidad que los generó (Mañana et al. 2002: 27).

Los estudios sobre el espacio arquitectónico dependen del concepto de espacio base que se utilice. Norberg-Schulz (1980: 13 y ss.) distingue los estudios que se fundamentan en el espacio euclidiano, el tridimensional, y estudian su gramática, es decir, se basan en el desarrollo de modelos de dos o tres dimensiones de carácter geométrico, formando parte ésta de la sintaxis del espacio arquitectónico; y aquellos otros que tratan de desarrollar una teoría del espacio sobre la base de la psicología de la percepción, sobre todo de las impresiones, sensaciones y análisis de los efectos generados sobre el ser humano que percibe. El autor considera que ambos tipos de estudios serían deficientes y parciales. El primero porque excluye al ser humano, discutiendo de geometría abstracta, y el otro porque reduce el espacio y la arquitectura a impresiones, olvidándose del espacio como dimensión existencial y como lugar de relación entre el hombre y el medio que lo rodea. Para salvar esta carencia, propone introducir el concepto de espacio existencial dentro del estudio del espacio en arquitectura y de su interpretación, ya que si los aspectos geométricos y perceptivos se analizan dentro de un esquema de comprensión más general, cada uno de ellos adquiere una mayor significación que la que tendrían por separado (Norberg-Schulz 1980). Un estudio de la espacialidad de una construcción arquitectónica que no está integrado dentro de la racionalidad que la generó, queda mutilado y sin sentido. Ésta es precisamente una de las 
teorías esenciales de las que parte nuestra investigación, la asunción de que "las actividades que tienen lugar en relación con el espacio están organizadas de forma coherente con la representación ideal del mundo que tiene el grupo social que las realiza" (Criado-Boado 1999: 10), por lo que es fundamental integrar estos análisis, tanto el gramatical como el de la percepción espacial, en un determinado patrón de racionalidad. Esta teoría da sentido a nuestra conceptualización de la arquitectura y el paisaje como materialización de un concepto, tal como hemos expuesto.

Conviene también a nuestro propósito observar la relación entre los conceptos de paisaje y espacio. Recordaremos que cuando tratamos el de paisaje comentábamos que uno de los objetivos principales de su estudio desde la ArPa es analizar, reconstruir e interpretar los paisajes arqueológicos a partir de los elementos que los concretan, es decir, analizar de manera integral los procesos y formas de culturización del espacio a lo largo de la historia, comprendidos como entidades espaciales y fenómenos sociales y no como hechos aislados (CriadoBoado 1999: 6). En ArPa se parte de que las actividades que tienen lugar en relación con el espacio, están organizadas de forma coherente con la representación ideal del mundo que tiene el grupo social que las realiza, al igual que sucedía con la arquitectura. Es decir, en el proceso de construcción de los espacios intervienen tanto dispositivos mecánicos (físicos) como dispositivos conceptuales, necesarios para poder llevar a cabo la "humanización" o "antropización" de un espacio. Analizando los dispositivos mecánicos (las formas), su configuración o los cambios según el distinto tipo de sociedad, se debería poder llegar a acceder en cierta medida a los dispositivos conceptuales que los han generado, a su patrón de racionalidad (Criado-Boado 1999: 10).

La definición de paisaje que utilizamos arriba como producto socio-cultural (Criado-Boado 1999: 5), es un concepto foucaultiano del que dimanan varias derivaciones útiles para la Arqueología (Criado-Boado 1993c): espacio, pensamiento y sociedad están íntimamente ligados, siendo la construcción del espacio una parte fundamental de la construcción de la realidad de un determinado sistema de saber-poder. Del mismo modo, nuestra investigación parte del presupuesto teórico de la multidimensionalidad del paisajelespacio, donde éste se encuentra constituido por tres dimensiones ya apuntadas: el espacio en cuanto entorno físico; en cuanto entorno social; y en cuanto entorno pensado (Criado-Boado 1996b: 17 y 1999: 6).
De acuerdo con este marco teórico y conceptual, la ArPa prioriza el estudio del espacio, analizado y pensado a través del registro y de la cultura material, integrando en este estudio la parte imaginaria-simbólica del mismo, es decir, intenta elaborar modelos de interrelaciones entre los tres tipos de espacios definidos (Criado-Boado 1995: 8 y 1996b: 17) y articular el análisis complementario de estas tres dimensiones del espacio, tratando de no centrarse en una de ellas como representación de la globalidad del paisaje.

Cada uno de estos ámbitos está determinado por códigos espaciales compatibles y semejantes entre sí, presentando relaciones de compatibilidad y configurando una regularidad espacial, ya que obedecen a la misma estrategia de construcción del espacio social (en el sentido lefebvriano del término, Lefebvre 2013: 125 y ss.), al mismo patrón de racionalidad. Desde este punto de vista, destaca la importancia del estudio de las formas y del espacio que éstas definen, ambas constituyen realmente el registro arquitectónico y paisajístico, su aspecto físico es lo que se conserva en el tiempo. Para llegar a profundizar en la sociedad que los construyó, además de estudiar los tipos de materiales, la forma en que se disponen en el edificio o las técnicas constructivas, es fundamental definir cómo se han organizado estos volúmenes y qué espacios han sido formados (Ching 1984), o bien qué recursos (simbólicos) se han empleado para crear una determinada escena, ambiente en el que se desenvuelven las relaciones sociales a todos los niveles, desde las relaciones individuales, familiares hasta los más generales (intergrupales).

Igualmente, el espacio arquitectónico, como los restantes elementos formales del registro, es esencialmente un espacio social que se construye culturalmente; es el producto o efecto de la acción social. Constituye un paisaje cultural en sentido amplio, que participa de lleno en la construcción del aparato simbólico, el imaginario colectivo y las prácticas rituales de la comunidad que lo construye y habita; así por ejemplo, la forma arquitectónica aparece interrelacionada con variables sociológicas como la familia, el estilo de vida, la solidaridad intergrupal o el sistema de poder, como en el caso de los PF modernos. De este modo, el espacio arquitectónico se puede definir como un producto humano que utiliza una realidad dada (el espacio físico) para crear una realidad nueva: el espacio construido y, por consiguiente, social, al que se confiere un significado simbólico (Mañana et al. 2002: 28).

Esta es la base de la primera consecuencia de nuestra investigación, que realmente se viene gestando ya desde 
uno de los primeros trabajos que abordamos en esta línea (Mañana et al. 2002: 2002). Haciendo un breve recorrido por los aspectos que acabamos de analizar, podríamos concluir diciendo que el espacio es multidimensional y multivocal. La arquitectura es forma y es espacio definido por la forma, es significado y es significado traducido en una forma. En este sentido se aboga por hablar de espacio arquitectónico, un espacio social que se construye culturalmente. Este espacio arquitectónico se inserta además en un entorno físico. Ambos acaban formando parte del paisaje, una construcción social donde espacio, pensamiento y sociedad están íntimamente ligados, siendo la construcción del espacio una parte fundamental de la construcción de la realidad de un determinado sistema de saber-poder. Arquitectura y paisaje construyen espacio a escalas distintas. Abordar la multidimensionalidad de su carácter, como hemos propuesto aquí, implica abordar estas escalas; hacerlo de forma conjunta demanda atender a un concepto que englobe ambas formas del espacio. Abogamos pues en aproximaciones del tipo que presentamos en este trabajo por el uso del término más contextual espacio construido. Es decir, se propone adoptar el concepto de espacio construido cuando se use una aproximación simbiótica a la arquitectura y el paisaje como concepto operativo, de manera que no se aborde únicamente y por separado la arquitectura y/o el paisaje, sino ambos como parte de una misma realidad que supone la manifestación de códigos sociales de un determinado grupo humano, el paisaje que éste construye y cómo lo construye muestra unos códigos de lenguaje que reflejan a esa sociedad concreta. La arquitectura no sólo es espacio, sino que se manifiesta en un espacio; el paisaje sólo se comprende si trascendemos el concepto de territorio y atendemos a su ordenación, de la que forma parte la arquitectura. El concepto de espacio construido pretende englobar la visión y aproximación conjunta a ambas manifestaciones. "Una vez más, el espacio exhibe el orden mejor que el tiempo. ¿Cuándo los arqueólogos e historiadores aprenderán esta lección?" (Criado-Boado 2002: 92).

\section{Sobre Arqueología del Paisaje, Arqueología de la Arquitectura y Arqueología del Espacio Construido}

La asunción del concepto de espacio construido, nos llevó a plantearnos la necesidad también de abogar por un programa de investigación interno que abarcase el estudio conjunto de la arquitectura y el paisaje, como ya hemos visto.
Hemos manifestado que la ArPa y la AA son los modelos interpretativos del registro arqueológico en los que basamos la investigación. Pero nos interesa focalizar en la repercusión que tuvo el uso de ambas estrategias de investigación en el estudio de un tipo de registro arqueológico concreto.

Recordemos que definíamos ArPa como un modelo interpretativo que analiza los objetos que forman parte del registro arqueológico como objetos implicados en y participantes del paisaje; pero también como una estrategia de investigación derivada de este modelo. Esto implica que desde ArPa el paisaje se entiende, por un lado, como un contexto en el que se inserta el registro arqueológico $\mathrm{y}$, por otro, como un objeto susceptible de ser analizado con metodología arqueológica. Es decir, los paisajes se entienden como una dimensión relevante de las sociedades humanas, puesto que no sólo constituyen la base en la que éstas se desarrollan sino también su resultado, por lo que se considera que representan a esas sociedades. ArPa es además una herramienta de gestión, pues comprende una cierta utilidad crítica y actual, se relaciona con temas que están muy próximos de la sensibilidad y preocupaciones a las que en la actualidad se enfrentan nuestras sociedades (Criado-Boado 1999: 1).

Esta doble dimensión también se observa en la AA, entendida como una estrategia de investigación que estudia la arquitectura con una metodología arqueológica y tiene como principal objetivo el conocimiento histórico de los contextos construidos y de las sociedades que los generaron $\mathrm{y}$, como finalidad última, contribuir a su gestión integral. De hecho proponíamos para la AA una finalidad múltiple, como herramienta para el conocimiento histórico, para la praxis restauradora, para la conservación y para la gestión. Al igual que la ArPa, la AA ha demostrado su utilidad crítica y actual en numerosos proyectos orientados hacia la resolución de problemas reales muy enraizados con importantes cuestiones patrimoniales. Si en los años 90 la ArPa se convirtió en una importante herramienta para la gestión patrimonial en el marco del desarrollo de grandes obras públicas (Criado-Boado 1996b y 1996c; Barreiro et al. 1999; Amado et al. 2002), la AA lo hizo también en las mismas fechas y a principios del siglo XXI gracias a su participación directa e integración dentro de importantes programas de restauración y rehabilitación arquitectónica (Azkarate 2002b, 2009 y 2011). Este hecho viene de la mano de un cambio de concepción en la comprensión de la arquitectura por parte de la AA, en relación 


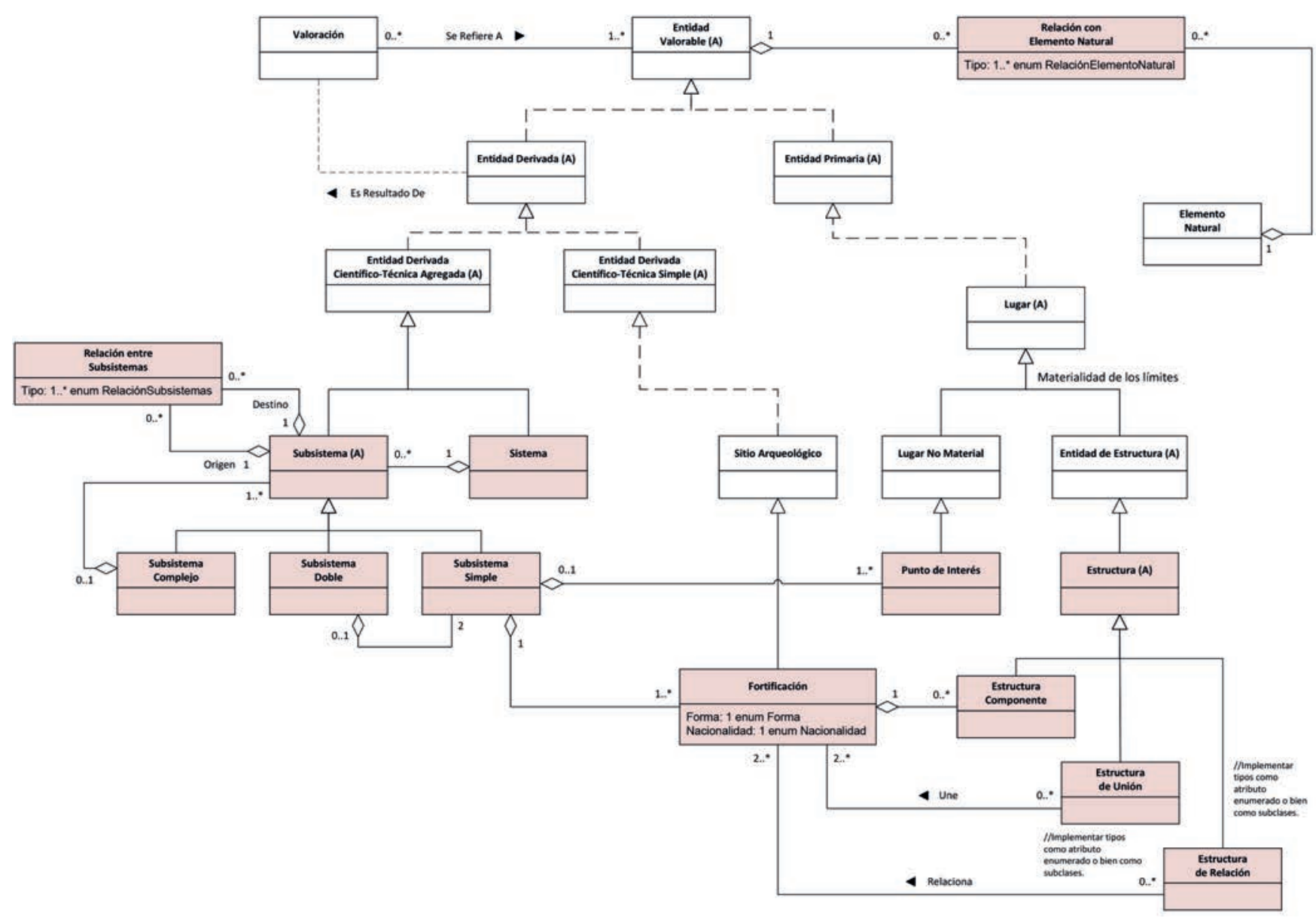

Figura 27. Modelo abstracto de paisaje fortificado empleado en esta investigación. Para su realización se ha empleado el lenguaje abstracto ConML (Conceptual Modelling Language; http://www.conml.org/). Las líneas de puntos expresan que entre las clases que unen existen otras clases intermedias. Las clases en blanco corresponden a clases definidas en CHARM (Cultural Heritage Abstract Reference Model; http://www.charminfo. org/), mientras que las clases en color corresponden a clases definidas en el marco de este análisis y suponen una extensión a CHARM.

con otras aproximaciones a ésta desde la Arqueología, la Historia de la Arquitectura o la Historia del Arte, entendiéndose ahora la arquitectura como el resultado final de un proceso histórico. Al igual que el paisaje, no sólo es el contexto en el que se producen las acciones humanas que dejan su propio registro arqueológico, sino que es resultado de esas acciones, por lo que también las representa.

Ello implica redescubrir en la arquitectura ciertas dimensiones que habían quedado ocultas, al menos parcialmente, para estudiarlas, analizarlas, gestionarlas de forma integral: la arquitectura es yacimiento, es cultura material, es tiempo, es espacio, construye paisaje, refleja un patrón de racionalidad, se transforma, evoluciona, cambia,... y no es únicamente producto de un hecho concreto de la historia, de un gusto estético determinado o del saber de un arquitecto. Tiene otros significados que van más allá de su singularidad como objeto.
Nuestra propuesta intentó fusionar ambas estrategias de manera que pudiéramos abordar de forma conjunta nuestro objeto de estudio, el espacio construido, un concepto que intenta entender la arquitectura y el paisaje en clave espacial, temporal, funcional, social y simbólica. Esta propuesta conceptual nos permite ir un paso más allá y abogar por una Arqueología del Espacio Construido (AEC) que, al igual que en el caso del objeto de estudio, es un término operativo que pretende abordar las dimensiones espaciales del paisaje y la arquitectura para comprender, precisamente, el espacio construido en las claves que acabamos que comentar.

No pretendemos invalidar otros modos de investigar el registro arquitectónico, ni sustituir las estrategias de investigación propuestas, AA y ArPa, sino maximizar sus potencialidades aplicándolas de forma conjunta y dentro de programas que aborden el espacio construido de manera integral, tratando de trazar las líneas básicas de un 


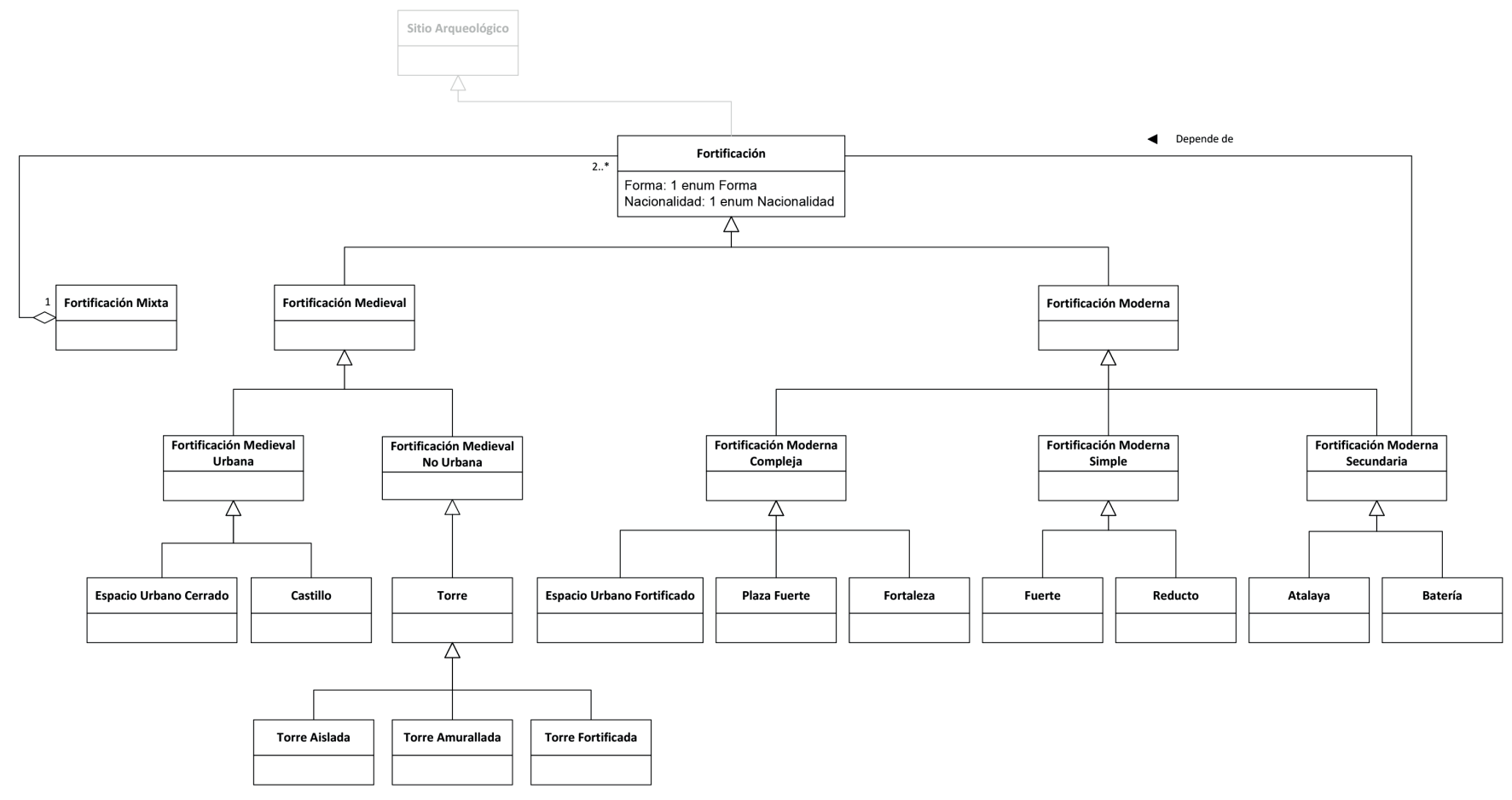

Figura 28. Diagrama correspondiente a la clase Fortificación del modelo abstracto anterior, definida dentro de este estudio.

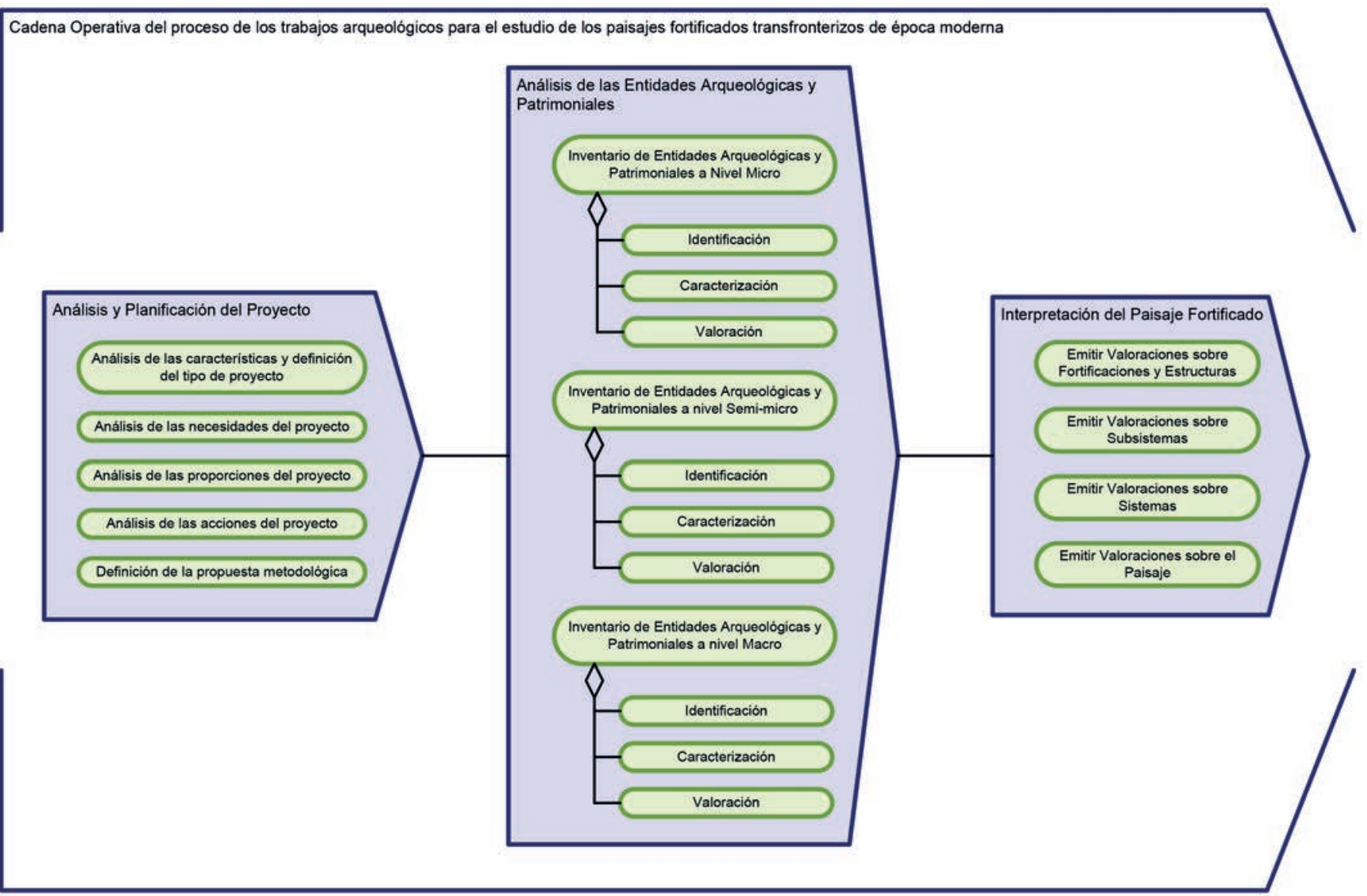

Figura 29. Diagrama de ciclo de vida que muestra la estructura de la propuesta metodológica para estudiar los paisajes fortificados transfronterizos de época moderna. Se ha utilizado para desarrollar el modelo el estándar internacional ISO/IEC 24744 (ISO/IEC 2007 y 2010). 
programa de investigación que pretende ser transdisciplinar, con el fin de obtener la mayor información posible de los espacios construidos, una forma de analizar el registro que trata de buscar regularidades. ${ }^{77}$ Más que como una subdisciplina la AEC se entiende como una línea de investigación que pretende abordar a la vez todas las escalas del espacio construido, acercándonos a ellas de forma global (pero flexible, como veremos) y observando las relaciones que se producen entre estas escalas. De la misma manera que se defiende la idea básica de que la Arquitectura en todo tiempo y lugar es una tecnología de construcción de la realidad social, la Arqueología es una práctica social en el presente. En nuestros días, el registro arquitectónico deviene en Patrimonio Construido por lo que creemos que es necesario dar respuestas y servir de herramienta básica a la gestión de este registro arquitectónico como elemento significativo del Patrimonio Cultural. En este sentido, abogamos por una perspectiva

\footnotetext{
77 Dicho programa de investigación ha sido desarrollado por la autora como propuesta en su tesis doctoral (Blanco-Rotea 2015), pero no es el objetivo de este texto por lo que sólo se esboza aquí como ejemplo del desarrollo de programas de este tipo desde las bases propuestas; aunque sí esperamos que el mismo tenga continuidad en otro trabajo en el que se aborde su materialización de manera más concreta. Nuestro objetivo, como ya hemos expuesto, era tratar aquí esos aspectos conceptuales y teóricos que son la base del programa de investigación y de la propuesta metodológica llevada cabo.
}

diacrónica en el tratamiento del espacio construido, una Arqueología del Espacio Construido aplicable tanto a la Prehistoria Reciente, como a la Arquitectura histórica, que se implique de lleno en proyectos de puesta en valor de los espacios construidos, de rehabilitación, en programas de corrección...

Nuestra propuesta presenta un modelo para el análisis arqueológico de los paisajes fortificados de época moderna ${ }^{78}$ que hunde sus raíces en programas que apostaron por una gestión integral del patrimonio, articulados desde un modelo teórico como la Cadena de Valor del Patrimonio Cultural (CVPC) que propició, precisamente, su naturaleza integral. Este modelo se compone de cuatro instrumentos básicos, un modelo abstracto del paisaje fortificado de época moderna (Figuras 27 y 28) gracias al cual se definieron las entidades arqueológicas que conforman nuestro objeto de estudio y las relaciones que se establecen entre esas entidades, ya que éste era el primer paso que nos permitiría proceder a la identificación y caracterización de los elementos que conforman el paisaje $\mathrm{y}$, al final, del propio paisaje. Un segundo instrumento es una propuesta metodológica, que presenta los planteamientos, principios, y alternativas de orden teórico

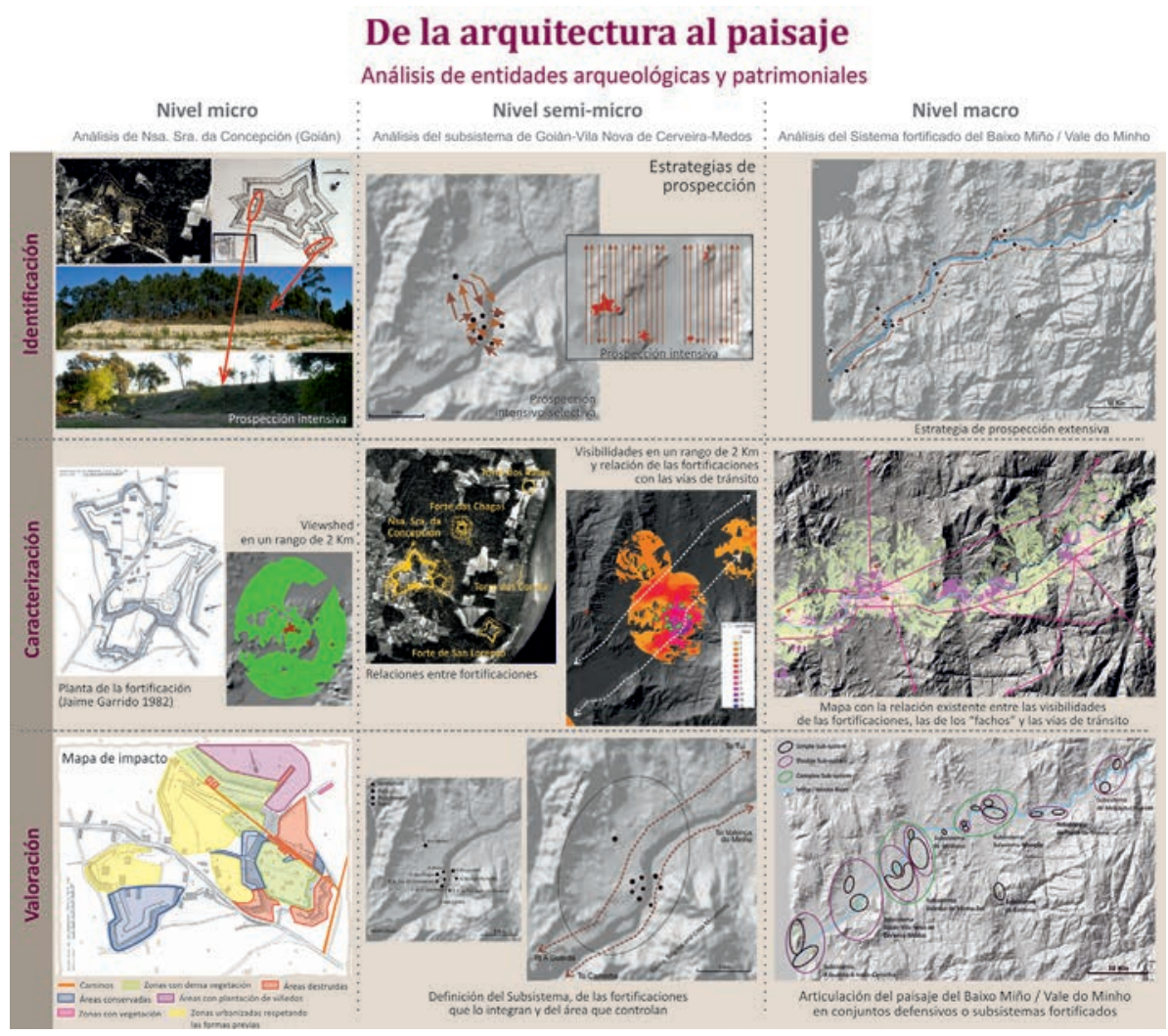

Figura 30. Ejemplo del proceso metodológico seguido a partir de la propuesta que se muestra en la Figura 29. Se pueden observar algunas de las metodologías aplicadas en los tres niveles espaciales analizados en la fortificación de la frontera miñota. 
y práctico que orientan la investigación (Criado-Boado 2012: 178). Para ello diseñamos la cadena operativa de los trabajos arqueológicos (Figura 29) que consideramos necesarios para llevar a cabo el proceso de identificación, caracterización, valoración e interpretación del paisaje y sus componentes. En esta propuesta determinamos tres escalas espaciales de análisis, y se permite una gran flexibilidad entre estas escalas, moviéndonos en sentido vertical y horizontal. Es decir, el haber caracterizado cada una de estas escalas, los elementos que las componen y las herramientas metodológicas que debemos utilizar en cada caso, podemos seleccionar la escala de aproximación que queramos abordar primero, en función de múltiples factores y variables (objetivos, presupuesto, accesibilidad, etc.), y luego movernos horizontalmente entre escalas, pasando de lo macro a lo micro, de lo micro a la macro, de la semi-micro a lo micro, etc. El tercer instrumento fue la propuesta metodológica (Figura 30), para lo que seleccionamos el repertorio de análisis que mejor nos permitía extraer datos, analizarlos y obtener conocimiento inédito; estas herramientas tienen multitud de procedencias, tanto de la AA o la $\mathrm{ArPa}$, pero también de la arquitectura, archivística, informática,... El último instrumento fue la abstracción de un modelo teórico del paisaje fortificado (Figura 31) en el que se representan las entidades principales del paisaje de la frontera del río Miño, las relaciones entre éstas y las fronteras entre entidades y entre el paisaje y su entorno. Este modelo, se observó en su momento en la zona del Miño, pero actualmente está siendo contrastado en el paisaje fortificado de la raia seca que responde al mismo fenómeno de fortificación que en el caso del Miño, para observar su funcionamiento y comprobar si el modelo teórico es aplicable a otras zonas o sólo es un caso específico de la frontera miñota. Y, del mismo modo, comprobar si el programa de investigación propuesto articulado desde el concepto contextual de "espacio construido" y desde la perspectiva simbiótica de una AEC, es aplicable al estudio de otros paisajes fortificados. ${ }^{79}$

\footnotetext{
79 Investigación que la autora está llevando a cabo actualmente dentro de su proyecto "Paisajes culturales de frontera: arquitectura, territorio, arqueología y modelos metodológicos (PAIX)" financiado por un contrato postdoctoral de la Xunta de Galicia.
}

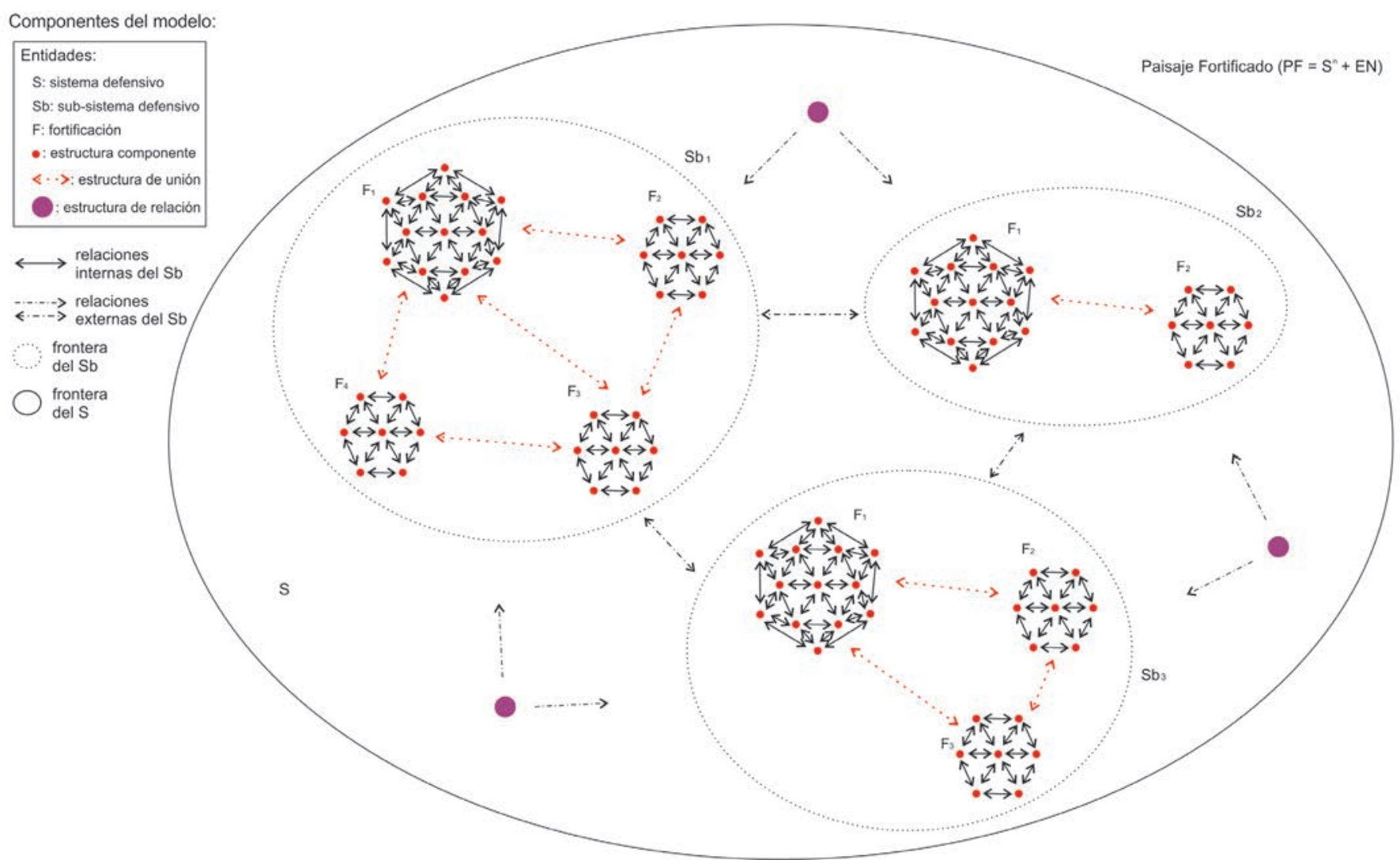

Figura 31. Modelo teórico final del paisaje fortificado del tramo bajo del río Miño, en el que se representan las entidades principales, las relaciones entre estas entidades y las fronteras de las entidades sistema y subsistema. 


\section{AGRADECIMIENTOS}

A Felipe Criado-Boado, Agustín Azkarate y Juan M. Monterroso Montero por su apoyo a esta investigación. A Patricia Mañana-Borrazás y Xurxo Ayán por haber iniciado un camino. A Anxo Rodríguez Paz, Sonia García Rodríguez y Cristina Mato Fresán por acompañarme.

A los evaluadores $y / o$ evaluadoras, porque sus comentarios creemos que han permitido mejorar el presente texto.

\section{BIBLIOGRAFÍA}

Almeida, C. A. B. de 2002. Relatório da Intervenção Arqueológica. Ponte Internacional de Vila Nova de Cerveira. Pilar A. Informe inédito. Vila Nova de Cerveira.

Amado Reino, X., Barreiro, D., Criado-Boado, F. y Martínez López, M. ${ }^{a}$ C. 2002. Especificaciones para una gestión integral del impacto desde la Arqueología del Paisaje. TAPA (Traballos de Arqueoloxía e Patrimonio), 26. Laboratorio de Patrimonio, Paleoambiente e Paisaxe, Santiago de Compostela.

Anschuetz, K. F., Wilshusen, R. H. and Scheick, C. L. 2001. "An Archaeology of Landscapes: Perpectives and Directions", Journal of Archaeological Research, 9 (2), pp. 157-211.

Antunes, J. M. 1996. Obras militares do Alto Minho: A Costa Atlântica e a Raia ao serviço das Guerras de Restauração. Dissertação de Mestrado em Arqueología apresentada na Facultade de Letras da Universidade de Porto. Inédita.

Ashmore, W. and Knapp, A. B. (Eds.) 1999. Archaeologies of Landscape: Contemporary Perspectives. Blackwell Publishers, Malden, MA.

Ayán Vila, X. 2003. “Arquitectura como tecnología de construcción de la realidad social", Arqueología de la Arquitectura, 2, pp. 17-24, doi:https:// doi.org/10.3989/arq.arqt.2003.20

Ayán Vila, X. 2006. Análisis especial aplicado a la arqueología de los asentamientos de la Edad del Hierro. Lección impartida dentro del módulo Arqueología de la Arquitectura del Máster en Técnicas de Gestión Integral del Patrimonio Cultural 2006-2007 (Santiago de Compostela). Documento inédito.

Ayán Vila, X. 2008. "A Round Iron Age: The Circular House in the Hillforts of the Northwestern Iberian Peninsula", E-Keltoi, Journal of Interdiciplinary Celtic Studies, 6. http://www4.uwm.edu/celtic/ekeltoi/volumes/ vol6/6 19/ayan_6 19.html

Ayán Vila, X.; Blanco-Rotea, R. y Mañana Borrazás, P. (eds.) 2003. Archaeotecture. Archaeology of Architecture. BAR International Series, 1175. Archaeopress, Oxford.

Ayán Vila, X. y Gago, M. 2012. Herdeiros pola forza. Patrimonio cultural, poderes e sociedade na Galicia do século XXI. 2.0 Editora, Ames.

Azkarate Garai-Olaún, A. 2001. Arqueología de la Arquitectura "Experiencias de investigación desde la Universidad del País Vasco”. Lección inaugural del Curso Académico de la Universidad del País Vasco / Euskal Herriko Unibertsitatea, 2001-2002. Bilbao: UPV-EHU.

Azkarate Garai-Olaun, A. (dir.) 2002a. "Actas del Seminario Internacional de Arqueología de la Arquitectura (I)”, Arqueología de la Arquitectura, 1. http://arqarqt.revistas.csic.es/index.php/arqarqt/issue/view/1

Azkarate Garai-Olaun, A. 2002b. "Intereses cognoscitivos y praxis social en Arqueología de la Arquitectura", Arqueología de la Arquitectura, 1, pp. 55-71, doi: https://doi.org/10.3989/arq.arqt.2002.6.

Azkarate Garai-Olaun, A. (dir.) 2003. "Actas del Seminario Internacional de Arqueología de la Arquitectura (II)", Arqueología de la Arquitectura, 2. http://arqarqt.revistas.csic.es/index.php/arqarqt/issue/view/2.

Azkarate Garai-Olaun, A. 2008. "La Arqueología de la Arquitectura en el siglo XXI", Arqueología de la Arquitectura, 5, pp. 11-13, doi: https://doi. org/10.3989/arq.arqt.2008.86.
Azkarate Garai-Olaun, A. 2009. "Reflexiones, desde una universidad que aún no existe, sobre patrimonio y socialización. (Un estudio de caso: VitoriaGasteiz, la ciudad de las tres catedrales)", en J. Carrasco Pérez (coord.), La historia medieval hoy: percepción académica y percepción social, pp. 285-303. Gobierno de Navarra, Institución Príncipe de Viana, Pamplona.

Azkarate Garai-Olaun, A. 2011. "Por un modelo de conocimiento socialmente distribuido: 'abierto por obras' en Vitoria-Gasteiz”, en M. A. Querol (ed.), Manual de gestión de Patrimonio Cultural, pp. 156-158. Akal, Madrid.

Azkarate, Garai-Olaun, A., 2013. "La construcción y lo construido. Arqueología de la Arquitectura", en J. A. Quirós (dir.), La materialidad de la historia. La arqueología en los inicios del siglo XXI, pp. 271-298. Akal, Madrid.

Azkarate Garai-Olaun, A., Caballero Zoreda, L. y Quirós Castillo, J. A. 2002a. "Arqueología de la Arquitectura: definición disciplinar y nuevas perspectivas", Arqueología de la Arquitectura, 1, pp. 7-10. http://arqarqt. revistas.csic.es/index.php/arqarqt/article/view/1/1.

Azkarate Garai-Olaun, A., Cámara, L., Lasagabáster, J. I. y Latorre, P. 2002b. Catedral de Santa María de Vitoria-Gasteiz. Plan Director de Restauración. Diputación Foral de Álava, Fundación Catedral Santa María, Vitoria-Gasteiz.

Azkarate Garai-Olaun, A., Escribano Ruiz, S., Sánchez Pinto, I. y Benedet, V. 2012. "Recuperación y gestión integral del Fuerte Sancti Spiritus y su entorno (Puerto Gaboto, Santa Fe, Argentina)", en Informes y Trabajos $n^{\circ}$ 9. Excavaciones en el exterior 2011, pp. 42-57. Ministerio de Educación, Cultura y Deporte, Madrid.

Ballesteros Arias, P. 2003. La Arqueología de la gasificación de Galicia 17: el paisaje agrario. CAPA (Cuadernos de Arqueoloxía e Patrimonio) 18. Laboratorio de Patrimonio, Paleoambiente e Paisaxe (IIT - USC), Santiago de Compostela.

Barreiro Martínez, D. 2005. Arqueología y sociedad: Propuesta epistemológica y axiológica para una arqueología aplicada. Tesis doctoral. Laboratorio de Arqueoloxía da Paisaxe, IEGPS, Santiago de Compostela. http:// digital.csic.es/handle/10261/23969

Barreiro Martínez, D. 2009. "Arqueología Aplicada: la Revalorización del Patrimonio Arqueológico", comunicación presentada en el III Seminario Internacional Municipio de Envigado. Gestión del Patrimonio Arqueológico (Envigado, Colombia, 4 de Agosto de 2009). Inédito.

Barreiro Martínez, D., Criado-Boado, F., García Quintela, M. V., Parcero-Oubiña, C. y Santos-Estévez, M. 2009. La Arqueología del Paisaje: una defensa innecesaria frente a un ataque inconsistente. http://hdl.handle.net/10261/17897

Bermejo Tirado, J. 2009. "Leyendo espacios: una aproximación a la sintaxis espacial como herramienta de análisis arqueológico", Arqueología de la Arquitectura, 6, pp. 47-62, doi: https://doi.org/10.3989/arqarqt.2009.09004.

Bernardi, M. (a cura di) 1992. Archeologia del Paesaggio. Edizioni all'Insegna del Giglio, Firenze - Consiglio Nazionale delle Ricerche, Università degli Studi di Siena.

Blanco-Rotea, R. 1997. Introducción al estudio arqueológico del patrimonio construido: El análisis estratigráfico de paramentos. Tesis de licenciatura. Universidade de Santiago de Compostela. http://digital.csic.es/handle/10261/24003.

Blanco-Rotea, R. 1998a. "La arqueología en el muro: lectura estratigráfica de paramentos en San Fiz de Solovio”, Gallaecia, 17, pp. 481-500.

Blanco-Rotea, R. 1998b. "Las construcciones históricas desde una perspectiva arqueológica", en Actas del Segundo Congreso Nacional de Historia de la Construcción (La Coruña, 22-24 de octubre de 1998), pp. 49-56. EFCA, Madrid.

Blanco-Rotea, R. 1999. Metodología para el análisis estratigráfico del Patrimonio Construido y su aplicación en San Fiz de Solovio (Santiago de Compostela - A Coruña). Trabajo de Investigación Tutelado (TIT). Santiago de Compostela: Grupo de Investigación en Arqueología del Paisaje. http://digital.csic.es/handle/10261/29650.

Blanco-Rotea, R. 2011. "Las fortificaciones de Goián-Vila Nova de CerveiraMedos en el territorio fortificado transfronterizo galaico-portugués", Castillos de España, 164-165-166, pp. 139-154.

Blanco-Rotea, R. 2015. Arquitectura y paisaje. Fortificaciones de frontera en el sur de Galicia y norte de Portugal. Tesis doctoral inédita. Universidad del País Vasco. 
Brogiolo, G. P. 2002. 'L'archeologia dell'architettura in Italia nell'ultimo quinquenio (1997-2001)", Arqueología de la Arquitectura, 1, pp. 19-26, doi: https://doi.org/10.3989/arq.arqt.2002.3.

Brogiolo, G. P. y Quirós Castillo, J. A. 2002. “Conclusiones. Actas del Seminario Internacional de Arqueología de la Arquitectura (Vitoria-Gasteiz, 1820 de febrero de 2002)", Arqueología de la Arquitectura, 1, pp. 207-210. http://arqarqt.revistas.csic.es/index.php/arqarqt/article/view/16/16

Burillo, F. (ed. y coord.) 1998. "Arqueología del Paisaje", Arqueología Espacial, 19-20.

Caballero Zoreda, L. 1995. "Método para el análisis estratigráfico de construcciones históricas o "lectura de paramentos", Informes de la Construcción, 46 (435), pp. 37-46, doi: https://doi.org/10.3989/ic.1995.v46. i435.1096.

Caballero Zoreda, L. 1997. "En torno a algunas experiencias de lectura arqueológica de edificios", Quaderns cientifics i tecnics, 9, pp. 307-324.

Caballero Zoreda, L. 2002. "Sobre límites y posibilidades de la investigación arqueológica de la arquitectura. De la estratigrafía a un modelo histórico", Arqueología de la Arquitectura, 1, pp. 83-100, doi: https://doi.org/10.3989/ arq.arqt.2002.8.

Caballero Zoreda, L. 2004. "Una experiencia en Arqueología de la Arquitectura". Arqueología de la Arquitectura, 3, pp. 127-143, doi: https://doi. org/10.3989/arq.arqt.2004.65.

Caballero Zoreda, L. 2009. "Edificio Histórico y Arqueología: un compromiso entre exigencias, responsabilidad y formación”, Arqueología de la Arquitectura, 6, pp. 11-19, doi: https://doi.org/10.3989/arqarqt.2009.09005.

Caballero Zoreda, L. 2011. "Experiencia metodológica en Arqueología de la Arquitectura de un grupo de investigación. Instituto de Historia. CSIC. Madrid", en M. a Domingo Fominaya y A. J. Sánchez Luengo (dir. y coord. ed.), Arqueología aplicada al estudio e interpretación de edificios históricos. Últimas tendencias metodológicas, pp. 103-119. Ministerio de Cultura, Madrid.

Caballero Zoreda, L. y Escribano Velasco, C. (eds.) 1996. Arqueología de la Arquitectura: El método arqueológico aplicado al proceso de estudio y de intervención en edificios históricos. Junta de Castilla y León, Burgos.

Caballero Zoreda, L. y Latorre, P. (coords.) 1995. "Leer el documento construido" (monográfico), Informes de la Construcción, 435.

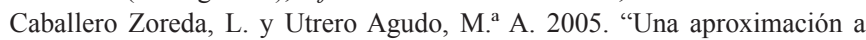
las técnicas constructivas de la Alta Edad Media en la Península Ibérica”, Arqueología de la Arquitectura, 4, pp. 169-92, doi: https://doi.org/10.3989/ arq.arqt.2005.82.

Cámara Muñoz, L. y Latorre González-Moro, P. 2002. “Anamnesis de una estructura. La Catedral de Vitoria entre los siglos XII y XX", Arqueología de la Arquitectura, 1, pp. 145-58, doi: https://doi.org/10.3989/arq. arqt.2002.12.

Ching, F. 1984. Arquitectura: Forma, Espacio y Orden. Ediciones G. Gili, México.

Cobos-Guerra, F. 2011. "El sistema de fortificaciones abaluartadas de la raya hispano portuguesa como patrimonio de la humanidad. Caracterización y valoración del sistema. Estado de la cuestión", Castillos de España, 164165-166, pp. 155-66.

Criado-Boado, F. 1993a. "Visibilidad e Interpretación del registro arqueológico", Trabajos de Prehistoria, 50, pp. 39-56, doi: https://doi.org/10.3989/ tp.1993.v50.i0.488.

Criado-Boado, F. 1993b. "Límites y posibilidades de la arqueología del paisaje", Spal, 2, pp. 9-55, doi: https://doi.org/10.12795/spal.1993.i2.01.

Criado-Boado, F. 1993c. "Espacio monumental y paisajes prehistóricos en Galicia”, en Asociación Galega de Historiadores (ed.), Concepcións espaciais e estratexias territoriais na Historia de Galicia, pp. 23-54. Tórculo Edicións, Santiago de Compostela.

Criado-Boado, F. 1995. "El control arqueológico de obras de trazado lineal: planteamientos desde la arqueología del paisaje", en Actas del XXII Congreso Nacional de Arqueología (Vigo, 1993), I, pp 253-259. Consellería de Cultura/Concello de Vigo.

Criado-Boado, F. 1996a. "El futuro de la arqueología, ¿la arqueología del futuro?", Trabajos de Prehistoria, 53 (1), pp. 13-26, doi: https://doi. org/10.3989/tp.1996.v53.i1.403.
Criado-Boado, F. 1996b. "La Arqueología del Paisaje como programa de gestión integral del Patrimonio Arqueológico", Boletín del Instituto Andaluz del Patrimonio Histórico, 14, pp. 15-9.

Criado-Boado, F. 1996c. "Hacia un modelo integrado de gestión de investigación y gestión del Patrimonio Histórico: La cadena interpretativa como propuesta", Boletín del Instituto Andaluz del Patrimonio Histórico, 16, pp. 73-78.

Criado-Boado, F. 1999. Del Terreno al Espacio: Planteamientos y perspectivas para la Arqueología del Paisaje. CAPA (Criterios y Convenciones en Arqueología del Paisaje), 6. Grupo de Investigación en Arqueología del Paisaje, Universidade de Santiago de Compostela.

Criado-Boado, F. 2002. "El final de las valoraciones", en P. Mañana Borrazás, R. Blanco-Rotea y X. Ayán Vila, Arqueotectura 1: Bases teóricometodológicas para una Arqueología de la Arquitectura. TAPA (Traballos de Arqueoloxía e Patrimonio), 25, pp. 90-92. Santiago de Compostela.

Criado-Boado, F. 2012. Arqueológicas. La razón perdida. Edicions Bellaterra, Barcelona.

Criado-Boado, F., Bonilla Rodríguez, A., Cerqueiro Landín, D., Díaz Vázquez, M., González Méndez, M., Infante Roura, F., Méndez Fernández, F., Penedo Romero, R., Rodríguez Puentes, E. y Vaquero Lastres, J. 1991. La Arqueología del Paisaje en Galicia. El área Bocelo-Furelos entre los tiempos paleolíticos y medievales. (Campañas de 1987, 1988 y 1989). Arqueoloxía / Investigación, 6. Xunta de Galicia, Santiago de Compostela.

Criado-Boado, F. y Mañana Borrazás, P. 2003. "Arquitectura como materialización de un concepto. La espacialidad Megalítica”, Arqueología de la Arquitectura, 2, pp. 103-11, doi: https://doi.org/10.3989/arq.arqt.2003.31.

Derrida, J. 1986. "La metáfora arquitectónica", trad. de Architetture ove il desiderio può abitare, entrevista de Eva Meyer en febrero de 1986, Domus, 671, pp. 16-24, [en J. Derrida, No escribo sin luz artificial. Cuatro ediciones, Valladolid, 1999, pp. 133-140]. https://redaprenderycambiar.com.ar/ derrida/textos/arquitectura.htm.

Doglioni, F. 2002. "Ruolo e salvaguardia delle evidenze stratigrafiche nel progetto en el cantiene di restauro", Arqueología de la Arquitectura, 1, pp. 113-30, doi: https://doi.org/10.3989/arq.arqt.2002.10.

Doglioni, F. 2011. "I Segni della stratificacione nelle'architettura construita. Identificazione e conservazione nel restauro", en M. a Domingo Fominaya y A. J. Sánchez Luengo (dir. y coord. ed.), Arqueología aplicada al estudio e interpretación de edificios históricos. Últimas tendencias metodológicas, pp. 129-143. Ministerio de Cultura, Madrid.

Ericeira, C. da 1945. História de Portugal Restaurado. 4 volúmenes. Livraria Civilização, Porto.

Fernández de Medrano, S. 1700 [2001 Facsímil]. El Architecto perfecto en el Arte Militar. Casa de Lamberto Marchant, Bruselas (Ed. Facsímil, Editorial Maxtor, Valladolid).

Fontenla San Juan, C. 1997. Curso As actuacións no patrimonio construido: un diálogo interdisciplinar (Santiago de Comportela, Xunta de Galicia, setembro de 1995). Consellería de Cultura, Comunicación Social e Turismo, Santiago de Compostela.

Fontenla San Juan, C. (dir.) 1998. Curso Documento, Espacio e Contorno (Santiago de Compostela, Xunta de Galicia, do 18 ó 21 de setembro de 1996). Consellería de Cultura, Comunicación Social e Turismo, Santiago de Compostela.

Galindo, J. A. 2002. El conocimiento constructivo de los ingenieros militares del siglo XVIII. Un estudio sobre la formalización del saber técnico a través de los tratados de arquitectura militar. Tesis doctoral, Universidad Politècnica de Catalunya, marzo de 1996. http://www.tdx.cat/handle/10803/6105.

Gallego Roca, J. (coord.) 2000. Italia, recuperación arquitectónica y urbana: nuevos usos de edificios históricos. Universidad de Granada, Servicio de Publicaciones, Granada.

Giedion, S. 1980. Espacio, tiempo y arquitectura: el futuro de una nueva tradición. Deddatt, Madrid.

Giedion, S. 1988. El presente eterno: Los comienzos de la arquitectura. Alianza Editorial, Madrid.

González Méndez, M. 1999. Investigación y puesta en valor del Patrimonio Histórico. Planteamientos y Propuestas desde la Arqueología del Paisaje. Humanidades y Ciencias Sociales. Tesis doctorales en CDRom. Universidade de Santiago de Compostela. 
González Moreno-Navarro, A. 1999a. "El uso sensato del patrimonio arquitectónico, requisito de la restauración objetiva", en Congreso Internacional de Restauración "Restaurar la Memoria” (Valladolid, 1998), pp. 139-166. Diputación Provincial de Valladolid e Instituto Español de Arquitectura de la Universidad de Valladolid.

González Moreno-Navarro, A. 1999b. La restauración objetiva (Método SCCM de restauración monumental). Memoria SPAL 1993-1998. Servei de Patrimoni Arquitectònic, Diputació de Barcelona. Institut d'Edicions de la Diputació de Barcelona.

González Moreno-Navarro, A., Lacuesta, R. y López, A. 1990. Com e per a qui restaurem. Objectius, mètodes i difusió de la restauració monumental. Memòria 1985-1989. Servei de Patrimoni Arquitectònic, Diputació de Barcelona. Institut d'Edicions de la Diputació de Barcelona.

González Sabater, J. 2012. Transferencia de tecnología 2.0. Conectar hoy con empresas desde universidades y centros tecnológicos. http://www.bubok. es/libros/212282/Transferencia--de-tecnologia-20.

Gordillo, G. 2013. "Bringing a place in ruins back to life", en A. González Ruibal (ed.), Reclaiming Archaeology: Beyond the Tropes of Modernity. Routledge, London.

Gude Méndez-Serois, P. 2009. Mitos e lendas de Tomiño. Artes Gráficas Prelo, S.L., A Guarda.

Gutiérrez Lloret, S. y Cánovas Guillén, P. 2009. "Construyendo el siglo VII: Arquitecturas y sistemas constructivos en el Tolmo de Minateda", en L.

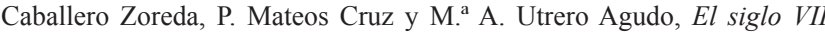
frente al siglo VII: arquitectura: Visigodos y Omeyas, Anejos de Archivo Español de Arqueología, 51, pp. 91-132. CSIC, Instituto de Arqueología de Mérida.

Harris, E. C. 1991. Principios de Estratigrafia Arqueológica. Crítica, Barcelona.

Harris, E. C. 1993. Practices of Archaeological Stratigraphy. Academic Press, London.

Hodder, I. 2012. Entangled: An Archaeology of the Relationships between Humans and Things. Wiley Blackwell, Oxford.

Knapp, A. B. and Ashmore, W. 1999. "Archaeological Landscapes: Constructed, Conceptualized, Ideational" in W. Ashmore and A. Bernard Knapp (eds.), Archaeologies of Landscape. Contemporary Perspectives, pp. 1-30. Blackwell, Malden, Massachusetts.

Latorre González-Moro, P. y Caballero Zoreda, L. 1995. “Análisis arqueológico de los paramentos del faro romano llamado Torre de Hércules (La Coruña-España)", Informes de la Construcción, 435, pp. 47-50, doi: https://doi.org/10.3989/ic.1995.v46.i435.1097.

Lefebvre, H. 2013. La producción del espacio. Capitán Swing, Madrid.

Leone, M. P, Harmon, J. M. and Neuwirth, J. L.. 2005. "Perspective and Surveillance in Eighteenth-Century Maryland Gardens, Including William Paca's Garden on Wye Island", Historical Archaeology, 39 (4), pp. 138158, doi: https://doi.org/10.1007/bf03376708.

López Hermida, J. 2005. "Descripción del Castillo de la Palma", en M. Sánchez, Memoria Histórico-Artística del Castillo de la Palma. [Memoria inédita entregada en la DXPC en enero de 2005].

López Mullor, A. 1993. “Arqueología y función social: Alguna teoría y unos cuantos ejemplos", Arqueología y Territorio Medieval, 1, pp. 51-66, doi: https://doi.org/10.17561/aytm.v1i0.1591.

López Mullor, A. 1999. "Arqueología del patrimonio edificado. Una definición y dos ejemplos", en Congreso Internacional de Restauración "Restaurar la Memoria" (Valladolid, 1998), pp. 139-166. Diputación Provincial de Valladolid e Instituto Español de Arquitectura de la Universidad de Valladolid.

Lopez Mullor, A. 2002. "Veinte años después", Arqueología de la Arquitectura, 1, pp. 159-174, doi: http://dx.doi.org/10.3989/arq.arqt.2002.13.

López Mullor, A. 2011. "La construcción de un método de intervención en el patrimonio arqueológico edificado", en M. ${ }^{a}$ Domingo Fominaya y A. J. Sánchez Luengo (dir. y coord. ed.), Arqueología aplicada al estudio e interpretación de edificios históricos. Últimas tendencias metodológicas, pp. 65-101. Ministerio de Cultura, Madrid.

Lull, V. 1988. "Hacia una teoría de la representación en arqueología", Revista de Occidente, 81, pp. 62-76.
Lucas, G. 2012. Understanding the Archaeological Record. Cambridge University Press, Cambridge.

Lucuze, P. de 1772. Principios de Fortificación, que contienen las definiciones de los terminos principales de las obras de Plaza, y de Campaña, con una idea de la conducta regularmente observada en el Ataque, y Defensa de las Fortalezas. Thomas Piferrer, Barcelona.

Manieri Elia, M. 2002. "La restauración como recuperación del sentido", Loggia, Arquitectura \& Restauración, 12, pp. 20-25, doi: https://doi. org/10.4995/loggia.2001.3604.

Mannoni, T. 1990a. "Conoscenza e recupero edilizio", Notiziario di Archeologia Medievale, 53, pp. 3-4.

Mannoni, T. 1990b. "Archeologia dell'Architettura", Notiziario di Archeologia Medievale, 54, pp. 28-29.

Mannoni, T. 1994. Caratteri costruttivi dell'edilizia storica. Venticinque anni di Archeologia Globale, 3. ESCUM, Génova.

Mañana Borrazás, P. 2003. "Arquitectura como percepción”, Arqueología de la Arquitectura, 2, pp. 177-183, doi: https://doi.org/10.3989/arq. arqt.2003.44.

Mañana Borrazás, P.; Blanco-Rotea, R. y Ayán Vila, X. 2002. Arqueotectura 1: Bases teórico-metodológicas para una Arqueología de la Arquitectura. TAPA (Traballos de Arqueoloxía e Patrimonio), 25. Santiago de Compostela.

Martín González, J. J. 1995. "Prólogo", en C. Porras Gil, La organización defensiva española en los siglos XVI-XVII desde el Río Eo hasta el Valle de Arán, pp. 9-17. Secretariado de Publicaciones, Universidad de Valladolid.

Martín Hernández, M. J. 1997. La invención de la Arquitectura. Celeste Ediciones, Madrid.

Mileto, C. 1999. "Algunas reflexiones sobre el Análisis Estratigráfico Murario", Loggia, Arquitectura \& Restauración, 9, pp. 80-93, doi: https://doi. org/10.4995/loggia.2000.5265.

Mileto, C. y Vegas, F. 2004. "El análisis estratigráfico constructivo y el proyecto de restauración arquitectónica", Arqueología de la Arquitectura, 3, pp. 155-62, doi: https://doi.org/10.3989/arq.arqt.2004.67.

Norberg-Schulz, C. 1980. Existencia, espacio y arquitectura. Blume, Barcelona.

Nowotny, H., Scott, P. and Gibbons, M. 2003. “'Mode 2' Revisited: The New Production of Knowledge”, Minerva, 41 (3), pp. 179-194.

Orejas, A. 1995a. "Arqueología del paisaje: de la reflexión a la planificación", Archivo Español de Arqueología, 68 (171-172), pp. 215-24.

Orejas, A. 1995b. "Territorio, análisis territorial y Arqueología del Paisaje", Studia histórica. Historia antigua, 13-14, pp. 61-68.

Orejas, A. 1998. "El estudio del paisaje: visiones desde la Arqueología", en F. Burillo (ed. y coord.), Arqueología del Paisaje, Arqueología Espacial, 19-20: pp. 9-19.

Orejas Saco del Valle, A., Ruiz del Árbol Moro, M. y López Jiménez, O. 2002. "Los registros del paisaje en la investigación arqueológica", Archivo Español de Arqueología, 75, pp. 287-311, doi: https://doi.org/10.3989/ aespa.2002.v75.140.

Parcero-Oubiña, C. 2000. La construcción del paisaje social en la Edad del Hierro del Noroeste ibérico. Tesis doctoral. Universidade de Santiago de Compostela. http://digital.csic.es/handle/10261/40064

Parenti, R. 1995. "Historia, importancia y aplicaciones del método de lectura de paramentos", Informes de la Construcción, 435, pp. 19-29, doi: https:// doi.org/10.3989/ic.1995.v46.i435.1094.

Parenti, R. 2001. "Arqueología de la Arquitectura", en R. Francovich y D. Manacorda (eds.), Diccionario de Arqueología. Editorial Crítica, Barcelona.

Plata Montero, A. 2008. Génesis de una villa medieval. Arqueología, paisaje $y$ arquitectura del valle salado de Añana (Álava). Vitoria Gasteiz, Universidad del País Vasco.

Plata Montero, A. 2009. “Arqueología de las Salinas. El método de estudio de un paisaje cultural construido". KOBIE Serie Paleoantropología, XXVIII, pp. 255-266.

Porras Gil, C. 1995. La organización defensiva española en los siglos XVIXVII desde el Río Eo hasta el Valle de Arán. Secretariado de Publicaciones, Universidad de Valladolid.

Quirós Castillo, J. A. 2002. "Arqueología de la Arquitectura en España”, Arqueología de la Arquitectura, 1, pp. 27-38, doi: https://doi.org/10.3989/ arq.arqt.2002.4. 
Quirós Castillo, J. A. 2005. “Excavar en las ciudades o historiar las ciudades? El debate sobre la Arqueología Urbana a la luz de algunas experiencias europeas", Arqueología y Territorio Medieval, 12.1, pp. 107-32, doi: https://doi.org/10.17561/aytm.v12i1.1722.

Quirós Castillo, J. A. 2006. “Arqueología de la Arquitectura. Objetivos y propuestas para la conservación del Patrimonio Arquitectónico. Arqueología Medieval", Arqueología Medieval http:/www.arqueologiamedieval.com/ articulos/74/arqueologia-de-la-arquitectura-objetivos-y-propuestas-parala-conservacion-del-patrimonio-arquitectonico

Quirós Castillo, J. A. 2013. “El fin de la arqueología? La arqueología a inicios del siglo XXI”, en J. A. Quirós (dir.), La materialidad de la historia. La arqueología en los inicios del siglo XXI, pp. 9-34. Akal, Madrid.

Rabí, S. 2004. "Representación y producción de sentido en Arquitectura", Revista Electrónica DU\&P. Diseño Urbano y Paisaje, 1. http://www. ucentral.cl/du\&p/representacion.htm

Ramos, C. y Branco, A. 2010. Paisagens culturais e valorização de bens históricos e arqueológicos no âmbito da actividade da EP-SA. Exemplos de aplicação de medidas minimizadoras em contexto de obra.

Rivera Blanco, J. y Pérez Arroyo, S. (comp.) 2000. Carta de Cracovia 2000. Principios para la conservación y restauración del patrimonio construido. Versión española del Instituto Español de Arquitectura (Universidad de Valladolid). http://www.mcu.es/museos/docs/CartaDeCracovia.pdf.

Rodríguez Basulto, B. y Hernández Mora, I. 2005. "La Arqueología de la Arquitectura en el centro histórico de La Habana Vieja: Un estudio de caso", Gabinete de Arqueología, 5, pp. 4-15.

Rolón, G. y Rotondaro, R. 2010. "Empleo del método estratigráfico en el estudio de la vivienda rural vernácula construida en tierra. Un caso de aplicación en La Rioja, Argentina", Arqueología de la Arquitectura, 7, pp. 213-222, doi: https://doi.org/10.3989/arqarqt.2010.10011.

Rossignol, J. and Wandsnider, L. 1992. Space, Time and Archaeological Landscapes. Plenum Press, New York.

Sánchez, J. 1998. "La Arqueología de la Arquitectura. Aplicación de nuevos modelos de análisis a estructuras de la Alta Andalucía en época ibérica”, Trabajos de Prehistoria, 55 (2), pp. 89-109, doi: https://doi.org/10.3989/ tp.1998.v55.i2.305.
Santos Solla, X. M. 1999. Guia da raia pola beira do Miño en Galicia e Portugal. Xunta de Galicia-CCRN, Santiago de Compostela.

Schiffer, M. B. 1987. Formation Process of Archaeological Record. The University of New Mexico Press, Albuquerque.

Scruton, R. 1979. The aesthetics of Architecture. Methuen \& Co, London.

Sennet, R. 1991. La conciencia del ojo. Versal, Barcelona.

Smith, A. 2003 The Political Landscape: Constellations of Authority in Early Complex Polities. The University of California Press, Berkeley.

Soler Segura, J. 2007. "Redefiniendo el registro material. Implicaciones recientes desde la arqueología del paisaje anglosajona", Trabajos de Prehistoria, 64 (1), pp. 41-64, doi: https://doi.org/10.3989/tp.2007.v64.i1.93.

Strathern, M. 2003. "Re-Describing Society”, Minerva, 41 (3), pp. 263-76.

Tilley, C. 1994. A Phenomenology of Landscape. Places, Paths and Monuments. Berg Publishers, Oxford.

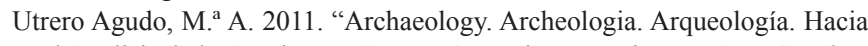
el Análisis de la Arquitectura”, en M. a Domingo Fominaya y A. J. Sánchez Luengo (dir. y coord. ed.), Arqueología aplicada al estudio e interpretación de edificios históricos. Últimas tendencias metodológicas, 11-23. Ministerio de Cultura, Madrid.

Vecoña, M. (coord.) 2006. Descubrir a historia. Plan director das fortalezas transfronteirizas do Baixo Miño. Xunta de Galicia, Consellería de Cultura e Deporte, Dirección Xeral de Patrimonio, Santiago de Compostela.

Vega García, E. de 2011. "Presentación", en M. 'Domingo Fominaya y A. J. Sánchez Luengo (dir. y coord. ed.), Arqueología aplicada al estudio e interpretación de edificios históricos. Últimas tendencias metodológicas, 7. Ministerio de Cultura, Madrid.

Ven, C. van de 1981. El espacio en arquitectura. La evolución de una idea nueva en la teoría e historia de los movimientos modernos. Cátedra, Madrid.

VV. AA. 1880. La Ilustración Gallega y Asturiana. Tomo II. Madrid.

Whittlesey, S. M. 1997. "Archaeological landscapes: A methodological and theoretical discussion”, in S. M. Whittlesey, R. Ciolek-Torrello and J. H. Altschul (eds.), Vanishing River: Landscapes and Lives of the Lower Verde Valley. The Lower Verde Valley Archaeological Project: Overview, Synthesis, and Conclusions, pp. 17-28. SRI Press, Tucson. 